University of Tennessee Health Science Center

UTHSC Digital Commons

\title{
Health Barriers, Health Perceptions, and Cardiovascular Risk Factors of Adolescent Black American Males
}

Desmarie Jackson DeCuir

University of Tennessee Health Science Center

Follow this and additional works at: https://dc.uthsc.edu/dissertations

Part of the Community Health Commons, Community Health and Preventive Medicine Commons, and the Nursing Commons

\section{Recommended Citation}

DeCuir, Desmarie Jackson, "Health Barriers, Health Perceptions, and Cardiovascular Risk Factors of Adolescent Black American Males" (2007). Theses and Dissertations (ETD). Paper 56. http://dx.doi.org/ 10.21007/etd.cghs.2007.0065.

This Dissertation is brought to you for free and open access by the College of Graduate Health Sciences at UTHSC Digital Commons. It has been accepted for inclusion in Theses and Dissertations (ETD) by an authorized administrator of UTHSC Digital Commons. For more information, please contact jwelch30@uthsc.edu. 


\title{
Health Barriers, Health Perceptions, and Cardiovascular Risk Factors of Adolescent Black American Males
}

\begin{abstract}
Area of Investigation: Cardiovascular (CV) diseases are the leading cause of death among Black American adult males. Health behaviors that contribute to $\mathrm{CV}$ disease are probably learned during adolescence yet few researchers have studied the factors that influence health promotion behaviors in adolescent Black American males. This study described the health barriers, health perceptions (health self-efficacy and health status), and CV risk factors reported by and the influence of these variables on health promotion behaviors of a sample of Black American adolescent males without known CV disease.
\end{abstract}

Methods and Procedures: A descriptive correlation study design was used to explore the associations among self-reported health barriers, self-efficacy, perceived health status, CV risk factors, and health promotion behaviors in 92 adolescent Black American males 13 to 18 years of age. Participants were recruited from two sites in Tennessee and Louisiana, respectively. Health barriers were assessed by asking adolescents "What are the 3 major things in your life that will keep you from making lifestyle changes for the sake of your health?" Health self-efficacy was examined using a 12-item survey, SelfEfficacy Scale, which measured perception of one's ability to attend to and promote personal health. Perceived health-status was assessed using the 25-item Self-Rated Abilities for Health Practices Scale. A 40-item Adolescent Health Promotion Scale assessed health promotion behaviors. Modifiable and nonmodifiable risk factors were examined using the 49-itemYouth Risk Behavior Survey. Modifiable risk factors included blood pressure measurement, height and weight (to assess body mass index or BMI), fasting blood glucose and total cholesterol levels. Non-modifiable risk factors including gender, age, and family medical history were examined using health screening and demographic questionnaires. Descriptive statistics were used to summarize sample characteristics. The a priori alpha level for the study was $p \leq .05$. Spearman Rho's correlation coefficients estimated study variable associations as many of the study variable distributions were non-normal. Stepwise multiple regression analysis with backward elimination was used to estimate the amount of variance in health promotion behavior scores explained by self-efficacy, perceived health, and CV risk factors. This analysis was limited to adolescents from Louisiana as these participants were significantly younger, more apt to be free lunch participants, and many had experienced Hurricane Katrina in the months prior to data collection. Candidate variables for the regression analysis were those that were significantly associated with the health promotion behaviors at a significance level of $p \leq 0.20$.

Findings: Study adolescents reported four categories of perceived health barriers: diet (32\%), environment (39\%), finances (4\%), and other (17\%). Perceived health status and self-efficacy levels were moderately high, while reported health promoting behaviors indicated a moderate level of participation. Results of CV risk factors indicated that $8.5 \%(n=6)$ were hyperglycemic and $11.42 \%(n=8)$ were hypoglycemia.

Borderline for high total cholesterol levels occurred in $23 \%(n=16)$ of the sample. More than $50 \%$ of the sample $(n=49)$ had systolic blood pressures of $120 \mathrm{~mm} / \mathrm{Hg}$ or more, while diastolic blood pressures of 80 $\mathrm{mm} / \mathrm{Hg}$ or greater were assessed in $32 \%(\mathrm{n}=30)$ adolescents. Body mass index results indicated that $21 \%$ $(n=17)$ were at risk for being overweight and $13 \%(n=12)$ were overweight. Reported tobacco use included $34 \%$ who reported having tried smoking. Physical activity participation levels reported included $16.48 \%$ $(n=15)$ that engaged in 20 minutes of daily physical activity 7 days a week. Sedentary activity that included television watching 5 or more hours per day was reported by $42 \%(n=42)$. Results of the Spearman Rho correlation coefficient indicated a moderate positive association between perceived health status and self-efficacy $(r=0.5608 ; p=<.0001)$. Approximately $2.7 \%$ of the adjusted variance in health promotion behavior in the sample was explained by self-efficacy, perceived health status, and fasting glucose levels, suggesting that the study framework did not adequately explain health promotion behavior 
for the study sample. As the study independent variables were not significantly associated with health promotion behaviors, clinicians must consider other variables, such as family and community factors that may influence the health promotion practices of this population. Significant proportions of adolescents in this study had one-time blood pressure values suggestive of pre-hypertension, many were over weight or at risk for overweight, several had one-time hyperglycemic blood glucose levels, and $19.56 \%$ of adolescents reported clinically significant inactivity although $59.34 \%$ reported participating in team sports. These results are of concern as many participating adolescents had a significant family history of $\mathrm{CV}$ disease. Future studies are needed to gain insights about the factors that predict health promotion behaviors in this population. Until this information becomes available clinicians must continue to assess the health practices and behaviors of adolescents and their families and encourage the inclusion of health promotion practices in daily life.

Document Type

Dissertation

Degree Name

Doctor of Philosophy (PhD)

Program

Nursing

Research Advisor

Mona N. Wicks, R. N., Ph. D.

Keywords

Black American, adolescent, male, health barriers, health perceptions, cardiovascular risk factors

Subject Categories

Community Health | Community Health and Preventive Medicine | Medicine and Health Sciences | Nursing 
Health Barriers, Health Perceptions, and Cardiovascular Health Risk Factors of Adolescent Black American Males

\author{
A Dissertation \\ Presented for \\ The Graduate Studies Council \\ The University of Tennessee \\ Health Science Center
}

In Partial Fulfillment

Of the Requirements for the Degree

Doctor of Philosophy

From The University of Tennessee

By

Desmarie Jackson DeCuir

May, 2007 
Copyright $@$ Desmarie Jackson DeCuir, 2007

All rights reserved 


\section{DEDICATION}

This dissertation is dedicated to my husband and best friend, Patrick Joseph DeCuir.

Together we have experienced the highs and lows of this lifetime academic achievement.

Thank you for your love and support during many stressful moments.

You are truly my gift from God. 


\section{ACKNOWLDEGMENTS}

I would like to thank my major professor, Dr. Mona Newsome Wicks, for her guidance and patience. I would also like to thank the other committee members, Dr. Jerome Blakemore, Dr. Melissa Faulkner, Dr. Margaret Hartig, Dr. Judy Martin, and Dr. Muriel Rice for their comments and assistance over the past three years. Funding for this research was provided by a scholarship from the National League of Nursing Foundation.

I would like to express my sincere gratitude to my husband, Patrick Joseph, for his understanding, patience, encouragement, and emotional support during many long hours of study in pursue of this lifetime academic achievement. I am also thankful to my children, Patrick Jr., Sara, Ryan, Christopher, and Reijin for their continued encouragement. Finally, I am most thankful to my parents, the late Desmond J. Jackson, Jr. and Thelma LaMotte Jackson who taught me endurance and perseverance. I know I have made you very proud. 


\begin{abstract}
Area of Investigation: Cardiovascular (CV) diseases are the leading cause of death among Black American adult males. Health behaviors that contribute to CV disease are probably learned during adolescence yet few researchers have studied the factors that influence health promotion behaviors in adolescent Black American males. This study described the health barriers, health perceptions (health self-efficacy and health status), and CV risk factors reported by and the influence of these variables on health promotion behaviors of a sample of Black American adolescent males without known CV disease.
\end{abstract}

Methods and Procedures: A descriptive correlation study design was used to explore the associations among self-reported health barriers, self-efficacy, perceived health status, CV risk factors, and health promotion behaviors in 92 adolescent Black American males 13 to 18 years of age. Participants were recruited from two sites in Tennessee and Louisiana, respectively. Health barriers were assessed by asking adolescents "What are the 3 major things in your life that will keep you from making lifestyle changes for the sake of your health?" Health self-efficacy was examined using a 12-item survey, Self-Efficacy Scale, which measured perception of one's ability to attend to and promote personal health. Perceived health-status was assessed using the 25 -item Self-Rated Abilities for Health Practices Scale. A 40-item Adolescent Health Promotion Scale assessed health promotion behaviors. Modifiable and non-modifiable risk factors were examined using the 49-itemYouth Risk Behavior Survey. Modifiable risk factors included blood pressure measurement, height and weight (to assess body mass index or BMI), fasting blood glucose and total cholesterol levels. Non-modifiable risk factors 
including gender, age, and family medical history were examined using health screening and demographic questionnaires. Descriptive statistics were used to summarize sample characteristics. The a priori alpha level for the study was $p \leq .05$. Spearman Rho's correlation coefficients estimated study variable associations as many of the study variable distributions were non-normal. Stepwise multiple regression analysis with backward elimination was used to estimate the amount of variance in health promotion behavior scores explained by self-efficacy, perceived health, and CV risk factors. This analysis was limited to adolescents from Louisiana as these participants were significantly younger, more apt to be free lunch participants, and many had experienced Hurricane Katrina in the months prior to data collection. Candidate variables for the regression analysis were those that were significantly associated with the health promotion behaviors at a significance level of $\mathrm{p} \leq 0.20$.

Findings: Study adolescents reported four categories of perceived health barriers: $\operatorname{diet}(32 \%)$, environment (39\%), finances (4\%), and other (17\%). Perceived health status and self-efficacy levels were moderately high, while reported health promoting behaviors indicated a moderate level of participation. Results of CV risk factors indicated that $8.5 \%(n=6)$ were hyperglycemic and $11.42 \%(n=8)$ were hypoglycemia. Borderline for high total cholesterol levels occurred in $23 \%(n=16)$ of the sample. More than $50 \%$ of the sample $(\mathrm{n}=49)$ had systolic blood pressures of $120 \mathrm{~mm} / \mathrm{Hg}$ or more, while diastolic blood pressures of $80 \mathrm{~mm} / \mathrm{Hg}$ or greater were assessed in $32 \%$ $(n=30)$ adolescents. Body mass index results indicated that $21 \%(n=17)$ were at risk for being overweight and 13\% $(n=12)$ were overweight. Reported tobacco use included 34\% who reported having tried smoking. Physical activity participation levels reported 
included $16.48 \%(\mathrm{n}=15)$ that engaged in 20 minutes of daily physical activity 7 days a week. Sedentary activity that included television watching 5 or more hours per day was reported by $42 \%(n=42)$. Results of the Spearman Rho correlation coefficient indicated a moderate positive association between perceived health status and self-efficacy $(r=$ $0.5608 ; p=<.0001)$. Approximately $2.7 \%$ of the adjusted variance in health promotion behavior in the sample was explained by self-efficacy, perceived health status, and fasting glucose levels, suggesting that the study framework did not adequately explain health promotion behavior for the study sample. As the study independent variables were not significantly associated with health promotion behaviors, clinicians must consider other variables, such as family and community factors that may influence the health promotion practices of this population. Significant proportions of adolescents in this study had one-time blood pressure values suggestive of pre-hypertension, many were over weight or at risk for overweight, several had one-time hyperglycemic blood glucose levels, and $19.56 \%$ of adolescents reported clinically significant inactivity although $59.34 \%$ reported participating in team sports. These results are of concern as many participating adolescents had a significant family history of CV disease. Future studies are needed to gain insights about the factors that predict health promotion behaviors in this population. Until this information becomes available clinicians must continue to assess the health practices and behaviors of adolescents and their families and encourage the inclusion of health promotion practices in daily life. 


\section{TABLE OF CONTENTS}

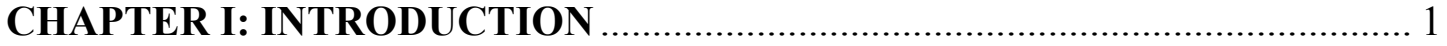

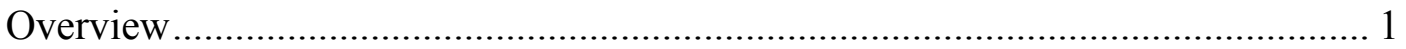

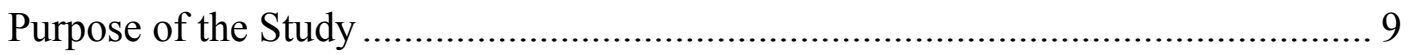

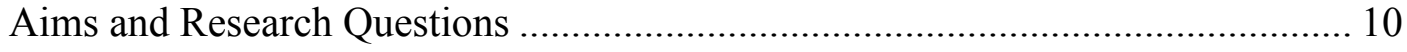

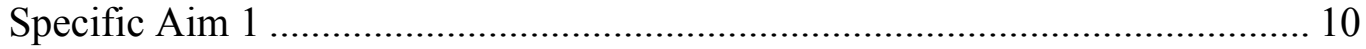

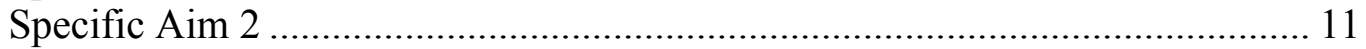

Specific Aim 3 ....................................................................................... 11

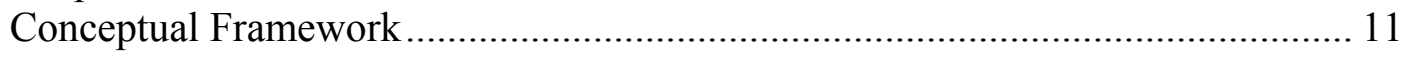

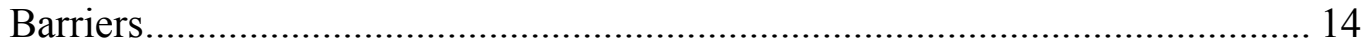

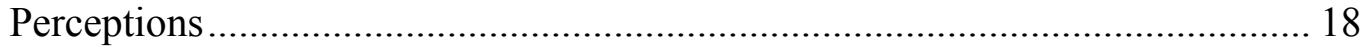

Cardiovascular Risk Factors ......................................................................... 22

Health Promotion Behaviors ......................................................................... 23

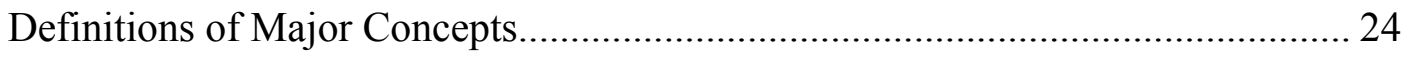

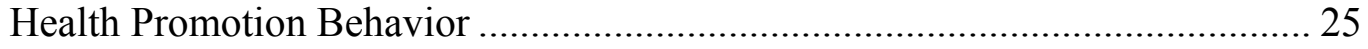

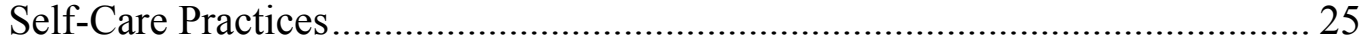

Health Barriers .......................................................................................... 25

Health Perceptions ..................................................................................... 26

Cardiovascular Health Risk Factors............................................................ 26

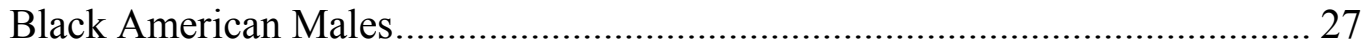

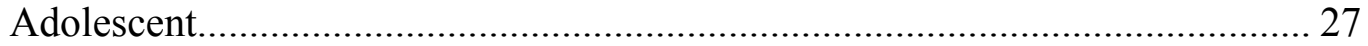

Cardiovascular Diseases .......................................................................... 27

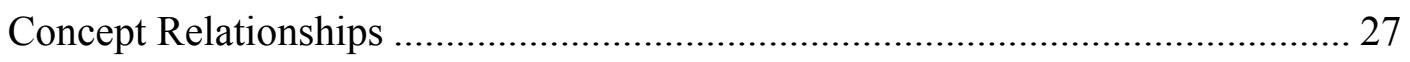

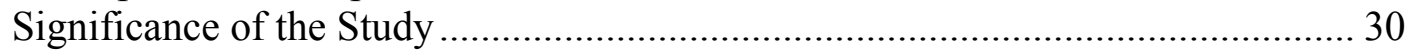

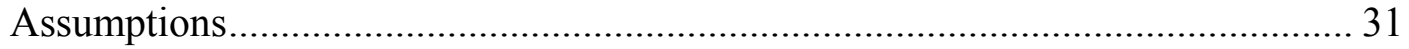

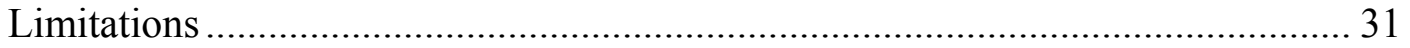

CHAPTER II: REVIEW OF LITERATURE ............................................. 33

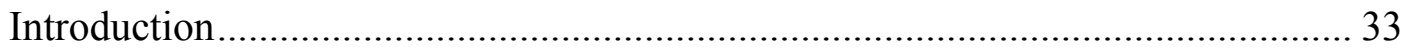

Cardiovascular Health of Adult Black Americans.............................................. 33

Cardiovascular Health and Health Risk Factors of Black American Adolescents . 36

Health Barriers of Black American Adolescents ................................................ 41

Health Perceptions of Black American Adolescents and Adults .......................... 43

Health Behaviors of Black American Adolescents and Adults ............................ 46

Summary of the Review of Literature .......................................................... 50

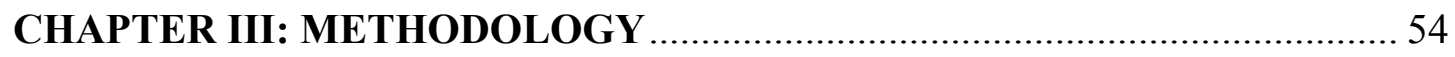

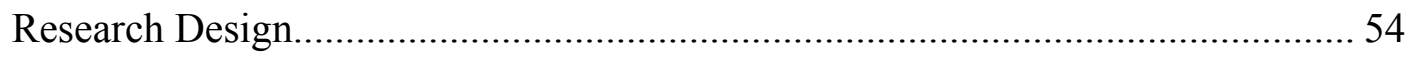

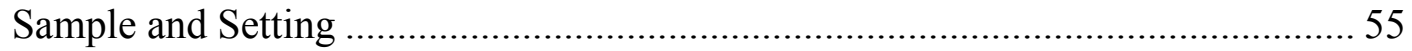

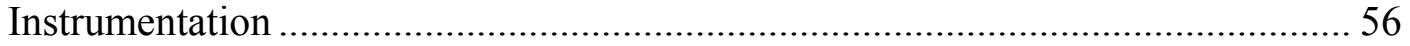

Adolescent Demographic Questionnaire ................................................. 57

Adolescent Health Screening Form …..................................................... 57

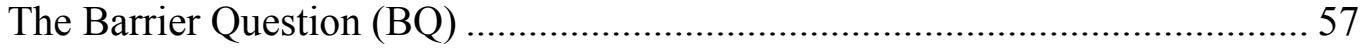

viii 
Self-Rated Abilities for Health Practices Scale (SRAHP) …………………….... 58

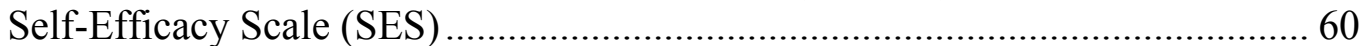

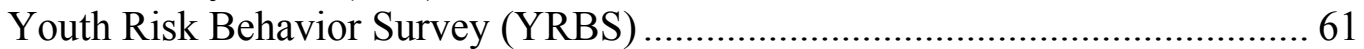

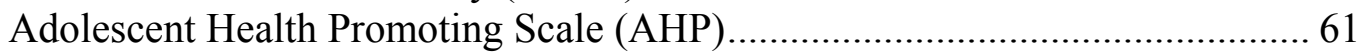

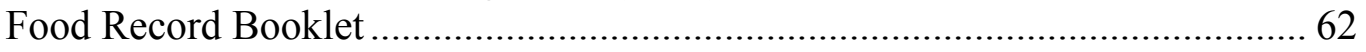

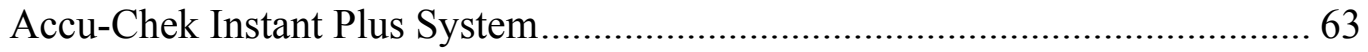

Blood Pressure, Heart Rate, Weight, and Height Screening.................................. 64

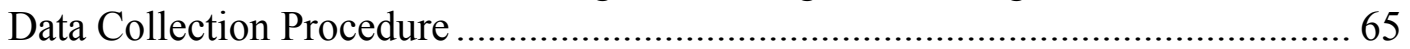

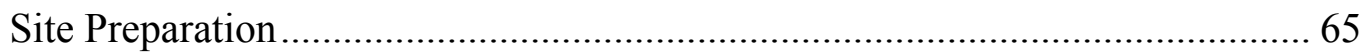

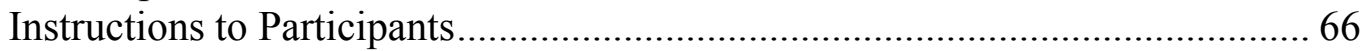

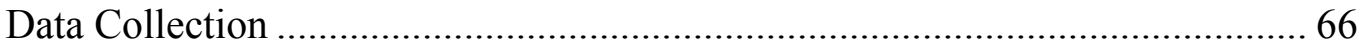

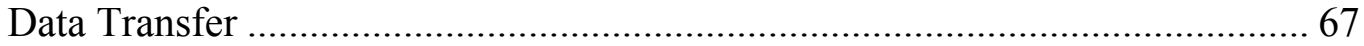

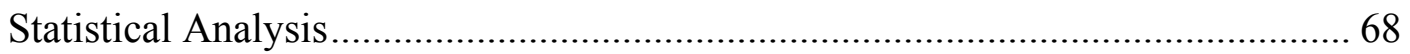

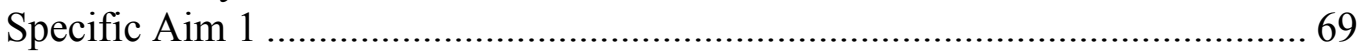

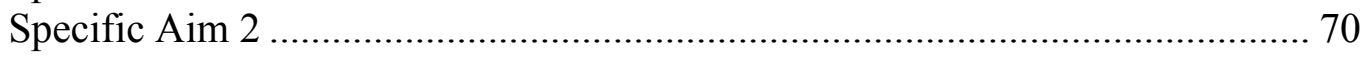

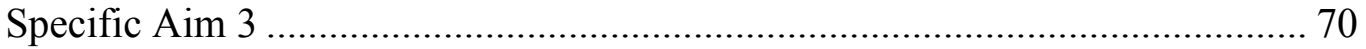

Consideration of Human Subjects .................................................................. 71

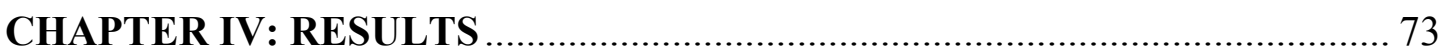

Adolescent Characteristics............................................................................... 73

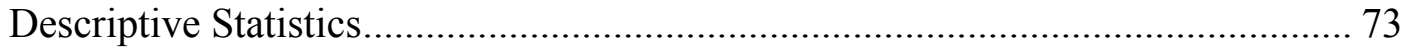

Research Aims, Questions, and Findings ………………..................................... 77

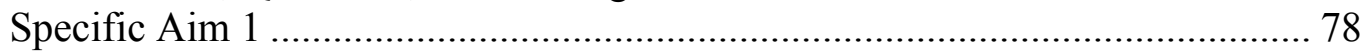

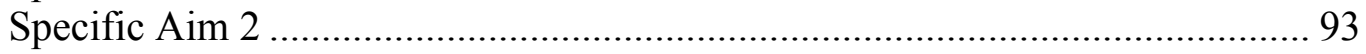

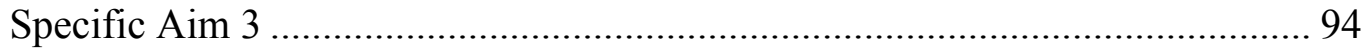

CHAPTER V: DISCUSSION AND IMPLICTIONS ……………………..........

Perceived Health Barriers ............................................................................ 100

Perceived Health Status and Self-Efficacy ........................................................... 102

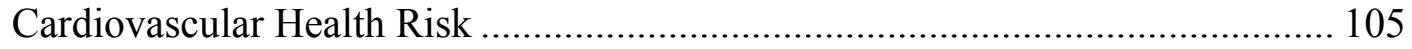

Health Promotion Behaviors........................................................................... 109

The Association Between Perceived Health Status and Self-Efficacy ................. 112

The Influence of Perceived Health Barriers, Perceived Health Status, Self-

Efficacy, and Cardiovascular Health Risk on Health Promotion Behaviors ........ 113

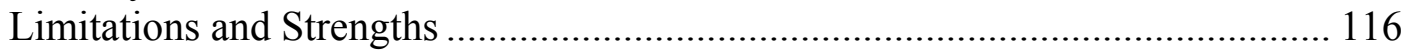

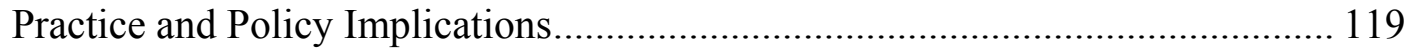

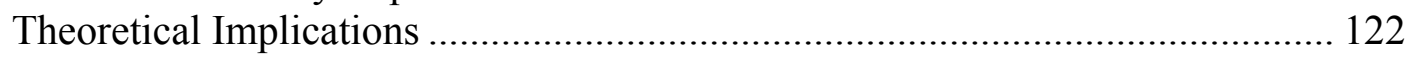

Recommendations for Future Research ........................................................ 123

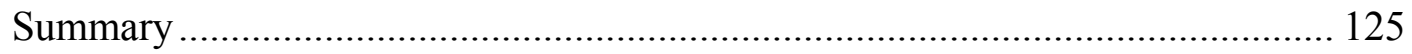

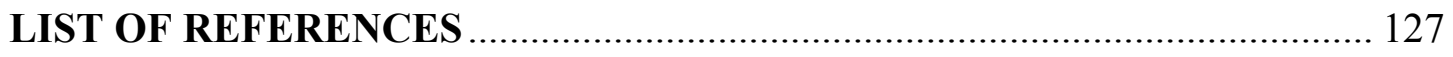

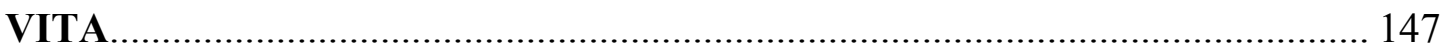




\section{LIST OF TABLES}

Table 1. Adolescents' Demographic Characteristics by Study Site.............................75

Table 2. Adolescents' Demographic Characteristics for the Sample and by State of Residence.

Table 3. Barriers to Health for Black American Adolescent Males $(\mathrm{N}=92) \ldots \ldots \ldots \ldots \ldots . . . .81$

Table 4. Barriers to Health for Black American Adolescent Males by State .81

Table 5. Youth Risk Behavior Survey Item Measuring Perceived Health for the Sample and by State of Residence

Table 6. Descriptive Statistics for Adolescent Health Promoting Scale Subscales for the Sample

Table 7. Tobacco Use in the Study Sample .88

Table 8. Physical Activity Reported by the Study Sample .90

Table 9. ANOVA Table of Adolescents' Self-efficacy, Perceived Health, and Fasting Glucose by Health Promotion Behaviors

Table 10. Comparison of the Youth Risk Behavior Survey Results for Adolescent Males in the Current Study and in the 2005 Adolescent National Dataset....110 


\section{CHAPTER I: INTRODUCTION}

\section{Overview}

Health promotion is a broad concept that is closely associated with disease prevention, health risk reduction, and health education. It is an essential component of efforts to increase the overall health of individuals, communities, and societies. Whitehead (2004) suggests that health promotion activities facilitate change in communities by serving as the foundation upon which new health structures can be established and maintained.

While the body of research on health promotion continues to grow, few studies have focused on this topic as it relates specifically to the cardiovascular health of Black American male adolescents. To date, most studies linking Black Americans and cardiovascular risk factors have used middle-aged or elderly participants. When this is considered, the significance of the present study is evident. The researcher seeks to fill a critical gap in the literature by exploring the barriers to health, health perceptions (health status and self-efficacy), cardiovascular health risks, and health promotion behaviors of 13- to 18-year-old Black American males. These findings are particularly important because self-care and health promotion behaviors learned early in life have the potential to influence future health status (Pender, 1996). The data collected will be used by the investigator to design tailored interventions to increase health promotion behaviors among Black American male adolescents in postdoctoral research. If the cardiovascular health and health promotion behaviors of today's Black American male adolescents are 
improved, one can anticipate that American society will have a healthier population of older Black American males with improved cardiovascular health outcomes in the future.

Researchers such as Daviglus, Liu, Pirzada, Yan, Garside, Feinglass, Guralnik, Greenland, and Stamler (2003) have documented the relationships among health promotion, health motivation, and self-rated health. In a study with male and female participants these authors discovered that having a favorable cardiovascular profile in middle age is associated with improved future health status. In another study exploring the health of men, Loeb (2004) found that self-motivation is a key factor to consider in health promotion efforts.

Major cardiovascular diseases include cerebrovascular disease, coronary heart disease, heart failure, and hypertension (American Heart Association [AHA], 2004; World Health Organization [WHO], 2004). Undiagnosed and untreated cardiovascular disease can damage major organs that are essential for life, including the heart (heart attack), brain (stroke), kidneys (kidney failure), and the peripheral circulatory system (peripheral vascular disease). Relative to other ethnic groups within the United States, the Black American population bears a disproportionate burden of death and disability due to cardiovascular disease. Each year cardiovascular disease claims the lives of $36.4 \%$ of 290,000 Black Americans (AHA, 2005), and is well documented (DeForge, Stewart, DeVoe-Weston, Graham \& Charleston, 1998; He, Klang, Appel, Charleston, \& Whelton, 1998; Nash, 2003; National Center for Health Statistics, 1997; Nesbitt \& Victor, 2004; Ofili, Igho-Pemu, \& Bransford, 1999; Onwuanyi, Hodges, Avancha, Weiss, Rabinowitz, Shea, and Francis, 1998; Pickering, 2001; Schneider, Castillo-Richmond, Alexander, Hector, Kaushik, Aranguri, Norris, Haney, Rainforth, Calderon, \& Nidich, 2001; Sharma, 
Malarcher, Giles, \& Myers, 2004). Hypertension, the most prevalent form of cardiovascular disease (Hopkins \& Hunt, 2003), has the highest incidence among Black Americans in the southeastern region of the United States (AHA, 2004). Compared to other ethnic groups, more than $40 \%$ of Black Americans are hypertensive (AHA, 2005), and this population is more likely to develop the disease at an earlier age (Nesbitt \& Victor, 2004) and suffer negative cardiovascular events early in life.

Several risk factors influencing the development of cardiovascular disease in Black Americans have been identified. Modifiable risk factors for cardiovascular disease are related to behaviors that an individual can change. Examples of such factors include cigarette smoking, sedentary lifestyle, high-fat diet, and obesity (Graves \& Miller, 2003; Keil et al., 1995; Nash, 2003). In contrast, non-modifiable risk factors arise from the phenomena that an individual cannot change, such as ethnicity, age, and genetic predisposition (Hopkins \& Hunt, 2003; Nesbitt \& Victor, 2004; Onwuanyi et al., 1998). However, there is disagreement among researchers regarding the existence of a genetic component that predisposes Black Americans to hypertension. He, Klang, Appel, Charleston, and Whelton (1998) compared middle-aged Black and White Americans of the same age with similar initial blood pressures and body mass indexes. Study findings using two blood pressure measurements and current body mass index indicated that ethnicity was not a predictor for developing hypertension.

Black Americans also experience premature cardiovascular disease when compared to other populations, suggesting that factors contributing to its early onset may begin in childhood. Furthermore, cardiovascular diseases and cardiovascular disease risk once associated only with adults (e.g., hyperlipidemia, hypertension, and hyperglycemia) 
are increasing in children. The incidence of these conditions in children is especially high among Black American youth (Colon \& Franklin, 1997; Dietz, 2004; Kohn \& Jacobson, 2004; Sorof, Lai, Turner, Poffenbarger, \& Portman, 2004). The increasing rate of obesity among adolescents is of particular concern in light of obesity's relationship with cardiovascular disease, which has the potential to cause organ damage in adulthood (Sinaiko, Donahue, Jacobs, \& Prineas, 1999).

The population of interest in this study—adolescent Black American males— faces particular challenges in health promotion and cardiovascular disease prevention, as well as in the maintenance of general health. In the United States, men die an average of 6 years earlier than do women, and Black American men die 7 years earlier than White American men (U. S. Department of Health and Human Services [USDHHS], 2000). Furthermore, research has shown that Black Americans, as a group, have poorer overall health than members of other groups and are exposed to a broad range of environmental and social risk factors (Williams, 2003).

Gender is a social risk that influences health outcomes placing men at a higher health risk compared to women. The health disparity that exists between men and women has been widely discussed throughout healthcare literature (Courtenay, 2000; Courtenay, McCreary, \& Meirghi, 2003; Meyer, 2003; Piper, 1997; Rees, Jones, \& Scott, 1995;

Williams, 2003). Males of all ages and races are more likely than females to participate in behaviors that increase their risk of disease, injury, and death. For example, men are more likely to join high-risk occupations (construction worker, fire fighter, law enforcement), participate in dangerous sports (football, auto racing), and engage in hazardous behaviors (smoking, alcohol consumption, and fast driving). Williams (2003) identified several 
factors that can adversely affect men's health: absence of employment, work insecurity, working environment, inability to deal with stressors, lack of medical intervention, and cumulative social and economic disadvantages throughout the course of life.

In addition to these factors, cultural beliefs about masculinity and manhood have significant effects on males' health behavior (Courtenay, 2000). Young boys are socialized at an early age regarding acceptable behavior within the male community through a process referred to as childhood conditioning (Bem, 1981). Boys are taught to project an image of strength, dominance, autonomy, and physical aggression (Courtenay, 2000), which carries over into adulthood. Learned "masculine" traits tend to include holding back emotions, as emotional expression is perceived as vulnerability (Courtenay, 2000). Research has revealed that many males experience difficulty with expressing feelings (Rees, Jones, \& Scott, 1995) and that this difficulty may increase men's risk of developing mental illness. An understanding of these characteristics helps to explain the relative lack of health promotion and preventive behaviors among males of all racial and ethnic groups (Courtenay, 2002).

A study by Courtenay (2000) suggested that men view asking for help and caring for their health as feminine behaviors that demonstrate weakness. Courtenay contended that men and boys avoid behaviors coded as "feminine" in an effort to display and achieve manhood. For example, a man who refuses to stay home when sick may insist that he needs little rest, while a man who brags that alcohol consumption does not impair his driving ability may believe that he is exhibiting his masculinity or manhood. If men are to live longer and healthier lives, they need to change unhealthy beliefs and behaviors (Courtenay, 2002). 
Social cognitive theory specifies six core determinants of effective health practices (Bandura, 2004): knowledge, perceived self-efficacy, outcome expectations, goals, perceived facilitators of change, and impediments or barriers to change. The subject of self-efficacy has been widely studied within the field of healthcare research (Bandura, 2004; Cervone, 2000; Holloway \& Watson, 2002). Perceived self-efficacy and barriers to change are especially important factors to consider with regard to understanding the health-related behaviors of Black American males. Obtaining this information affords an opportunity to conduct future intervention studies to improve these behaviors in this at-risk population.

Self-efficacy refers to how an individual views their ability to invoke change. In this study self-efficacy is determined by reviewing the self-reported information of Black American adolescent males regarding their ability to determine, perform, and maintain health-promotion behaviors. Self-efficacy has been identified as an important determinant of current health behavior, future health behavior, and health behavior change (Holloway $\&$ Watson, 2002).

Cervone's (2000) analysis of the cognitive processes through which people appraise their efficacy for performance revealed two themes. The first theme is the importance of perceived control in determining and changing health outcomes. The second is the significance of self-concept and self-referent thinking to health-related behavior. Strong self-efficacy encourages an individual to set high goals and secures a firm commitment to sustaining positive behavioral changes (Bandura, 2004).

Interestingly, findings from studies comparing southern Black American males to non-southern Black American males have suggested that the former have lower levels of 
self-esteem and overall life satisfaction (Huff-Corzine, Corzine, \& Moore, 1991; Middleton, 1976). Results of these studies serve as an additional impetus for conducting the current study to determine how southern Black American adolescent males perceive their self-efficacy and how this self-efficacy affects their health promotion behavior. Knowledge of self-efficacy may provide information that can be used to design relevant health promotion programs and other health interventions for Black American males.

Perceived barriers to health may also influence health outcomes. Results of studies on health barriers have suggested that social and economic inequalities motivated by racism are fundamental causes of unfairness in healthcare provision (Nazroo, 2003). Researchers investigating the health of Black American males have identified several barriers. Smith (2003) and Rich (2001) pointed to structural barriers related to healthcare delivery systems, lack of insurance, poverty, and access to healthcare. A random sample of 1,028 Black Americans (537 were men), reported the highest incidence of racial discrimination in the workplace (18\%), government agencies $(6.7 \%)$, and police interaction (6.3\%) (Gary, 1995).

Provider bias and cultural incompetence are emphasized by Johnson, Saha, Arbelaez, Beach, and Cooper (2004) as major factors in the perception of unequal healthcare by Black American males. Lower levels of educational attainment, poorer health status, having unanswered questions, and perceiving less participation in care were identified as reasons why Black Americans develop perceptions of provider bias and cultural incompetence. Moreover, findings suggest that racism and class bias alienate Black American males from the healthcare system and encourage members of this population to seek episodic emergent care rather than regular preventative care (Gary, 
1995). Black American males are not alone in their experience of healthcare barriers. Meyer (2003) argued that barriers related to ethnic discrimination and racial stereotyping block healthcare access for males of many minority groups. Male immigrants, for instance, may experience barriers related to their immigration status and language proficiency, which may hinder them from seeking preventative care.

Former U. S. Surgeon General David Satcher (2003) addressed the question of why healthcare barriers exist for Black American males. Satcher attributed Black American males' healthcare disadvantages to their sociopolitical environment. Satcher's interpretation of this problem is consistent with that of other scholars who have perceived institutionalized racism and sexism within American healthcare systems (Gary, 1995; Johnson et al., 2004; Lillie-Blanton et al., 2000; Nazoo, 2003; Rich, 2001; Smith, 2003). Satcher offered two solutions to eliminate non-financial barriers to health for Black American men: (a) increase the representation of Black American males at all levels of the healthcare workforce and (b) improve efforts to recruit linguistically and culturally competent providers. According to Satcher, when clients have access to providers who look like them, they may be more likely to seek services. Black American males may perceive Black American providers as more understanding of and sensitive to their needs.

Research that gathers the self-reported perspectives of Black American males can help to clarify the reasons that ethnic and gender-related disparities exist in health promotion behaviors and health outcomes. In the current literature, there is a particular knowledge gap regarding young Black American male's health promotion behaviors and cardiovascular health risk factors. The findings of this study provide foundational information necessary for future efforts to design health promotion interventions and 
programs for this at-risk population - a population significantly affected by premature cardiovascular disease.

\section{Purpose of the Study}

The purposes of this study were to examine cardiovascular health promotion behaviors of adolescent Black American males without known cardiovascular disease and key factors associated with health promotion behaviors in this population. Factors examined in this study include perceived barriers to health, perceived health status, selfefficacy, and self-reported cardiovascular health risk behaviors. Studies examining the health of Black American males focused on knowledge of cancer detection, primarily prostrate cancer; none of these studies focused on cardiovascular health risk and health promotion behaviors. Study participants were either teens or adults greater than 21 years of age; these studies did not include both age groups. Neither of these studies examined perceived barriers to health, perceived health status, perceived self-efficacy, or selfreported health promotion behaviors of Black American adolescent males. The reason for including these variables in the current study is twofold. First, variables include health promotion, which is a correlate for cardiovascular risk among Black American adult males and second, the relevance of theses variables with regard to cardiovascular morbidity and mortality are well documented in the literature (Bandura, 2004; Courtenay, 2000; Gary, 1995; Graves \& Miller, 2003; Hopkins \& Hunt, 2003; Nash, 2003; Nesbitt \& Victor, 2004; Onwuanyi et al., 1998). Understanding these self-reported factors in this population of adolescent Black American males will contribute to the design and implementation of health promotion interventions that may improve cardiovascular 
morbidity and mortality observed later in life, ultimately reducing cardiovascular health disparities.

\section{Aims and Research Questions}

The conceptual framework and aims of this study were derived from available literature regarding the health of Black American adult males. A detailed discussion of the conceptual framework follows the presentation of the specific aims and research questions.

\section{Specific Aim 1}

Following are questions that were asked during this study to determine the perceived health barriers, perceived health status, self-efficacy, health promotion behaviors, and cardiovascular risk factors reported by adolescent Black American males without known cardiovascular disease:

(1a) What are the perceived health barriers reported by adolescent Black American males without known cardiovascular disease.

(1b) What is the level of perceived health status reported by adolescent Black American males without known cardiovascular disease?

(1c) What is the level of self-efficacy reported by adolescent Black American males without known cardiovascular disease?

(1d) What are the cardiovascular health risk factors present in and reported by adolescent Black American males without known cardiovascular? 
(1e) What are the health promotion behaviors reported by adolescent Black American males without known cardiovascular disease?

\section{Specific Aim 2}

One question was asked to examine the association between perceived health status and self-efficacy of adolescent Black American males without known cardiovascular disease: Question 2. What is the association between perceived health status and perceived self-efficacy of adolescent Black American males without known cardiovascular disease?

\section{Specific Aim 3}

To determine the influence of perceived health barriers, perceived health status, self-efficacy, and cardiovascular health risks on the health promotion behaviors of adolescent Black American males without cardiovascular disease, the following question was asked: Question 3. What is the influence of perceived health barriers, perceived health status, self-efficacy, and cardiovascular health risks on the health promotion behaviors of adolescent Black American males without cardiovascular disease?

\section{Conceptual Framework}

A conceptual framework is defined as an abstract and logical structure that guides the development of a study (Burns \& Grove, 2001). The conceptual framework for this study (Figure 1) was developed by the investigator to test the relevance of study concepts in an adolescent male Black American sample. A conceptual framework is a structure of 


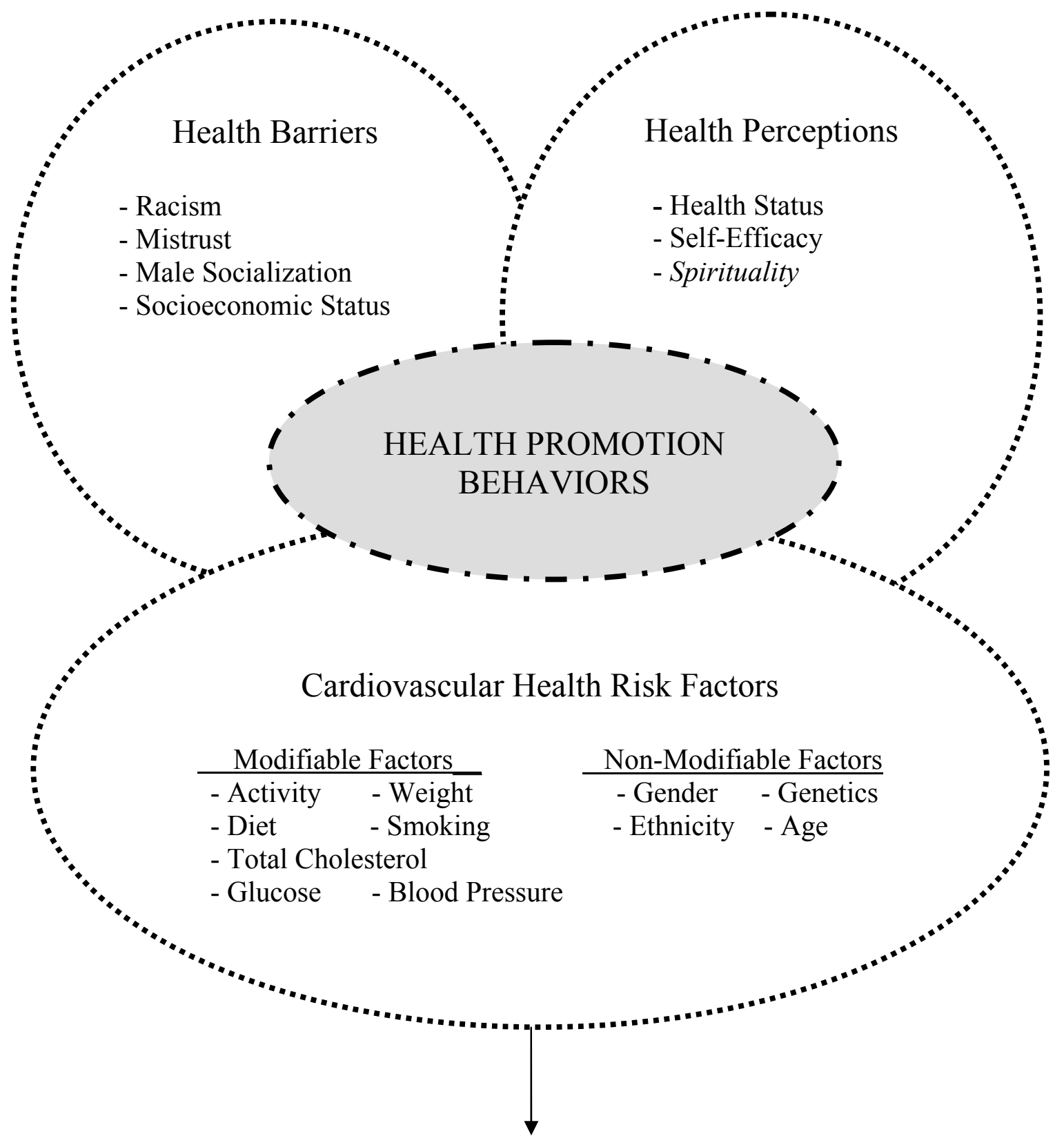

Cardiovascular Health

Figure 1. Correlates of Health Promotion Behavior of Black American Adolescent Males 
the concepts and/or theories that the researcher brings together as a map for the study (LoBiondo-Wood \& Haber, 2002).

The conceptual framework of the current study depicts relationships among health promotion practices of adolescent Black American males and barriers to health, healthrelated perceptions, and cardiovascular health risk factors. Ultimately, these factors contribute to cardiovascular health, are significant factors to consider related to health promotion behaviors among adult Black American males, and have not been addressed in health promotion models.

In general, health promotion models stress the importance of tailoring interventions to match the needs of individuals or communities (Prochaska \& DiClemenite, 1983). Several health promotion models that focus on individual health behavior are found in the literature. Social cognition models (Bandura, 1977; Poss, 2001; Rise, 2004; Werner \& Mendelson, 2001; Whitehead, 2004; Yarcheski, Mahon, \& Yarcheski, 1997) and nursing models (Carter \& Kulbok, 1995; Cox, 1982; Loeb, 2004; Pender, 1987; Simmons, 1990) that address promotion activities are the most prominent in published literature. These models focus on adult health behaviors. To date, no health promotion model centered on adolescent Black American males 13-18 years of age has been published.

Health promotion models in the literature neither address minority populations nor their experience of early onset of health problems, in particular cardiovascular health disparities. Many findings regarding health disparities between men and women and majority and ethnic minority populations have been reported (AHA, 2002; Albert, Torres, Glynn \& Ridker, 2004; Freedman, 2003; Graham-Garcia, Raines, Andrews, \& Mensah, 
2001; He, Klang, Appel, Charleston, \& Whelton, 1998; Jones, Granger, Short, \& Taylor, 2004; Nesbitt \& Victor, 2004; Olifi, Igho-Pemu, \& Bradford, 1999; Schneider et al., 2001). However, a closer review of the literature suggests that Black American males face health-related challenges that non-Black American males are less likely to encounter, placing them at an even greater disadvantage than the general male population.

While the investigator acknowledges the existence of health facilitators for Black American males, this study's focus is on the factors that negatively influence the health promotion behaviors of Black American adolescent males without known cardiovascular disease. This study is predicated on the premise that to understand the health promotion behaviors of Black American males, researchers must conduct studies that examine selfreported data of adolescents related to barriers of health, health-related perceptions (e.g., health status and self-efficacy), and cardiovascular health risk. The variables examined in this study represent the interactions among these three phenomena.

\section{Barriers}

The barriers to health represented in the conceptual model are designated as racism, mistrust, male socialization, and socioeconomic status. Significant interactions among these barriers to health are supported throughout the literature (Courtenay, 2000; Gary, 1995; Holloway \& Watson, 2002; Rich, 2001; Williams, 2003) revealing that each barrier influences the other. The researcher's intention in using this conceptual framework was not to suggest that every Black American male experiences the same barriers to health or that the barriers are experienced with equal frequency. The 
investigator acknowledges that barriers to health exist with significant individuality. While many Black American males encounter racism, for example, socioeconomic status does not represent a significant barrier for every Black American male. The model is intended to indicate that the specific barriers that should be considered as potential factors that influence adolescent Black American males' health promotion behaviors (e. g., self-care practices) and service utilization. Racism is widely recognized as contributing to the development of stress in Black American males (Gary, 1995; Rich, 2001; Williams, 2003). Fearing racism members of this population may be reluctant to seek medical care. At the same time, racism-induced stress may exacerbate chronic disease (e. g., hypertension) in this population. Racism is thought to contribute to existing health disparities via healthcare access and type of health services received (Johnson er al., 2004; Mayberry Mili, \& Ofili, 2000; Williams, 2003). Healthcare providers may unintentionally express negative racial stereotypes when caring for Black American males (Gary, 1995; Rich, 2001; Satcher, 2003; Williams, 2003). Stereotyping is a concern not only for Black American men of lower SES, but also for college-educated Black American males. Rich (2001) reported that Black American males of various socioeconomic statuses receive patronizing and biased counsel when treated by nonBlack American physicians. This historical experience of biased healthcare can influence Black American males' belief that they can be helped through the healthcare system. Published literature documents Black American's mistrust of the healthcare community. Historical events such as the U. S. government supported Tuskegee Syphilis Study (Corbie-Smith, 1999; Earl \& Penney, 2001; Thomas \& Curran, 1999; Whaley, 2001) have engendered wariness toward the medical establishment on the part of many 
Black Americans, particularly males. The Tuskegee study illustrates for many Black Americans that systematic racism exists within the United States healthcare system. According to Earl and Penney (2001), fundamental mistrust initiated during the American slavery era culminated in the Tuskegee Syphilis Study. Black American males' mistrust of the non-Black American medical community is endemic. Snowden (1999) revealed that Black Americans utilize health services far less than other ethnic groups, while others have suggested that Black Americans are frequently misdiagnosed (Garb, 1997; Neighbors, Jackson, Campbell, \& Williams, 1989). The resulting mistrust and healthcare dissatisfaction serve as further deterrents to seeking healthcare (Becker \& Newsom, 2003; LaVeist, Nickerson, \& Bowie, 2000). A general suspicion toward medical personnel has been identified by Corbie-Smith (1999) as a significant factor in the underutilization of healthcare services by Black American males.

Unsuccessful attempts to recruit Black Americans for clinical trials offer additional evidence of the cultural mistrust embedded in the Black American healthcare experience. Hatchett, Holmes, Duran, and Davis, (2000), however, contradict this conclusion, suggesting that the lack of participation in clinical trails by Black Americans is not attributed to racism, but to the fact that Black Americans are not recruited by researchers. The paucity of health research specific to Black American males serves to widen existing healthcare disparities. Health barriers in the current study were measured collectively by asking adolescents to identify perceived barriers using an open-ended questionnaire.

Several factors are directly related to Black American males' health including occupational status, daily stressors, beliefs regarding masculinity and manhood, 
inadequate use of health services, and cumulative adversity over the course of life (Williams, 2003). Occupational status and stress are often intertwined. When a man's occupational status does not permit him to fulfill cultural expectations to provide for his family, he is likely to experience the burden of stress. Chronic psychological stress has been identified as a precursor to cardiovascular diseases such as hypertension (Schneider et al., 2001). The effects of cardiovascular diseases and stress are compounded for individuals who lack medical coverage because they are unemployed, employed only part-time, or work for employers who do not provide health benefits (Williams, 2003). Through the process of male socialization, men internalize societal gender expectations that influence their health decisions and lifestyles (Griffiths, 1996). Social norms may encourage men to ignore their health needs. If men associate masculinity with being strong, independent, and powerful, they may perceive attending to their health as an act of "feminine" weakness (Courtenay, 2000). Health neglect contributes to the higher death rate among men compared to women.

Socioeconomic status is one of the greatest predictors of access to healthcare and is among the most significant determinants of health disparities (Mayberry, Mili, \& Ofili 2000; Smith, 2003; Williams, 2003). Men with low-incomes are less likely to have health insurance and are consequently less likely to seek medical treatment, which increases their chance of developing chronic health problems. In addition to lack of insurance, other barriers can prevent Black American males from seeking or receiving healthcare. These barriers include such as the perceived hostility of medical professionals, racial stereotyping, discrimination in the healthcare delivery system, lack of minority 
physicians, and poor cultural competence across the healthcare provider community (Meyer, 2003).

\section{Perceptions}

Perceptions of health status, self-efficacy, and spirituality are significantly interrelated. In the current study, only health status and self-efficacy will be measured to examine the influence of these health perceptions on the health promotion behaviors of Black American adolescent males. The examination of the influence of spirituality as a health perception among Black American males has been reserved for postdoctoral research. In a national survey of public perceptions of the United States healthcare system (Lillie-Blanton, Brodie, Rowland, Altman, Kaiser Family Foundation, \& Princeton Survey Research Associates, 2000), Black American respondents expressed perceptions of receiving poor medical treatment and being treated disrespectfully by healthcare providers. Individuals' perceptions are molded by their experiences and are reflected in their actions (Mendelson, 2003); thus, perceptions can exert a powerful influence on healthcare-seeking and health-promotion behaviors.

Many researchers have gathered data on subjects' perceptions of health status rather than data on actual physical health status, due to the difficulty of obtaining measures of health through physical examinations (Nyamathi, Sands, Pattatucci-Aragon, Berg, Leake, Hahn, \& Morisky, 2004). Self-rated health status levels have been directly linked to mortality rates. Adults who rate their health status as fair to poor have a higher mortality rate when compared to those who rate their health as excellent (Idler \& Stanislav, 1995; McGee, Liao, Cao, \& Cooper, 1998; Rodin \& McAvay, 1992; 
Schoenfeld, Malmroso, Blazer, Gold, \& Seeman, 1994). The perceptions component of the present conceptual framework carries tremendous relevance, as Black American males are more likely than White American males to report poor health status associated with lower socioeconomic status (Ferraro, 1993; Johnson \& Wolinsky, 1994; Kim, Bramlett, Wright, \& Poon, 1998; Ren \& Amick, 1996). However, Kim, Gynn, McMahon, Voorhees, Striegel-Moore, and Daniels (2006) found that Black American males with higher socioeconomic status reported better perceptions of their health status than those with low socioeconomic status did.

Settersten and Lauver (2004) conducted research to determine whether the relationship between cognitive abilities and participation in health behaviors is encouraged by health status perception. Their results revealed that health perception is directly related to an individual's decision to participate in health promoting behavior and activities. Positive perceptions of healthy behavior, however, do not necessarily coincide with health-promoting behavior. Merrill, Friedrichs, and LaDene (2000) reported that knowledge of health-promoting activities (regular exercise, not smoking, maintaining an ideal weight, and eating a healthy diet) did not ensure healthy behavior. In order to address this issue, the concept of self-efficacy is included in the conceptual framework. Self-efficacy relates to one's ability to attend to personal health and achieve health promotion activity.

In the conceptual framework, self-efficacy specifically refers to the self-reported ability of Black American adolescent males to attend to and conduct health promotion activity to enhance health outcomes. The fact that self-efficacy beliefs have an impact on health supports the notion that psychosocial influence directly affects health functioning 
(Bandura, 1977). The literature includes research (Callaghan, 2003; Cervone, 2000) and discourse (Bandura, 1977; Holloway \& Watson, 2001) on the significance of selfefficacy. However, there has been no scholarly exploration of the relationship between self-efficacy and the health of Black American adolescent males. An individual's perception of their self-efficacy has a direct influence on their choice of activities (Bandura, 1997), especially as these activities relate to health behavior. Thus there is an established basis for examining the correlation between perceived health status and selfefficacy as well as cardiovascular health risk factors among Black American adolescent males.

A clear and broad understanding of how Black American males perceive their ability to exert control over their health is necessary if research is to address reported disparities. After conducting a longitudinal study of the influence of knowledge and selfefficacy on behavior, Rimal (2000) reported findings suggesting that knowledge, behavior, and self-efficacy are mutually supportive components of change. Exploring the self-efficacy of adolescent Black American males as it applies to their health offers an opportunity to understand the ways of knowing that are experienced within this population.

Spirituality is a significant component of Black American culture and serves multifaceted functions in the community. It has been described as a coping mechanism (Bowen-Reid \& Harrell, 2002; Ferraro \& Koch, 1994), a means of empowerment (Reed, 1992), a buffer of negative impact (Ellison, 1991; Levin, Chatters \& Taylor, 1995; Krause \& Tran, 1989), a means of connecting to a higher power (Ellison \& Taylor, 1996), and as an avenue for defining one's life purpose (McSherry \& Ross, 2002). 
Spiritual beliefs can also produce a sense of well being among individuals with lifethreatening illnesses that positively influences recovery (Levin, Lyons, \& Larson, 1993; Levin, Chatters, \& Taylor, 1995). Much research has been conducted on the positive effects of spiritual and religious beliefs on health promoting behavior (Ferraro, \& KelleyMoore, 2000; Miller, 1995; Thorson, 1983). Nevertheless, no researchers have investigated the relationship between the spiritual beliefs and health promotion behaviors of Black American adolescent males. Within this study's conceptual framework, it is recognized that spirituality plays an important role in the lives of Black Americans, as affirmed by the literature. However, a study that explores the association between spirituality and health promotion behaviors among Black American male adolescents has been reserved for post doctoral research and is not examined in the current study.

Several researchers have examined the predictors of Black Americans' health (Becker \& Newsom, 2003; Kneipp \& Drevdabl, 2003; Rutledge, Reis, Olson, Owens, Kelsey, Pepine, Reicheck, \& Rogers, 2003; Sankar, Cho, Condit, Hunt, Koenig, Marshall, Soo-Jin, \& Spicer, 2004). These predictors include racism, socioeconomic status, perceived health status, and self-efficacy. Racism, in the literature, includes issues related to the socialization of Black American males and their general mistrust of the medical community. Socioeconomic status includes questions of employment, healthcare utilization, access, and insurance. Perceived health status and self-efficacy are closely related to health behaviors. How an individual perceives his or her health status is also associated with actions that can lead to healthy or unhealthy outcomes. Examining predictors of the health promotion behavior is an important step in developing 
interventions that promote better healthcare practices within this understudied, at-risk population.

\section{Cardiovascular Risk Factors}

Promoting the cardiovascular health of Black American males is essential to enhancing the overall health of this population. Relative to other ethnic groups, Black American males have higher morbidity and mortality rates linked to cardiovascular disease. Cardiovascular-related deaths often prematurely occur in Black Americans perhaps because of earlier disease onset (Nesbitt \& Victor, 2004). By assessing the cardiovascular health risk of adolescent healthy Black American males, this investigator provides essential background information relevant to designing future interventions that may decrease existing health disparities.

The major cardiovascular risk factors for heart disease and stroke among Black Americans are hypertension, elevated cholesterol levels, kidney disease, and obesity (AHA, 2004). Researchers can gain a clearer understanding of Black American males' daily health-related activities by identifying the status of modifiable and non-modifiable cardiovascular risk factors among adolescent Black American males without cardiovascular disease using self-reported perspective and actual physiological indicators (e.g., blood pressure, heart rate, and body mass index). Modifiable cardiovascular risk factors included in this conceptual framework (e.g., activity, diet, weight, smoking,) will provide insight into self-care practices that directly influence the cardiovascular health reported by participating adolescent Black American males. Additionally, results of the current study provide a foundation for designing future intervention studies focused on 
improving cardiovascular health outcomes. Physiological indicators measured in the current study sample (e.g., blood pressure, body mass index, and fasting glucose and total cholesterol levels) will contribute to the assessment of the adolescents' cardiovascular health risk factors.

\section{Health Promotion Behaviors}

While the body of research on health promotion continues to grow, very few studies have focused on this topic as it relates specifically to Black American adolescents, and none have focused primarily on Black American adolescent males. Literature related to health promotion behaviors in adult Black American males is sparse, and few researchers focus on this high-risk population. Research addressing health promotion behaviors among Black American men conducted by Millon-Underwood and Sanders (1990) examined the risk of developing cancer. Study findings revealed in a sample of 177 men that $56 \%$ reported that they assess their bodies for physical changes regularly and $42 \%$ reported that they make a conscious attempt to attend to their health needs. Twelve percent of the study participants indicated having a physical exam within the past three years.

Study findings examining health promotion behaviors of rural, southern seventh and eight grade adolescents (Hendricks, Murdaugh, Tavakoli, \& Hendricks, 2000) revealed that females rated themselves as having higher self-actualization, interpersonal support, and stress management skills, while males perceived themselves as having high health responsibility, exercise, and nutritional practices. The researchers conducted their study to test the use of the Health Promoting Lifestyle Profile (HPLP) instrument among 
adolescents. To date the HPLP is only recommended in participants 18 years of age or older. However, the authors used the instrument to measure of health promotion behaviors in rural southern Black and White American adolescents. This study was the only study found that addressed health promotion behaviors among Black American adolescent males. Because it is apparent from studies of adults that health promotion behaviors are essential for positive health outcomes; it is therefore reasonable to expect the same is true for adolescent males. The current study offers an opportunity to reduce the existing knowledge gap related to health promotion behaviors of Black American males, specifically adolescent males.

The conceptual framework of this study provides parameters for identifying the what, how, and why of Black American adolescent males' health. The framework presents the relationship between health barriers, health perceptions, and cardiovascular health-risk factors that play a role in the health promotion behaviors of Black American males. The investigator acknowledges that other factors contribute to the cardiovascular health of this population; the major health determinants reflected in the framework and included in the current study are those most often discussed in the research literature.

\section{Definitions of Major Concepts}

Various theoretical and operational definitions of the concepts of interest in this research study have been published in the literature. For the purposes of the current study, however, the following definitions are presented: 


\section{Health Promotion Behavior}

Health promotion behavior refers to activities that facilitate positive changes in health status by serving as the foundation upon which new health structures can be established and maintained (Whitehead, 2004). This variable was operationalized using the Adolescent Health Promoting Scale.

\section{Self-Care Practices}

Self-care practices are actions performed for the purposes of promoting and maintaining personal health.

\section{Health Barriers}

Health barriers are social, economic, and psychological obstacles that influence health promotion behaviors. In this study, health barriers have been identified as racism, which is discrimination based racial identity; mistrust, which is cultural suspicion embedded in the Black American male experience; socialization, which is the process by which Black American males internalize cultural expectations regarding gender and sex roles; and socioeconomic status, which is defined as economic limitations related to employment, income, education, the lack of health insurance, and poverty. Health barriers identified by adolescents in this study are determined by their response to the Barrier Question. 


\section{Health Perceptions}

Health perceptions are the interpretations of adolescent Black American males concerning health-promoting behaviors.

Perceived health status. This study concept reflects each adolescent's rating of his level of health based on his response to the Self-Rated Abilities for Health Practices Scale.

Self-efficacy. Self-efficacy refers to the study adolescents' self-reported ability to attend to and promote personal health as measured based on their individual responses using the Self-Efficacy Scale.

\section{Cardiovascular Health Risk Factors}

Cardiovascular risk factors are defined as facets of daily living that predisposes Black American male adolescents to the development of cardiovascular disease in adulthood. Cardiovascular risk factors are categorized as modifiable and non-modifiable.

Modifiable risk factors. Modifiable risk factors are the cardiovascular disease risk factors that adolescent Black American males can change in order to promote their cardiovascular health. Modifiable risk factors include physical activity level, body weight, dietary intake, and smoking. Modifiable risk factors are measured using results of the self-report Youth Risk Behavior Survey. 
Non-modifiable risk factors. Non-modifiable risk factors are cardiovascular disease risk factors that Black American adolescent males cannot change in order to promote their cardiovascular health. Non-modifiable risk factors include gender, age, and ethnicity and are determined based on self-report using the Adolescent Demographic Questionnaire.

\section{Black American Males}

Black American Males are self-identified males of Black American ethnicity.

\section{Adolescent}

Male participants born between 1987 and 1992 are adolescents, as defined in this study.

\section{Cardiovascular Diseases}

The term cardiovascular diseases refers to the major diseases of the cardiovascular system (e.g., heart and blood vessels) that afflict Black Americans. Examples include cerebrovascular disease, coronary heart disease, heart failure, and hypertension (AHA, 2004; WHO, 2004).

\section{Concept Relationships}

The lack of health promotion behaviors and the high incidence of cardiovascular disease among Black Americans males are widely documented. No single factor is entirely responsible for the health disparities suffered by this population. Likewise, several interrelated factors affect Black American males' health behavior activities. Black 
American males can control some of these factors, while unable to control others. Health barriers, health-related perceptions, and cardiovascular health risk factors are interlocked in the lives of Black American males.

Four types of health barriers have a direct influence on Black American men's health and health promotion behavior: racism, mistrust, socialization, and socioeconomic status. Racism can exert a negative impact on personal health; encounters with racism can lead to stress, which, in turn may lead to cardiovascular phenomena such as hypertension and stroke (Schneider et al., 2001). For Black American males, mistrust serves as a health barrier that influences their health status. A general lack of trust in the healthcare system can affect the health of Black American men by prompting them to underutilize available health services or to seek services after a health problem has worsened (Gary, 1995; Rich, 2001; Smith, 2003; Williams, 2003). Delayed medical intervention increases the incidence of mortality and morbidity (Gary, 1995). Other barriers against self-care practices and health promotion behavior relate to the male socialization process that Black American males undergo. In their formative years, Black American boys are taught what it means to be a Black American man in contemporary American society. Values associated with toughness, independence, and risk-taking has been shown to have a negative influence on health and health promotion activity (Courtenay, 2000). As the socioeconomic status of Black American males varies, one should be cautious when generalizing about interactions between health and socioeconomic status for this population. Although, Black American males with lower socioeconomic status tend to experience a higher occurrence of cardiovascular diseases (Mayberry, Mili, \& Ofili, 
2000; Smith, 2003; Weinrich et al., 2001; Williams, 2003), many males of high socioeconomic status also experience cardiovascular disease.

Perceptions of self are especially important elements in the lives of Black American males, as negative images of Black American males are prevalent in society (Gandy, 2001; Jenkins, 2006) Many Black American boys develop into adults who have negative perceptions of what it means to be a Black American man. An individual's view of himself, his perception of health status and self-efficacy play instrumental roles in determining their ability to meet the demands of personal health. How an individual rates their health status reflects their view of self-efficacy (e.g., whether or not the individual perceives having the ability to attend to self-care practices). Thus, health status and selfefficacy are interwoven factors in the health promotion behaviors of Black American men. Self-efficacy is the perception of having the ability to attend to and promote personal health. Health behaviors are directly influenced by the perception of selfefficacy (Bandura, 1997). Spirituality, related to health perception, may be viewed as a positive influence on health. Furthermore, spirituality provides a support to those who are seeking to understand reality and searching for meaning in their life (Conner \& Eller, 2004).

The cardiovascular health risks of Black American adolescent males hinge on the previously discussed concepts, barriers, and perceptions. Barriers are directly related to risks, as there are societal restraints associated with health. Meanwhile, perceptions address the cognitive component of self-care and contribute to health outcomes. Health promotion practices are actions that Black American adolescent males can implement to improve their cardiovascular health outcomes, contingent on the reduction of barriers and 
increase in positive perceptions (e.g., health status and health self-efficacy).

Cardiovascular health risk factors that are not modifiable, but are significant to personal health (e.g., gender and family genetics) may be addressed through educational interventions relevant to minimizing impact on their health.

\section{Significance of the Study}

High morbidity and mortality rates among Black American males are closely associated with cardiovascular disease. This study's significance lies in the fact that it contributes to the body of research regarding adolescent Black American males without known cardiovascular disease. The literature offers abundant information on older men with known cardiovascular disease, but limited data are available on the adolescent male population. The current study, which addresses factors that influence health promotion behaviors among Black American adolescent males, provides an opportunity to investigate elements that shape health promotion behaviors early in life that have the potential to influence health behaviors and outcomes later in life. Much of the research reported in the current literature presents findings from objective data. In contrast, the current study presents findings from objective as well as subjective data related to health barriers, health perceptions (perceived health status and self-efficacy), and cardiovascular health risk factors of adolescent Black American males. Both subjective and objective data likely provide the best explanation of health promotion behaviors in this population.

Studies examining the predictors of health promotion behaviors are especially relevant to nursing practice. This study contributes to nursing science in several ways. First, results described the incidence of cardiovascular disease risk in Black American 
male adolescents participating in the study. Second, the study results provide direction for the development of future intervention studies. Finally, findings could guide the development of health promotion programs directed specifically toward reducing cardiovascular morbidity and mortality rates in adolescent Black American males. Ultimately, findings of the current study should make a significant contribution to existing knowledge on the health promotion behaviors of Black American adolescent males without known cardiovascular disease. Additional significance is gained from the fact that most of the study data are self-reported. Such data should aid in understanding this population's perspectives on health promotion self-care practices.

\section{Assumptions}

The following assumptions are embedded in the present study's philosophical base, design, and conceptual framework:

(1) Participants in this study are honest and truthful in sharing their self-reported health practices. Candid answers are encouraged through participants' anonymity.

(2) The study framework, which is based primarily on research conducted in Black American adult males, is relevant for Black American male adolescents.

(3) Participants can read, write, and communicate using the English language.

\section{Limitations}

The limitations of this study are:

(1) The participants are located in three different southern urban communities; therefore the investigator acknowledges that each adolescent's response likely 
reflect the culture of these geographic regions.

(2) The study findings can be generalized only to similar populations residing in the southern region of the U. S.

(3) Participants may respond with answers they believe will be viewed favorably by the investigator. Anonymity, however, should encourage respondents to provide frank answers on questionnaires (Polit \& Hungler, 1987).

(4) The screening process limits participation to Black American adolescent males without known cardiovascular disease. Data were verified by parents completing the Adolescent Demographic Questionnaire and Adolescent Health Screening Form with their children. However, the PI recognizes that participants could have an undiagnosed cardiovascular disease. Although every effort was used to ensure these inclusion criteria were met, there may be adolescents without personal knowledge of having a diagnosed cardiovascular disease.

(5) The sites are located in urban communities; therefore results may not reflect adolescents living in non-urban communities.

(6) A non-probability sampling (convenience sampling) design was used for this study, which could limit the extent of generalization. Because this study is descriptive and correlational in nature and existing knowledge of Black American male adolescents is limited, convenience sampling is an appropriate sampling method. 


\section{CHAPTER II: REVIEW OF LITERATURE}

\section{Introduction}

The health of Black Americans has been investigated with many studies of this population focusing on cardiovascular health and risk factors that influence overall health. An extensive body of literature documents cardiovascular disease as the leading contributor to increased morbidity and mortality rates among Black Americans compared to other ethnic groups. However, few studies have concentrated exclusively on Black American adolescent males, the focus of the current study. This chapter presents a review of literature relevant to the cardiovascular health of adult and adolescent Black Americans, including studies about health barriers and health perceptions. The chapter concludes with a synthesis of the literature and a discussion of how prior research informs the current study.

\section{Cardiovascular Health of Adult Black Americans}

Cardiovascular disease is the leading cause of death among Black Americans, claiming the lives of 290,000 persons annually (AHA, 2006). Several factors contribute to the cardiovascular health, morbidity, and mortality of Black Americans and are well documented in the literature (Brown, 2004; Haas, 2005; He, Klag, Appel, Charleston, \& Whelton, 1998; Sharma, Malarcher, Giles, \& Myers, 2004; Sowers, Ferdinand, Bakris, \& Douglas, 2002). Pender (1996) postulated that biological and sociocultural factors exert direct effects on health outcomes. The factors that contribute to the morbidity and mortality of Black Americans can be divided into two categories: nonmodifiable and 
modifiable risk factors. Nonmodifiable risk factors are intrinsic elements that are constant, such as race, age, gender, and inherent family disease. Conversely, modifiable risk factors are elements that an individual has the option to change, such as obesity, sedentary lifestyle, dietary habits, and smoking.

Hypertension is the prevailing cardiovascular disease among Black Americans (AHA, 2006). The disorder tends to develop earlier in life among Black American than among non-Black Americans (Hopkins \& Hunt, 2003). Some researchers contend that hypertension is caused by a genetic predisposition (Erlich et al., 2003; Freedman, 2003; Hopkins \& Hunt, 2003), while others have questioned whether other factors, such as those related to context, might better explain the development of cardiovascular disease in Black Americans (Dressler, Bindon, \& Neggars, 1998; Gary, 1995; Litaker, Koroukian, \& Love, 2005; Pickering, 2001).

Contextual factors that influence the occurrence of cardiovascular disease among Black Americans are defined as circumstances or conditions that surround the development of cardiovascular disease, such as racism (Krieger \& Sidney, 1996; Pickering, 2001), socioeconomic status (Becker \& Newsom, 2003; Rutledge et al., 2003; Sharma et al., 2004), chronic stress (Brown, 2004), and healthcare access (Litaker, Koroukian, \& Love, 2005; Mayberry, Fatima, \& Ofili, 2000; Satcher, 2003). These factors overlap in their influence. For example, racism leads to stress and stress contributes to chronic disease (e.g., hypertension, overeating). Lower socioeconomic status contributes to poor dietary habits and lack of resources that can influence healthcare access. Because of socioeconomic status and the prevalence of poverty among Black Americans, young Black Americans with cardiovascular risk factors continue to 
have the highest risk profile for developing cardiovascular disease later in life (Karlamangla et al., 2005). In addition, researchers have suggested that cardiovascular disease is more prevalent among residents of specific geographic locations, in particular the southeastern U.S (Fang, Madhaven, \& Alderman, 1996; Geronimus, Bound, Waidmann, Hillemerier, \& Burns, 1996). A significant proportion of the nations Black American population resides in the southeastern U.S. where cardiovascular diseases like hypertension and other cardiovascular risks like obesity are common.

In Black Americans, a significant relationship has been found between blood pressure dipping and the risk of cardiovascular disease (Stepnowsky, Nelesen, DeJardin, \& Dimsdale, 2004). Specifically, individuals who exhibit nocturnal nondipping have a higher mortality risk than those whose blood pressure dips at night (Ohkubo et al., 1997; Ohkubo et al., 2002). A nondipper is defined as a hypertensive individual whose blood pressure does not decline during sleep or rest periods, increasing the risk of stroke or endorgan damage (Takashi \& Genjiro, 1999). Although blood pressure dipping is not investigated in the current study sample, adolescents with higher blood pressure readings may need to be screened to rule out nondipping during annual physical examinations.

The cardiovascular health of adult Black Americans plays a significant role in the future cardiovascular health of adolescent Black Americans, as children often implement behaviors they have learned from parents and other significant adults. Additionally, interventions and health programs are needed earlier, as in adolescence, to ensure that young Black Americans are taught health-promoting activities.

In summary, the current literature identifies several factors that influence the cardiovascular health of adult Black Americans. The specific factors identified in 
previous studies include contextual and genetic factors. Contextual factors refer to environmental variables that are adjustable. Examples of contextual factors include lower socioeconomic status, societal racism, chronic stress, and lack of medical access and resources. In contrast, genetic factors are inherent tendencies that may be minimized via health-related behavioral changes such as dietary modifications. Genetic factors that predispose Black Americans to increased cardiovascular disease include gender, ethnicity, and a family history of cardiovascular disease, such as hypertension and blood pressure dipping.

\section{Cardiovascular Health and Health Risk Factors of Black American Adolescents}

Many published studies demonstrate that Black American adolescents are at risk for cardiovascular disease as adults as a result of several risk factors (Davy, Harrell, Stewart, \& King, 2004; Freedman, Khan, Dietz, Srinivasan, \& Berenson, 2001; King, Meadows, Engelke, \& Swanson, 2006; Kupper, Ge, Treiber, \& Sneider, 2006; Palacios et al., 2004; Robinson, Batisky, Hayes, Nahata, \& Mahan, 2005; Schmidt et al. 2005; Snieder, Harshfield, \& Treiber, 2003; Sorof, Lai, Turner, Poffarger, \& Portman, 2004; Wilson, Bayer, \& Sica, 1996). The findings of these studies identify hypertension, left ventricular mass, overweight, impaired glucose level, increased insulin level, increased carotid artery intimal-medial thickness, and decreased physical activity as contributing significantly to the cardiovascular health of Black American adolescents. Of the factors identified, the current study investigates overweight, impaired glucose levels, and reported physical activity levels among adolescent Black American males. 
If children, as compared to adults, have elevated blood pressure or hypertension it is more likely to be manifested as an increase in systolic pressure. In contrast, diastolic increases are seldom a problem for adolescents. In fact, mild to moderate blood pressure elevation is associated with left ventricular mass and is an important factor in the morbidity of all children (Sorof, 2001). Findings from the Bogalusa Heart Study (Berenson \& Srnivasan, 2004; Deshmukh-Taskar, Nicklas, Morales, Yang, Zakeri, \& Berenson, 2005; Freedman, Khan, Dietz, Srinivasan, \& Berenson, 2001; Freedman, Khan, Serdula, Dietz, Srinivasan, \& Berenson, 2005) supported the conclusion that cardiovascular risk factors present in adolescence increase the risk of adult-onset cardiovascular disease. Davis, Flickinger, Moore, Bassali, Baxter, and Yin (2005) reported significant overweight and cardiovascular risk factors in Black and White American adolescents, including elevated systolic and diastolic blood pressure, and impaired fasting glucose (IFG) and elevated total cholesterol levels, all of which were examined in the current study. These authors do not discuss participants' socioeconomic status and family health histories as potential confounding variables that might explain their study results. The difference between the two studies is the following: Davis et al. used a rural sample, while the current study employs an urban sample. Elevated systolic blood pressure in children has been identified not only as a precursor to adult hypertension, but also as a significant predictor of arterial stiffness in adulthood (Shengxu et al., 2003), which underscores the relevance of conducting blood pressure measurements in the current study population.

Dietary salt intake and sensitivity and caffeine intake (Savoca, Evans, Wilson, Harshfield, \& Ludwig, 2004) have also been found to contribute to blood pressure 
changes in Black American adolescents. In particular, Black male adolescents, relative to Black female adolescents, experience increased sensitivity to dietary salt (Wilson, Bayer, \& Sica, 1996), which increases systolic blood pressure. Additionally, research investigating the eating habits of adolescent females (Schmidt et al., 2005) has found that Black adolescent girls, compared with White American adolescent girls, consume more fast food and thus consume greater amounts of dietary sodium, fat, and calories, which can lead to increased blood pressure.

Palacios et al. (2004) contradicted the finding that increased dietary salt contributes to increased systolic blood pressure in Black American adolescents. These researchers found that while Black American adolescent girls consumed more dietary sodium compared to White American girls, increased blood pressure was not present among the Black American girls in their sample. This finding suggests that additional research is needed on the effect of sodium intake on blood pressure in female adolescents. Palacios et al.'s study was conducted in a controlled environment that included two 3-week sessions in a metabolic unit. The participants' meals were prepared and monitored closely for portion control by dedicated staff, which may have contributed to the difference in the findings compared to the other studies. In the current study, dietary sodium is not examined exclusively, but a review of the 3-day food records indicated the amount of fast foods consumed by the study participants. Because fast-food items are well recognized for high sodium content this information will provide a general perspective of dietary sodium intake.

The chronic condition of overweight affects 10 to $15 \%$ of children in the United States (Ogden, Flegal, Carroll, \& Johnson, 2002). As among adults, the prevalence of 
overweight among Black American adolescents has increased, leading to higher body mass indices that, in turn, contribute to persistent elevated blood pressure readings in adolescents (Sorof, Lai, Turner, Poffenbarger, \& Portman, 2004). Several factors are thought to contribute to overweight status in children: decreased physical activity (Arluck, Branch, Swain, \& Dowling, 2003), increased television viewing (Gortmaker, Must, Sobol, Peterson, Colditz, \& Dietz, 1996), increased fast food consumption (Schlosser, 2001), and socioeconomic status (Lee \& Cubbin, 2002). Recent research has suggested that in Black American families the socioeconomic status of parents is not a protective barrier to overweight in children, as has been found in White American families (Crawford, Story, Wang, Ritchie, \& Sabry, 2001). In other words, in White American families, higher socioeconomic status was associated with a lower prevalence of overweight in children; this pattern has not been found among Black American families. The authors suggest that other factors such as culture and environment may explain observed differences between Black and White American families.

Prediabetic conditions such as IFG increase the risk of developing cardiovascular disease in adolescence (Williams et al., 2005). Several risk factors for IFG have been identified in Black American adolescent groups: high $\mathrm{HbA}_{1} \mathrm{c}$, which reflects the average blood glucose over past three months; total cholesterol; triglycerides; systolic blood pressure; and insulin levels. Williams et al. (2005) reported a prevalence of $4.2 \%$ of IFG among male and female Black American adolescents in their study.

Elevated total cholesterol levels and overweight among adolescents are also associated with an increased risk of cardiovascular disease (Berenson, 1999; Davis et al., 2005). Davis et al. reported fasting total cholesterol levels (26\%) that were greater that 
$170 \mathrm{mg} / \mathrm{dl}$, collected via finger sticks methods similar to the method used in the current study. Total cholesterol levels in Black American adolescent males have been identified as higher compared to White males (Gutin et al, 2005). As reported with IFG, the literature does not reflect studies that have focused exclusively on Black American adolescents, as does the current study.

Nondipping blood pressure status, identified in adult Black Americans, is also present in Black American adolescent males as a risk factor that predisposes individuals to the development of cardiovascular disease (Wilson, Kliewer, Teasley, Plybon, \& Sica, 2002). The phenomenon of blood pressure dipping is not explored in the current study, but the blood pressure findings will provide health information for parents of participating adolescents who demonstrate elevated blood pressures that warrant medical follow-up. Participants with hypertensive screening blood pressures could also have a nondipping blood pressure, which needs to be determined through follow-up assessment.

In summary, the health of Black American adolescents is associated with several risk factors for the development of cardiovascular disease. Documented risk factors influencing the cardiovascular health of Black American adolescents include elevated blood pressure, dietary salt intake, overweight, IFG, and elevated cholesterol levels. In particular, systolic blood pressure is reported to be a significant problem compared to diastolic blood pressure measurements in Black American adolescents. The effects of dietary salt on blood pressure may have greater clinical significance for Black American teen females compared to males, as in one study it was associated with increased blood pressure in this group although a second study disputed this finding. A clearer association seems to exist for IFG, cholesterol, and gender as increase in overweight among both 
males and females is closely associated with IFG and elevated cholesterol levels, predisposing Black American adolescents to cardiovascular disease in adulthood.

\section{Health Barriers of Black American Adolescents}

Presently, literature on perceived health barriers among Black American adolescents is limited. Of six studies related to perceived barriers for Black Americans, four included adolescents and two examined adult male and female samples. None of the studies investigated perceived health barriers in an all-male adolescent sample as the current study does.

Studies of Black American female adolescents (Kimm, Gynn, Mcmahon, Voorhees, Striegel-Moore, \& Daniels, 2006; Tappe, Dida, \& Ehrnwald, 1989; Robbins, Pender, \& Kazanis, 2003) note perceived barriers to physical activity such as being conscious of one's looks while exercising, having other things to do, and feeling too tired to participate in exercise. Kimm et al. examined barriers to activity participation by asking adolescents girls how often they participated in physical activities, such as dancing, sports, and exercising. Black American girls reported fewer barriers compared to White American after the physical activity scores were analyzed. The authors suggest that this difference may reflect cultural differences and beliefs about activity participation within the Black American community that were not captured in the study questionnaire.

The perception of barriers to seeking healthcare may differ on the basis of age and life experience. Pregnant Black American adolescent girls reported not experiencing barriers to seeking healthcare related to sexually transmitted disease (Crosby, Wingood, DiClemente, \& Rose, 2002), while adult Black American females seeking prenatal care 
identified several barriers to healthcare related to unsatisfying clinical visits, insensitive clinic staff, stress, and unwanted pregnancy (Daniels, Noe, \& Mayberry, 2006). Although the samples of these studies differed in that one was composed of adult females, who identified barriers, while the other consisted of adolescent females who denied barriers, they had one key similarity as reported by the authors: both reported a lack of social support from healthcare providers. Perceived health barriers among adult Black American males were investigated by Plowden and Young (2003), while Hines-Martin, Malone, Kim, and Brown-Piper (2003) examined perceived barriers to mental health among Black American males employing focus groups. Plowden and Young identified the lack of accessibility of resources as an environmental barrier. Similarly, the sample in the Hines-Martin, Malone, Kim, and Brown-Piper study reported family/community, knowledge deficiencies, and beliefs/values as barriers.

In review, several studies have identified health barriers among Black American adolescents that are similar to those identified in the current study's conceptual model. Researchers have investigated perceived health barriers of Black American adolescents focusing on two primary categories: physical activity and seeking health care. This understudied variable (e.g., health barriers) needs further exploration as knowledge about barriers could facilitate the development of appropriate interventions that foster health promotion behaviors and ultimately improve cardiovascular health in this at-risk population. 


\section{Health Perceptions of Black American Adolescents and Adults}

The subject of perceived health status among Black Americans has been investigated in studies using various age groups and focusing on various perspectives. Most studies have addressed adult populations (Blendon et al, 1995; Johnson \& Wolinsky, 1994; Kim, Bramlett, Wright, \& Poon, 1998; Loeb, 2004; MacDowell \& Short, 2002; Nyamathi et al., 2004; Weinrich, Weinrich, Priest, Fodi, \& Talley, 2001). No study retrieved from the literature search included an exclusively Black American male population. The literature indicates that adult Black males report lower perceived health status compared to non-Black American male populations (Blendon et al., 1995; Ferraro, 1993; Ren \& Amick, 1996). One study retrieved from the literature focused on perceived health reported by minority adolescents (Honig, 2002). The sample included 71 adolescents of which 12\% were Black American. The author reported that participants' perceived health status was moderately high, with a mean of 4.2 on a scale of $1(\mathrm{bad})$ to 5 (good). Results were not reported by race or ethnicity. Ratings of perceived health status were based on physical fitness, feelings, schoolwork, social support, family communication, and health habits. In a study with an adolescent sample that included participants from southern (Black American $n=2,455 ; 47 \%)$ and Midwestern $(n=140$; 13\% non-White) sites (Zullig, Valois, \& Drane, 2005), perceived health status was strongly influenced by perceived mental health, but less dependent on physical health status. Perceived health status was highest when mental health was perceived as high.

As with adult studies, significantly lower perceived heath status has been found in Black American adolescent populations compared to other ethnic/racial groups (Rew, 1997). One study was found in the literature that investigated perceived health status in 
an adolescent sample that included Black Americans. Rew found that Black American teens $(n=33 ; 34 \%)$ scored 78 out of a possible 110 points on a measure of perceived health status. In this study, Latino Americans received a score of 87 and White Americans received a score of 88 using the General Health Rating Index, which assessed perceived health by using four subscales: previous health, current health, resistance to illness, and outlook. This measure is different from the instrument employed in the current study, which measures perceived health status by rating the adolescents' responses to specific task-related health questions.

Like perceived health status, self-efficacy is not a subject that has been explored extensively among Black American adolescent populations. Two studies were found in the literature that investigated self-efficacy in adolescent samples that included Black American participants. One study explored self-efficacy in an exclusively Black American adolescent sample ( $\mathrm{N}=256)$ (Halpern-Felsher, Kropp, Boyer, Tschann, \& Ellen, 2004). The focus of this study was self-efficacy with regard to health risk behaviors rather than perceived health. Black American adolescent males reported higher levels of self-efficacy to communicate with parents about sex compared to females. Robbins, Pender, Ronis, Kazanis, and Pis (2004) assessed an adolescent sample's (Black American -89\%) perceptions of self-efficacy related to physical activity skills. Participants walked/ran on a treadmill for 20 minutes and provided ratings of their exertion every four minutes. Results indicated that females reported lower pre-activity self-efficacy levels with higher levels of exertion perception compared to male participants. The percentage of females versus males in the sample was not provided. Because self-efficacy is an important predictor of health behaviors in adult populations 
and few studies have been conducted to examine this variable in the Black American adolescent male population, more research is needed. There is a particular need for research using southern adolescent Black American male samples compared to nonsouthern Black American males as they have lower levels of self-esteem compared to White American males (Huff-Corzine, Corzine, \& Moore, 1991; Middleton, 1976). Selfefficacy is a cognitive mechanism that is fundamental to behavioral change across populations (Bandura, Adams, \& Beyer, 1977).

Self-efficacy as a cognitive mechanism among adult Black Americans has been investigated as well. Cromwell and Adams (2006) suggest that high levels of exercise self-efficacy in adult Black Americans increase the chances of participating in physical exercise activities. Findings from similar studies suggest that self-efficacy could determine whether or not adult Black Americans engage in exercise behavior (Anderson, Wojcik, Winett, \& Williams; Walcott-McQuigg \& Prohaska, 2001).

Additional examinations using adult samples have focused on the influence of self-efficacy for controlling glycemic blood levels in diabetics and the prediction of change without intervention. Chlebowy and Garvin (2006) conducted a study that included 91 adults (Black Americans=30\%) diagnosed with diabetes and investigated if their level of self-efficacy affected their ability to control their blood glucose level through increased self-care behavior. Results indicated non-significant relationships among glycemic control, self-care behavior, and self-efficacy. However, high levels of self-efficacy in an adult Black American sample predicted the stage of change, without intervention, over a one month period for smoking cessation, exercise adoption, and dietary fat reduction (O’Hea, Boudreaux, Jeffries, Carmack, Scarinci, \& Brantley, 2004). 
In summary, studies examining perceived health status among Black American adults and adolescents are limited. A review of the literature provided no studies that focused exclusively on males. Most of studies of perceived health have focused on adult females, thus supporting the need for the current study.

\section{Health Behaviors of Black American Adolescents and Adults}

Most research studies of health behaviors that have included Black American adolescent participants have focused on risky behaviors such as smoking (Adeyanju, 1990; Hu, Lin, \& Keeler, 1998; Watts \& Wright, 1990), sexual activity (Ensminger, 1990; Pete \& DeSantis, 1997), and substance use (Goodman \& Huang, 2002; Watts \& Wright, 1997). According to the (CDC, 2004), high-risk behaviors are the leading cause of morbidity and mortality among adolescents. The health behaviors of adolescents are critical; when an individual develops patterns of risky health behavior during adolescence, there is an increased chance that the individual will exhibit such behavior in adulthood (American Academy of Pediatrics, 2001; CDC, 2004).

The Youth Risk Behavior Survey (YRBS), which was used in the current study, is the primary source of information about the health risk behaviors of adolescents in the U. S. (CDC, 2006). Health risk behaviors in the survey include those behaviors that increase cardiovascular disease risk. Specific health behaviors pertinent to the current study are tobacco use, dietary habits, and physical activity, as these behaviors have a direct association with cardiovascular health and cardiovascular disease risk. Results of the 1997 Youth Risk Behavior Survey (Kann, Kinchen, Williams, Ross, Lowry, Hill et al., 1998) indicate that most of the unhealthy behaviors associated with cardiovascular 
disease, such as smoking, are initiated during adolescence. In this national survey, 16,262 questionnaires were completed in 151 schools. Data were not reported for each racial group. Cigarette smoking was reported by $36.4 \%$ of participants, while $70.7 \%$ had not eaten five or more servings of fruits and vegetables, and $72.6 \%$ did not participate in physical education classes daily.

Results of the 2005 Youth Behavior Survey (CDC, 2006) reflect the response of a national sample of adolescents in grades 9 through 12; the most recent data for this survey were collected from October 2004 to January 2006. The sample for this study $(\mathrm{N}=13,917)$ was $14.6 \%$ Black American. Results indicated that cigarette smoking was prevalent in $23 \%$ of high school adolescents, $67 \%$ reported that they did not participate in daily physical education school classes, and $13 \%$ of participating adolescents were overweight. The survey data were reviewed in aggregate without regard for ethnicity.

Using the Youth Risk Behavior Survey System to monitor health behaviors and the prevalence of overweight in American adolescents and young adults, the CDC employed a program called Steps to a Healthier US Cooperative Agreement Program (Brener, Kann, Garcia, MacDonald, Ramsey, Honeycutt, et al., 2007). The program conducted surveys of students $(\mathrm{N}=13,917$; Black American=2,031; 14\%) in selected communities and used a modified core questionnaire about physical behaviors, cigarette use, and overweight. Results revealed that $34 \%$ of adolescents participated in physical activity greater than five days a week. When asked about television viewing, $35 \%$ of teens reported watching television for more than three hours per day on an average school. Participants' current cigarette use, which was defined as one or more cigarettes smoked during the 30 days preceding the study, was $17 \%$. Overweight $\left(\geq\right.$ the $95^{\text {th }}$ 
percentile for BMI) was reported in $17.6 \%$ of study participants. The results of the survey were reviewed in aggregate without regards for race/ethnicity.

Many researchers have conducted secondary analyses using data from the Youth Risk Behavior Survey to compare the health risk status of American youths.

Socioeconomic status has been identified as a determinant of cardiovascular disease risk among Black American youth (Lee \& Cubbin, 2002). That is, socioeconomic status compromises youths' ability to sustain health habits, such as healthy eating and regular physical activity that deter cardiovascular disease. Whether or not environmental factors (e.g., neighborhood safety, walking trails, and parks) influence the health behaviors of adolescents is not entirely clear. Norman, Schmid, Sallis, Calfas, and Patrick (2005) suggested that sedentary habits developed in youth increase as individuals advance into the later adolescent years. Furthermore, these investigators found that minority males (Black males, $n=31,7.6 \%$ ) were more sedentary compared to non-minority youth. Using the Youth Risk Behavior Survey, physical activity levels were examined to determine reported levels of physical inactivity and other risk behaviors in Black American adolescent males.

Findings related to cardiovascular health risk behaviors (e.g., decreased physical activity) in Black American female adolescents indicate that a high level of social support from family and friends is needed in order to sustain regular physical activity (Frenn et al., 2005). However, videogame playing and television watching were found to contribute equally to decreased physical activity levels for both male and female Black American adolescents (Berkey et al., 2000). Other investigators have found that Black American adolescents participate in team sport more then the other ethnic groups (Dowda, 
Ainsworth, Addy, Saunders, \& Riner, 2001; Pate, Trost, Levin, \& Dowda, 2000). The significance of this finding is that participation in team sports may contribute to lower levels of overweight in males, compared to females. Data about team sports participation will be determined to characterize the current study sample.

Many studies exploring the health behaviors of adult Black Americans have focused on females. Guidry and Wilson (1999) described the health promoting behaviors of Black American registered nurses $(\mathrm{N}=49)$. Results indicated that more than $50 \%$ of the sample adhered to health-promoting behaviors, such as low alcohol intake, non-smoking, monitoring of cholesterol and glucose serum levels, and an annual pap smear and mammogram, and blood pressure screening.

Other variables are also documented as influencing Black American adults' health behaviors. Religion and education were found to be positively associated with health promoting behaviors, while smoking and ethnic background were found inversely correlated in a sample that included 198 adult females ( $n=145$ Black Americans). (Pettaway \& Frank, 1999). Jennings-Sanders (2003) investigated the health behaviors of men and women 65 to 85 years of age (mean $=78$ years) during the two consecutive health fairs. More than $50 \%$ of participants $(78 \%)$ were female and all participants had at least two chronic diseases. The study's framework was guided by the Transtheoretical Model of behavior change (Prochaska \& DiClemente, 1983). Educational information was provided during the first health fair and participants' base line health behaviors were assessed. The study findings revealed that most participants during the second health fair assessment were in the precontemplation stage regarding vision care, nutrition, exercise, smoking, and dental health behaviors. However, those individuals with hypertension and 
diabetes were in the maintenance stage of change, suggesting that they viewed their health as being more important than participants without chronic illnesses. Therefore, it may be more difficult for older individuals to change their health behaviors because of cost, transportation difficulty, and physical impairments (Jennings-Sanders, 2003). Healthy adolescent may not face these same barriers and may be more receptive to changes in health behaviors. Thus it is important to understand the factors that influence the health behaviors of adolescent male populations prior to designing intervention programs.

\section{Summary of the Review of Literature}

A review of the literature reveals that cardiovascular risk factors such as race and gender can predispose Black Americans, in particular adolescents to increased morbidity and mortality as they advance into adulthood. Although all risk factors cannot be modified, several risk factors such as physical inactivity, smoking, and overweight have been examined in adolescent and adult populations. While relationships between sustained physical activity and body mass index reduction have been documented related to Black American youths, more research is needed that tests interventions in order to improve their current risk profile and future health outcomes. One modifiable risk factor, cigarette smoking, has been found to be less prevalent among Black American adolescents, compared to other ethnic or racial groups. The important point regarding this information is that although reported smoking behavior among Black American youths is below the national average, their continued participation in other health risk behaviors (e.g., physical inactivity) increase their risk of cardiovascular disease early in adult life. 
Relevant literature about the cardiovascular health of adult Black Americans suggests multifaceted factors leading to cardiovascular disease. Cardiovascular disease in adults has been linked to contextual, genetic, and physiological factors. Contextual factors include racism, socioeconomic status, chronic stress, healthcare access, and geographic residence, while blood pressure dipping and family medical histories are implicated as possible physiological causes leading to the development of cardiovascular disease.

The current literature indicates that health behaviors of adolescent and adult Black Americans may be influenced by perceived health barriers, health status, and selfefficacy. Study findings related to Black American teens and adults, although limited, suggest that a person's perception of health barriers may depend upon their age and life experiences. Hence an older person may perceive more barriers depending on whether or not they already have health problems. Adolescents may not be as concerned about health behaviors as much as adults because their parents or guardians usually manage their health care and make many health care decisions; therefore they may not be conscious of health barriers.

Perceived health status has been found to be lower among adult Black American males compared to adult non-Black American males. But, most studies investigating perceived health status among Black American adolescents indicate an overall high level perceived health status. One study found in the literature, reported Black American adolescents in middle school as having a significantly lower level of perceived health status compared to other ethnic or racial groups. Regardless of the level of perceived 
health of Black Americans compared to other groups, this variable needs to be addressed as it may influence health behaviors and health outcomes.

Self-efficacy has also been explored in a limited fashion in adolescent Black American males. One study indicated that adolescent Black American males have high levels of self-efficacy compared to adolescent females. In general the current literature has focused on the influence of self-efficacy on health behaviors of adult Black American females investigating weight and physical activity and no studies were found that focused on adult Black American males. This gap in the literature provides support for the need to examine self-efficacy in Black American adolescent male populations.

This review of literature supports the need for the current study. There is a relative lack of research on Black American adolescents, in particular research related to the current study variables. No study was found that explored perceived health barriers, perceived health status, or self-efficacy as it relates to health promotion behaviors among Black American male adolescents. Additionally, the literature review suggests that elevated blood pressures and overweight are prevalent among Black American adolescent populations and these health conditions are influenced by risky health behaviors such as physical activity.

Many studies have focused on the negative outcomes experienced by these youth. In contrast, the current study focuses on health promotion activities. This review of literature has provided insight about future research needs regarding Black American adolescent males. Results from the current study will add to the literature, decreasing the knowledge gap that currently exists. In particular, the study findings provide data about perceived health barriers, health perceptions, cardiovascular health risk factors, and 
health promotion behaviors that could influence the health outcomes and guide community-based intervention program development for this at risk population. 


\section{CHAPTER III: METHODOLOGY}

Research indicates that Black American men's health behavior is linked to health barriers, health perceptions, and cardiovascular health risk factors. Limited research is available regarding the health behaviors of adolescent Black American males and the incidence of these predictor variables in this population. Thus, this study was designed to investigate the relationships among health promotion behaviors, health barriers, health perceptions (health status and self-efficacy), and cardiovascular health risk factors of adolescent Black American males. This chapter presents the research design, sample, setting, instrumentation, procedures used, and human subject considerations in this study.

\section{Research Design}

This study incorporated a descriptive-correlation cross-sectional design to explore the associations among health barriers, health perceptions, and cardiovascular health risk factors. In addition, these variables were examined as predictors of health promotion behaviors in the study sample. Because samples were derived from four recruitment sites in two southern states, data were compared to determine if data obtained from Tennessee and Louisiana participants could be combined to address the study aims. Multiple paper and pencil questionnaires and biological measures were used in the study. The health barriers questionnaire examined the adolescent's self-report of the obstacles that interfere with his ability to adhere to health-promoting behaviors. Health perceptions were examined using self-report questionnaires to assess perceived health status and health self-efficacy. Cardiovascular health risk factors examined included both modifiable and 
non-modifiable risk factors. Modifiable factors were examined by performing fasting blood glucose and total cholesterol levels, height and weight measurement (to calculate BMI), evaluation of a 3-day food record, and blood pressure monitoring. Non-modifiable risk factors such as family medical history were determined using the Student Health Screening and the Adolescent Demographic Profile Questionnaires. Adolescent health promotion behaviors were examined using a self-administered survey that has widespread use and addresses a full perspective of youth risk behavior, the Youth Risk Behavior Survey.

\section{Sample and Setting}

The targeted sample of 99 Black American adolescent males included six adolescents with known cardiovascular disease, who were excluded from the study. Adolescents who met the inclusion criteria resulted in a sample size of 92 participants. Recruitment was conducted from three urban geographic locations in the southern region of the United States. The data collection sites included Louisiana, middle Tennessee, and west Tennessee. Participants recruited in Louisiana $(n=63)$ had a mean age of 14.73 years, while Tennessee $(n=29)$ participants had a mean age of 16.51 years. The sample selection was open to Black American male adolescents who met the criteria described below.

Adolescents included in the study were required to:

(1) Self-identify as male and of Black American ethnicity.

(2) Be 13 to 18 years of age on last birthday.

(3) Understand, read, speak, and write using the English language. 
(4) State a willingness to participate in the study, as evidenced by verbal assent and signed consent.

(5) Have a signed parental consent form.

(6) Not have a known cardiovascular disease.

Adolescents were excluded from the study based on the following exclusion criteria:

(1) Self-identify as non-Black American male.

(2) Were less than 13 years old or older than 18 years of age as of last birthday.

(3) Were unable to understand, read, speak, or write the English language.

(4) Were not willing to provide verbal assent and signed consent.

(5) Were unable to provide written parental consent.

(6) Had a known cardiovascular disease (hypertension, coronary heart disease, or heart failure). Verification of diagnosis was confirmed by participants' parents.

\section{Instrumentation}

Eight instruments were used in the study: 1 questionnaire to assess demographic characteristics, 1 to assess health history, 5 questionnaires to assess study variables, and 1 food record to assess dietary intake. The estimated time to complete study questionnaires was 35-45 minutes for adolescents and 5-10 minutes for parents to assist participants with the demographic and health screening form. 


\section{Adolescent Demographic Questionnaire}

The Adolescent Demographic Data Form was developed by the principal investigator under the guidance of Dr. Mona Newsome Wicks and is a pencil and paper questionnaire that provided characteristics of the sampled population. Nine questions were included in the questionnaire with forced choice questions. Specific questions included: age, family structure, parent's educational level, annual household income, medical history, and participation status in school screenings, free lunch program, and school sports. The demographic questionnaire was completed jointly by the adolescent and parent and has a reading grade level grade 11.5. The estimated time to complete the demographic questionnaire was no more than 3 to 5 minutes.

\section{Adolescent Health Screening Form}

The principal investigator developed the Adolescent Health Screening Form under the guidance of Dr. Mona Newsome Wicks. The form is a pencil and paper questionnaire that solicited participant and family health history. Additional items on the questionnaire asked about allergies and if the adolescent has ever smoked cigarettes. The questionnaire included seven items that were a mixture of open-ended and forced choice questions with a reading grade level of grade 8.0.

\section{The Barrier Question (BQ)}

The Barrier Question item was used to measure perceived obstacles influencing adherence to health-promoting behaviors. The Barrier Question developed by Martin et 
al., (1999) used Pender's (1996) definition of perceived barriers and has a reading grade level of 7.7. The adolescent responded to one question "What are the 3 major things in your life that will keep you from making lifestyle changes for the sake of your health?" Each adolescent participant completed the BQ independently. The principal investigator analyzed the content to identify barrier categories based on participants' responses. The questionnaire has face and content validity. The barriers questionnaire provided information about the adolescent's perceptions of the obstacles that exist influencing his ability to affect his health.

\section{Self-Rated Abilities for Health Practices Scale (SRAHP)}

The Self-Rated Abilities Health Practice Scale was used to measure adolescent participants' perceived health status. The SRAHP Scale was developed to measure the perceived health status of individuals with disabilities. Stuifbergen (personal communication, February, 2005) reported that previous investigators have altered the instrument questions for use with non-disabled populations. Permission was granted for the current study to modify specific questions that did not apply to non-disabled individuals. Modifications to the questions were substituted with simple synonyms to increase the relevance of the questions for the study population. For example, the original question was written, I am able to watch for negative changes in my body's condition (pressure sores and breathing problems). The modified question read I am able to watch for negative changes in my body's condition (headache and stomach pain). The modified questionnaire was given to three groups of Black American male adolescents in Nashville and Memphis, Tennessee, and Baton Rouge, Louisiana. The adolescents were asked to 
review the revised questionnaire for clarity and to report if they experienced difficulties answering the revised questionnaire. Participants answered all questionnaire items and denied difficulty completing the questionnaire. The modified version of the SRAHP was used in this study to quantify perceived health status in the study population.

The instrument was chosen because the tool asks questions that reflect the individual's perception of their health. Perceived health status is directly related to the process of knowing healthy behaviors (Settersten \& Lauver, 2004). The SRAHP scale was developed by Becker, Stuifbergen, Oh, and Hall (1993). The instrument measures four dimensions of perceived health that reflect the ability to perform health-promoting practices in the domains of nutrition, physical activity / exercise, psychological wellbeing, and responsible health practices. Using a 5-point scale from 0 (not at all) to 4 (completely) the adolescents were asked to rate their ability perform 25 health behaviors. The sum of the response was totaled to yield a total score. The score ranges from 0 to 100. High scores indicate a high level of perceived health status. The stem for each question is "I am able to". Content validity of the original SRAHP has been reviewed and evaluated by nine expert reviewers in practice who cared for individuals with disabilities (Stuifbergen \& Becker, 1994). Reported (Becker, Stuifbergen, Oh, \& Hall, 1993) construct validity was determined using factor analysis, which identified a four-factor solution that accounted for $61 \%$ of the factor variance in the self-rated abilities for health practices. The internal consistency reliability is reported as a Cronbach's alpha of 0.94 for the total scale among health fair participants $(\mathrm{N}=188)$ and undergraduate nursing students $(\mathrm{N}=111)$. Two-week test-retest reliability in the student sample was .70. The subscale alphas are reported as exercise, 0.92 ; nutrition, 0.81 ; psychological well-being, 
0.90; and responsible health practices, 0.86 . The Cronbach alpha for the total scale in the current study sample was 0.87 . The reading grade level of the SRAHP is grade 8.7 and the instrument requires 3 to 5 minutes to complete.

\section{Self-Efficacy Scale (SES)}

The Self-efficacy Scale was used to measure adolescent perception of selfefficacy. The SES is a 12-item scale developed by Hardin, Weinrich, Weinrich, Hardin, and Garrison (1990). The scale measures perceptions of one's ability to attend to and promote personal health. The SES was chosen because it was developed to screen adolescents and has been used with adolescent Black American students. The instrument was constructed using a definition of self-efficacy that is consistent with the manner in which the principal investigator for this study defined the concept. Using a 5-point scale from 1 (not at all) to 5 (very much), the adolescents were asked to rate their belief that they can affect change in their lives. The sums of responses were totaled to yield an overall score. The possible range of overall scores is 12 (poor self-efficacy) to 60 (high self-efficacy). Sample items are "Once I know what I need to do, I can do it" and "I have a high opinion of my abilities". Internal consistency reliability was 0.90 for a population of 46.1\% Black American, 44.7\% European American, 45.3\% female, and $45.5 \%$ male participants (Grubbs et al., 1992). The Cronbach's alpha coefficient was estimated to measure internal consistency reliability within the current study sample $(r=0.87)$. The SES has moderate to strong content validity with a reading level grade 3.1. Required time for completion of questionnaire is 3 to 5 minutes. The total score on this instrument was used to describe the rating of health self-efficacy in the adolescent study sample. 


\section{Youth Risk Behavior Survey (YRBS)}

The Youth Risk Behavior Survey is a 49-item self-administered survey developed for use among adolescent youth by the CDC (2002). This tool was chosen because of its ability to address a full perspective of youth risk behavior and widespread use. The questionnaire includes seven items that assess demographic information, safety and violence, and body weight; eight items assess tobacco use, eight items assess alcohol and other drug use, four items assess sexual activity, four items assess physical activity, and one item assesses AIDS education. A test-retest of the YRBS was conducted by the CDC in a national sample of students enrolled in grades 7 through 12 in 1992 and 2000 (CDC, 2004). The questionnaire was administered 14 days apart and a kappa score of $61 \%$ $100 \%$ demonstrated a high level of test-retest reliability. The YRBS identifies the risk factors prevalent among the sampled population and was used to describe health risk. The questionnaire reading grade level is 6.6. Estimated completion time is 15-20 minutes.

\section{Adolescent Health Promoting Scale (AHP)}

The Adolescent Health Promotion Scale is a 40-item Likert-type self-report instrument that was used to measure health promoting behaviors in the study adolescents. The instrument was chosen because the tool asks questions that reflect health promoting behaviors used by adolescents. The instrument measures six domains of health promotion activity based on nutrition behaviors (6 items), social support (7 items), life appreciation (8 items), health responsibility (9 items), exercise behaviors (4 items), and stress management (6 items). Using a 5-point scale, the instrument obtains data regarding the 
frequency of reported behaviors ranging from never (1), sometimes (2), half the time (3), often (4), and always (5). The score range is 40 - 200. A high score suggest that the adolescent uses a high level of daily health promoting activities. The Cronbach's alpha reliability for the total scale is reported to be 0.932 . The alpha coefficients for the six subscales are range from 0.75 to 0.88 . For the current study the Cronbach alpha coefficient for the total scale in the sample was 0.93. The subscale Cronbach alpha coefficients for the current study are nutrition (.73), social support (.77), health responsibility (.75), life appreciation (.90), exercise (.72), and stress management (.72). The ADHP Scale reading level is grade 6.9 and estimated time of completion was 15 to 20 minutes. The ADHP has good construct validity and content validity (Chen, Wang, Yang, \& Liou, 2003).

\section{Food Record Booklet}

The food record booklet is a self-administered food record that requires the participant to document a complete record of his food and liquid intake for three days. The adolescents were instructed to document even the smallest of items consumed, such as a slice of gum. Four columns are listed on the food record: meal type, place where meal was prepared, food and beverages, and amount. The 3-day food record assisted with estimating the eating habits and dietary consumption of the sampled population and required less than 2 minutes per entry for the adolescent to record nutritional intake, which influences health outcomes. The use of 3-day food records provides an opportunity to identify food intake patterns and the most frequent foods of the diet (Togo, Heitmann, Sorenson, \& Osler, 2003). An analysis of the 3-day food record addressed research 
questions related to cardiovascular health risk factors influenced by diet patterns among the adolescent study population. Food records have been used successfully as a valid measure for assessing nutritional intake. Analyzed data provided by 3-day food records used in a longitudinal study of children from 3 to 12 years (Moore, Singer, Bradlee, Djousse, Proctor, Cupples, \& Ellison, 2005) suggested that diets rich in fruits, vegetables, and dairy products may have beneficial effects on blood pressure change among elementary and middle school students.

\section{Accu-Chek Instant Plus System}

The Accu-Chek Instant Plus System (Roche Diagnostics, 2002) is a palm-sized, battery operated glucose and cholesterol testing system. Capillary whole blood derived from a single finger stick, is collected onto a test strip, inserted into the handheld testing system, and glucose and total cholesterol levels are provided in 12 seconds and 3 minutes respectively. To assess precision and accuracy testing of the device, Boehringer Mannheim Corporation (1997) conducted ten test sessions comparing to another manufacturer's device. Results revealed Cramer's V (CV) for precision was less than 5\% and a mean bias of $-1.2 \%$ while the competitor exhibited an $8.4 \%$ mean bias. The predicted bias at 200 and $240 \mathrm{mg} / \mathrm{dl}$ were $-1.2 \%$ and $-1.0 \%$ respectively for Accu-Chek Instant Plus System. The comparative device displayed a predicted bias at 200-240 mg/dl of 8.3 and $8.9 \%$. Blood glucose and total cholesterol levels were measured using the device and collected by the principal investigator. The principal investigator's experience with operating glucose monitors includes 24 years as a professional nurse with hospital, public health, and home health care nursing. Quality control checks were performed 
before each testing session as recommended by the manufacturer using glucose and cholesterol control solutions sold by the Roche Laboratories.

\section{Blood Pressure, Heart Rate, Weight, and Height Screening}

Blood pressure (BP) and resting heart rate (HR) measurements were collected in this study to assess the adolescents' risk for developing cardiovascular disease. In adolescents BP standards that are based on sex, age, and height provide a precise classification of BP according to body size (USDHHS, 2005), therefore BP tables developed by the National Center for Health Statistics (2000) were used to determine if the participants' BP reading was prehypertensive. Normotensive BP in adolescence is defined as systolic BP (SBP) and diastolic BP (DBP) that is $<90^{\text {th }}$ percentile. Blood pressure readings were collected using an auscultatory sphygmomanometer, stethoscope, an appropriate sized BP cuff placed on the upper arm. The right arm is preferred only if repeated blood pressures measures are required in the clinical settings to ensure consistency and because of the possibility of coarctation of the aorta, which can lead to low or false blood pressure readings in the left arm (Rocchini, 2000). Prehypertension is defined as a BP level $\geq 120 / 80$ (USDHHS, 2005); therefore adolescent BP readings $\geq$ $120 / 80$ was repeated after five minutes. Blood readings that exceed 120/80 were reported to parents in writing for medical follow-up. Height without shoes was determined using a wall-mounted measuring device calibrated in inches. Weight was measured using a Healthometer floor-style medical scale in light clothing and without shoes. 


\section{Data Collection Procedure}

Permission from The University of Tennessee Institutional Review Board (IRB) was obtained and written approval for the school clinic director, church pastor, and community youth. A letter of approval was presented to each data collection site. The principal investigator collected all study data.

\section{Site Preparation}

Three weeks prior to the data collection date, IRB approved recruitment posters and brochures were placed in visible areas of the church, school clinics, and community center by the principal investigator to advertise for study participants. The principal investigator's name and toll free pager number were included on the brochure and flyer to answer parental questions. Parents were offered the opportunity to page the principal investigator free of charge and the principal investigator returned the call as soon as possible.

Two weeks prior to the data collection date a study information packet that included an IRB approved letter, study brochure, demographic questionnaire, health screening form, and consent form were presented to the parents by the respective secretaries of each location. Letters to the parents included the purpose, approximate time required to complete questionnaires, types of blood tests collected via finger stick, physiological measures to be collected, anonymity of the questionnaires, the monetary incentive given to participating adolescents upon completion of the study, time and place of data collection, and the need for students to fast six hours prior to finger sticks. The 
principal investigator's name and toll free phone number were available in the letter and on the brochure, in the event that additional information was needed or there are additional questions from the parents of potential participants. The church, school clinics, and community center staff was informed of the study's purpose, data collection procedures, and the principal investigator's contact number. Signed parental consent forms were returned to the church, school, and community center's secretaries for pickup by the principal investigator one week prior to the data collection date. Study participants who were 18 years provided their own written and consent.

\section{Instructions to Participants}

On the day of data collection the principal investigator provided instructions to the participants as a group and provided an opportunity for them to ask questions. The principal investigator emphasized that if an adolescent did not wish to participate in the study that his decision would over-ride his parental consent and he would not participate in this study.

\section{Data Collection}

The principal investigator using dedicated equipment provided by the investigator collected blood pressure, heart rate, height without shoes and weight with light clothing and without shoes. A nutritious snack was provided while adolescents completed the study questionnaires (after physiological data are collected). Approximately half a teaspoon of capillary whole blood was used to check the participants' blood glucose and cholesterol. Every effort was made to collect an adequate amount of blood with one 
finger prick. Each participant was required to wash his hands with antibacterial soap, warm water, and dry his hands prior to blood collection. Participants' arms hung down at their sides briefly to allow blood flow to fingertips. Keeping the hands down, the finger was pricked on the side of the fingertip and squeezed gently until a hanging drop of blood is collected. Universal precautions were used in the collecting of blood and disposal of used lancets, test stripes, and cotton balls and place in a designated biomedical hazardous sharps container.

Upon completing the physiological data (BP, HR, height, and weight), collection and study questionnaires the adolescent received a gift card from Wal Mart valued at $\$ 15.00$ as a thank you for participating in the study. The adolescent signed a form acknowledging receipt of the gift card; the principal investigator in secure file cabinet accessible only to the principal investigator stored this receipt. The questionnaires were anonymous and no names appeared on the questionnaires; only codes were used on the actual questionnaires.

The principal investigator reviewed completed questionnaires. If missing data were noted on the questionnaire, the participant was asked to review and complete the questionnaire at the time of collection. Assistance with these missing items was provided as needed by the principal investigator.

\section{Data Transfer}

Study data were transferred from the questionnaire to a password protected Microsoft Excel computer spread sheet, uploaded to the university's mainframe VAX cluster, and analyzed using Statistical Analysis System (SAS) software. Data were 
entered into the Microsoft Excel file after it was collected from each study site.

Adolescent data files were saved as password protected documents on computer disks for backup copies. All data were coded to protect the adolescent's confidentiality and anonymity. All collected physiological data were shared with participants' parents using a standard IRB-approved form developed for the study.

\section{Statistical Analysis}

Descriptive statistics were used to summarize the demographic data for the entire sample and by state (Louisiana and Tennessee). The sample was characterized using measures of central tendency (mean and median), variability (range and standard deviation), and frequency distributions (symmetrical and asymmetrical) using SAS software. The adolescent characteristics that were summarized included age, family structure, parental education level, annual household income, student's annual medical screening and physical exams, free-lunch program and school sports participation. These independent variables were coded as either continuous or categorical scores. Additional analyses of demographic data were conducted, based on state location using the KruskalWallis Test.

The relationships and degree of association among the variables perceived healthstatus, self-efficacy, and cardiovascular risk factors were examined using Spearman's Rho correlation coefficients. Stepwise mixed multiple regression analysis was used to examine the contribution and significance of each of the predictor variables to healthpromoting behaviors scores. 


\section{Specific Aim 1}

Describe the perceived barriers to health, perceived health status, self-efficacy, health promotion behaviors, and cardiovascular risk factors reported by adolescent Black American males without known cardiovascular disease. The research questions related to Aim 1 were as follows:

(1a) What are the perceived health barriers reported by adolescent Black American males without known cardiovascular disease?

(1b) What is the level of perceived health status reported by adolescent Black American males without known cardiovascular disease?

(1c) What is the level of self-efficacy reported by adolescent Black American males without known cardiovascular disease?

(1d) What are the cardiovascular health risk factors present in and reported by adolescent Black American males without known cardiovascular disease?

(1e) What are the cardiovascular health promotion behaviors reported by adolescent Black American males without known cardiovascular disease?

Inferential statistics were used to describe the perceived health barriers, perceived health status, self-efficacy, and cardiovascular health promotion behaviors as reported by the study sample. Data were reported for the entire sample and by state. Inferential statistics are estimates that describe the data in a population. Therefore, univariate descriptive statistics were used to describe the central tendency and dispersion of perceived health barriers, health status, self-efficacy, and cardiovascular health promotion behaviors among adolescent Black American males without known cardiovascular disease. 


\section{Specific Aim 2}

Examine the association between perceived health status and self-efficacy of adolescent Black American males without known cardiovascular disease. The related research Question 2 was: What is the association between perceived health status and self-efficacy of adolescent Black American males without known cardiovascular disease?

Correlational analysis was used to examine the direction and strength of the association between perceived health status and self-efficacy for the study sample. The Spearman Rho correlation coefficients were computed and a graphic plot of the relationship between variables was constructed to aid visualization of linearity.

\section{Specific Aim 3}

Determine the influence of perceived health barriers, perceived health status, selfefficacy, and cardiovascular health risk on the health promotion behaviors of adolescent Black American males without known cardiovascular disease. The related research Question 3 was: What is the influence of perceived health barriers, perceived health status, self-efficacy, and cardiovascular health risk factors on the health promotion behaviors of adolescent Black American males without known cardiovascular disease?

Correlation measured the degree to which the variables (perceived heath barriers, perceived health status, self-efficacy, cardiovascular health risk factors, and health promotion behaviors) co-varied. The Spearman Rho correlation coefficient $(r)$ was used to estimate the direction and magnitude of bivariate relationships among the predictor variables (perceived health status, self-efficacy, and cardiovascular health risk factors) 
and the outcome variable (health promotion behavior). A graphic plotting of the relationship between the variables was performed to facilitate visual examination of the relationships and to determine if they were linear.

Multiple regression analysis was conducted to find a linear relationship between the independent variables (perceived health barriers, perceived health status, selfefficacy, and cardiovascular health risk factors) and the outcome variable (health promotion behavior based on the entire sample. A predication was made to estimate the value of the dependent variable contingent upon the value of the outcome variable. The inclusion of the independent variables in the multiple regression model was determined using mixed direction stepwise regression. That is, the predictor variables (perceived health status, self-efficacy, and age and BMI) were included in the model and removed until the only statistically significant variables remained.

\section{Consideration of Human Subjects}

Human subject considerations are related to consent for participation, potential risks to subjects, and protection of confidentiality. An informed consent was obtained from the participants' parent or legal guardian prior to the initiation of the study. Participants who were 18 years provided written consent for participation in the study. The study was explained to each adolescent group in age-appropriate language. Voluntary participation was stressed to each adolescent who provided signed parental consent forms and assent. Parents and adolescents were provided an opportunity to ask questions and to call the principal investigator if they had additional questions. In the event that the participant refused to assent, the parent's consent was overridden and the 
participant was excluded from the study. Each participant was assigned a study code number and only the study code number was attached to the data to protect the confidentially of the participants. All participants' data were kept in a locked file. Consent forms and the table listing the participant name, pseudonym, and code number were kept in a separate locked file. 


\section{CHAPTER IV: RESULTS}

\section{Adolescent Characteristics}

Because the study sample was recruited from four sites in two states, the investigator examined the entire sample to determine whether there were differences between adolescents' demographic characteristics and to calculate the scores for the independent and outcome variables by state of residence. The four sites in the study included two study sites in Louisiana, a middle and high school, and two sites in Tennessee, a church community and a youth recreational center.

\section{Descriptive Statistics}

Descriptive statistics were used to summarize the demographic data and describe the sample as a group. Characteristics of the entire group included measures of central tendency (mean, median), variability (standard deviation, interquartile range), and frequency distributions. The Mann Whitney test was performed to assess differences by state of residence for variables that were continuous and Chi-square analysis provided an assessment of differences for variables measured at the nominal level. The Mann Whitney test rather than the independent t-test was performed for continuous variables as most study variables did not reflect normal distributions. For nominal data with greater than two levels and two categories, e.g., greater than $2 \times 2$ contingency tables, the Cramer's V statistic was manually calculated and the p-value for Chi square reported, as is convention. Cramer's V (symbolized by C) is the square root of Chi square divided by sample size (n), times $m$ where $m$ is the smaller of (rows-1) or (columns-1) (Lowry, 
2007) When appropriate, Fisher's exact test was used if greater than $20 \%$ of the contingency table cells were less than 5 .

The total sample consisted of 92 Black American male adolescents. The mean age of the study participants was 15.26 years $( \pm 2.09)$. Adolescents recruited from south Louisiana had a mean age of 16.8 years $( \pm 1.48)$ while subjects from middle Tennessee were on average 17 years $( \pm 1.10)$ of age and west Tennessee were 15.4 years of age $( \pm 2.00)$. Specific demographic information collected related to family structure, parental education, annual household income, if adolescents received annual medical and sports screenings, and received free lunch in school is summarized in Tables $\mathbf{1}$ and $\mathbf{2}$ for the entire sample and by study site and state of residence. Between-group differences by the four recruitment sites were not explored as the original intent was to enroll adolescents 13 to 18 years of age who lived in the two states. Instead between-group differences were examined by state as state of residence might influence student's responses to the study questionnaires.

Results revealed that adolescents in group 3 differed from the other three groups with regard to several demographic traits. The students recruited from a Louisiana middle school were significantly younger than the other three groups. Nonetheless, the study adolescents were recruited purposefully from the two schools in order to have teens in the study that met the inclusion criteria of 13 to 18 years of age, thus data are reported collectively for participants recruited from Louisiana. Results comparing adolescents based on their state of residence revealed significant differences for only three variables, age ( $p=.0007)$, parent education $(p=.002)$, and participation in the federal free lunch program $(p=0.048)$. Tennessee adolescents were significantly older and had parents who 
Table 1. Adolescents' Demographic Characteristics by Study Site

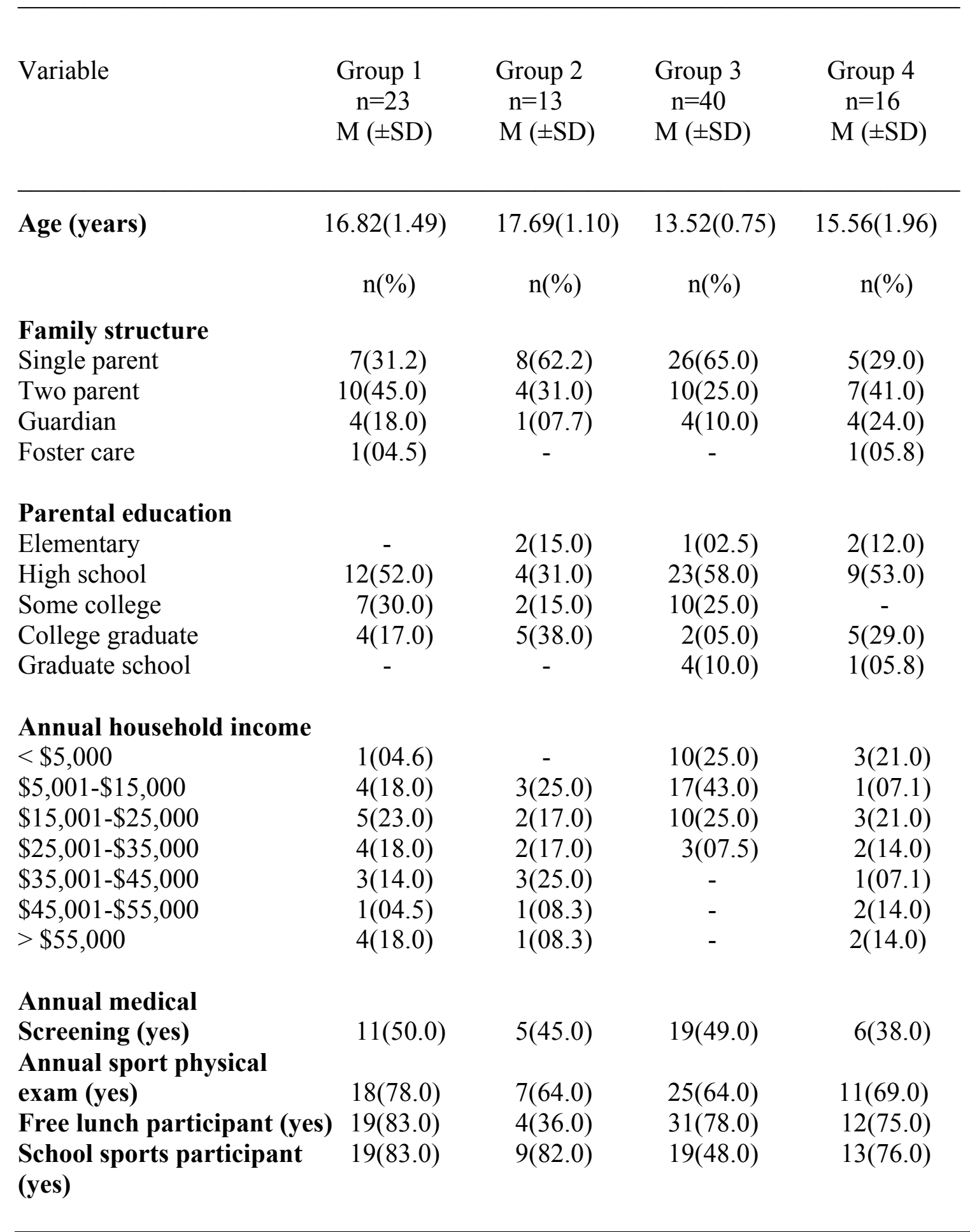

Note. Groups 1 and 3 are high and middle school adolescents, respectively in Louisiana. Groups 2 and 4 are from middle Tennessee and west Tennessee, respectively. - Indicates not applicable. 
Table 2. Adolescents' Demographic Characteristics for the Sample and by State of Residence

\begin{tabular}{|c|c|c|c|}
\hline & $\begin{array}{c}\text { Sample } \\
\mathrm{N}=92 \\
\mathrm{M}( \pm \mathrm{SD})\end{array}$ & $\begin{array}{c}\text { Louisiana } \\
\qquad \mathrm{n}=63 \\
\mathrm{M}( \pm \mathrm{SD})\end{array}$ & $\begin{array}{c}\text { Tennessee } \\
\mathrm{n}=29 \\
\mathrm{M}( \pm \mathrm{SD})\end{array}$ \\
\hline Age (in years) & $15.26(2.09)$ & $14.73(1.92)$ & $16.51(1.93)^{*}$ \\
\hline \multicolumn{4}{|l|}{ Family structure } \\
\hline Single parent & $46(50.00)$ & $33(53.00)$ & $13(43.00)$ \\
\hline Two parents & $31(33.69)$ & $20(32.00)$ & $11(37.00)$ \\
\hline Guardian & $12(13.04)$ & $8(13.00)$ & $5(17.00)$ \\
\hline Foster care & $1(1.08)$ & $1(1.58)$ & $1(3.44)$ \\
\hline \multicolumn{4}{|l|}{ Parental education } \\
\hline Elementary & $5(5.43)$ & $1(1.50)$ & $4(13.00)$ \\
\hline High school & $48(52.17)$ & $35(56.00)$ & $13(43.00)$ \\
\hline Some college & $19(20.65)$ & $17(27.00)$ & $2(06.00)$ \\
\hline College graduate & $16(17.39)$ & $6(9.50)$ & $10(33.00)$ \\
\hline Graduate school & $5(5.43)$ & $4(6.30)$ & $1(03.30)$ \\
\hline \multicolumn{4}{|l|}{ Annual income } \\
\hline$<\$ 5,000$ & $14(15.21)$ & $11(18.00)$ & $3(12.00)$ \\
\hline$\$ 5,001-\$ 15,000$ & $25(27.17)$ & $21(34.00)$ & $4(15.00)$ \\
\hline$\$ 15001-\$ 25,000$ & $18(19.56)$ & $15(24.00)$ & $5(19.00)$ \\
\hline$\$ 25,001-\$ 35,000$ & 11(11.95) & $7(11.00)$ & $4(15.00)$ \\
\hline$\$ 35,001-\$ 45,000$ & $8(8.69)$ & $3(4.80)$ & $4(15.00)$ \\
\hline$\$ 45,001-\$ 55,000$ & $4(4.34)$ & $1(1.6)$ & $3(12.00)$ \\
\hline$>\$ 55,000$ & $4(4.34)$ & $4(6.30)$ & $3(12.00)$ \\
\hline $\begin{array}{l}\text { Annual medical screening } \\
\text { (yes) }\end{array}$ & $46(50.00)$ & $31(50.80)$ & $15(56.00)$ \\
\hline Free lunch * (yes) & $66(70.96)$ & $50(79.00)$ & $16(59.00)$ \\
\hline $\begin{array}{l}\text { School sports participant } \\
\text { (yes) }\end{array}$ & $61(65.59)$ & $38(60.00)$ & $22(79.00)$ \\
\hline
\end{tabular}

Note. * Indicates a significance level of $\leq .05$ for age in Tennessee compared to Louisiana participants. 
were more highly educated. Although significantly more Louisiana participants were in the free lunch program, there was no significant difference in the income categories reported by parents of the two groups $(p=.12)$.

The examination of the study sample based on their state of residence was particularly important as many of the children from Louisiana were affected by hurricane Katrina in the months prior to data collection. Thus, the relocation experience could have influenced adolescents' responses to the study questionnaires, especially as it relates to the participation in the free lunch program. Given the significantly different subgroup characteristics in the areas of age, parental education, and free lunch program participation, the decision was made to examine the research questions for the entire sample and by state of residence.

The family medical histories reported by the study adolescents included hypertension $(55 \% ; n=33)$, heart problems $(29 \% ; n=11)$, and diabetes $(35 \% ; n=33)$. The prevalence of cardiovascular disease in the family histories of the study sample in the context of their personal risk factors is an important demographic finding providing validity to the investigator's concerns about future cardiovascular disease risk in this population.

\section{Research Aims, Questions, and Findings}

Study findings are reported for each specific aim and question in sequence, with each aim and relevant research questions restated followed by the results of the statistical analyses. Results are reported for the entire sample and by state of residence. Appropriate 
parametric statistical tests, such as median scores and interquartile ranges, were performed for those data that were not normally distributed.

\section{Specific Aim 1}

Describe the perceived barriers to health, perceived health status, self-efficacy, health promotion behaviors, and cardiovascular risk factors reported by adolescent Black American males without known cardiovascular disease. This aim had five accompanying questions.

Question 1a. What are the perceived health barriers reported by adolescent Black American males without known cardiovascular disease? The findings follow:

The data collected using the Barrier Questionnaire described the perceived barriers to health reported by the adolescents in the study. A qualitative methodology, content analysis, was used to facilitate the examination of the barriers through data reduction. During the reduction of the data, the researcher began attaching meaning to elements in the data (Burns \& Grove, 2001). Through a process of coding, each reported barrier was reviewed and placed in broad categories that did not overlap. After the initial step of organizing and dividing the data into broad categories, each category was collapsed using descriptive codes that identified the categories based on the original barriers reported by the adolescents. Descriptive codes classified elements of the data by using terms that the participant had used (Burns \& Grove, 2001). As the barriers were reviewed, remarks and memos were documented in the margins to assist the researcher in developing and linking themes together. The process of data analysis provided an 
opportunity to gain increased insight into the barriers to health faced by the adolescents in this study.

A review of the reported barriers revealed that several participants were uncertain how to answer of the barrier question: "What are the three major things in your life that will keep you from making lifestyle changes for the sake of your health?” Twenty-four percent $(n=22)$ of the adolescents responded to the question by providing an answer concerning how they could improve their health instead of explaining what prevents them from making lifestyle changes to improve their health. During the data collection phase of the study at each data collection site, this researcher provided instructions and adolescents were encouraged to ask questions while completing the questionnaire booklet. This obvious lack of understanding among the sample suggests that instruments designed for adults may not be appropriate for use in adolescent populations, requiring modifications and use in pilot studies prior to use in younger populations.

Results of the group data analysis revealed four categories of perceived barriers to health reported by Black American adolescent males: diet, environment, finances, and other. Thirty-two percent $(n=30)$ described their diet as a health barrier. For example, several adolescents wrote that eating foods high in fat and sugar and consuming fast foods was a health barrier. Specific responses were "not eating healthy," "eating wrong foods," "bad diet," "not eating right," and "eat a lot of candy." The reported environmental barriers focused on questionnaire responses related to stress and peer pressure. In particular, the precise responses written by the participants were "not exercising regularly," "hanging around the wrong crowd," "lack of time," "drinking alcohol," "new situations arise," "drugs," and "stress." 
The adolescents identified results in the finance category by using one word, money. No additional words or statement were documented by the sample, suggesting that Black American male adolescents view money as an important element in improving or maintaining their health $(n=4,4.30 \%)$. The last category identified using the Barrier Questionnaire was the category named other. The other category includes reported barriers that did not fit in the previously established categories. Three reported barriers were included: "a lack of confidence," "not knowing," and "race." Twenty-six percent $(n=24)$ of the study sample did not identify health barriers. Fourteen (58\%) of this subgroup were Louisiana residents and $10(42 \%)$ were Tennessee residents. A summary of the reported barriers to health of the group is provided in Table 3 .

A comparison of reported barriers to health revealed that environment was the most frequently reported barrier to health for adolescents in Louisiana and Tennessee. Details of the state findings are summarized in Table 4.

Question $1 b$. What is the level of perceived health status reported by adolescent Black American males without known cardiovascular disease? The findings follow.

The perceived health status of Black American adolescent males was described using the scores of the Self-Rated Abilities for Health Practice Scale and the Youth Risk Behavior Survey. Based on the scores on the Self-Rated Abilities for Health Practice Scale, the level of perceived health status was moderately high in the study sample. The mean score was 68 out of a possible 100 points with a standard deviation of \pm 14.82 . Mean score and standard deviation for Tennessee participants was $69 \pm 12.83$ and for Louisiana participants $66 \pm 18.56$ while the median and interquartile range scores were 
Table 3. Barriers to Health for Black American Adolescent Males ( $\mathrm{N}=92)$

\begin{tabular}{lr}
\hline Barrier & $n(\%)$ \\
& \\
Diet & $30(32)$ \\
Environment & $36(39)$ \\
Finances & $4(04)$ \\
Other & $16(17)$ \\
None & $24(26)$ \\
\hline
\end{tabular}

Note: The percentage total exceeds $100 \%$ because each adolescent was asked to list one to three barriers.

Table 4. Barriers to Health for Black American Adolescent Males by State

\begin{tabular}{lcccc}
\hline Barrier & $\begin{array}{c}\text { Diet } \\
n(\%)\end{array}$ & $\begin{array}{c}\text { Environment } \\
n(\%)\end{array}$ & $\begin{array}{c}\text { Finances } \\
n(\%)\end{array}$ & $\begin{array}{c}\text { Other } \\
n(\%)\end{array}$ \\
\hline $\begin{array}{l}\text { Louisiana } \\
(n=63)\end{array}$ & $19(30.15)$ & $29(46.03)$ & $3(4.76)$ & $10(15.87)$ \\
$\begin{array}{l}\text { Tennessee } \\
(n=29)\end{array}$ & $11(37.93)$ & $7(24.13)$ & $1(3.44)$ & $6(20.68)$ \\
\hline
\end{tabular}

Note: The percentage total exceeds $100 \%$ because each adolescent listed one to three barriers. 
$66.0 \pm 29.25$ and $70.50 \pm 16.50$, respectively. Group differences were not statistically significant when compared using the Wilcoxon Rank Sum Test ( $p=.357)$.

The principal investigator initially planned to measure perceived health using the SRAHP instrument; however the Youth Risk Behavior Survey also explores perceived health status. Using the Youth Risk Behavior Survey adolescents were asked, "How do you describe your general health?" Ninety-one of the 92 adolescents responded to the question. Of those responding, $34 \%(n=31)$ perceived their general health as excellent; very good health accounted for $33 \%(n=30)$; good health for $23 \%(n=21)$; fair health for $10 \%(n=9)$; and no adolescent perceived his health status as poor. Tennessee residents rated their health better than Louisiana residents $\left(X^{2}=8.69, d f=3, p=.0046\right)$. A greater proportion of the Louisiana adolescents rated their health as excellent or very good compared to Tennessee adolescents. We also, determined that scores on the Self-Rated Abilities Heath Practices Scale and Youth Risk Behavior Survey item as indicators of perceived health status were not significantly correlated $(r=-0.190, p=.073)$, suggesting that these instruments were valid indicators in the study sample. As the scores on the Self-Rated Abilities Health Practices Scale increased (better scores) scores on the Youth Risk Behavior Survey decreased (better scores). In this instance a Youth Risk Behavior Survey perceived health score of 1 (low) is excellent, while a high score on the SelfRated Abilities Health Practices Scale means better health perception. Detailed results of the Youth Risk Behavior Survey item related to perceived health for the sample and state residences are provided in Table 5. 
Table 5. Youth Risk Behavior Survey Item Measuring Perceived Health for the Sample and by State of Residence

\begin{tabular}{lccc}
\hline Rating & $\begin{array}{c}\text { Sample } \\
n(\%)\end{array}$ & $\begin{array}{c}\text { Louisiana } \\
n(\%)\end{array}$ & $\begin{array}{c}\text { Tennessee } \\
n(\%)\end{array}$ \\
\hline Excellent & $31(35.07)$ & $25(39.68)$ & $6(21.43)$ \\
Very Good & $30(32.97)$ & $25(39.68)$ & $6(21.43)$ \\
Good & $21(23.08)$ & $23(36.51)$ & $7(25.00)$ \\
Fair & $9(9.89)$ & $5(7.94)$ & $11(39.29)$ \\
Poor & - & - & - \\
\hline
\end{tabular}

Note: None of the subjects reported poor health.

- Indicates not applicable. 
Question 1c. What is the level of self-efficacy reported by adolescent Black American males without known cardiovascular disease? The findings follow.

The Self-Efficacy Scale provided data to describe the level of perceived selfefficacy in the study sample. The findings illustrated that the level of perceived selfefficacy was similar to the level of perceived health status. The adolescents in this study displayed a moderately high level of self-efficacy with median score of 49.0 and an interquartile range of 9.5. The scoring range for the scale is 12 to 60 . Black American adolescent males in this sample demonstrated confidence in their ability to attend to their health needs and to make needed changes in their behaviors. Adolescents' self-efficacy scores by state of residence revealed a higher level of self-efficacy among Louisiana participants compared to Tennessee with median and interquartile range scores of $50.0 \pm 8.0$ and $46.0 \pm 15.25$, respectively. Results indicated a significant difference between participants by state of residence with $p$-value of .009 .

Question 1d. What are the cardiovascular health risk factors present in and reported by adolescent Black American males without known cardiovascular disease? The findings follow.

Details of perceived health-promoting behaviors among the study sample were investigated using the Adolescent Health Promoting Scale, which has a total possible score of 200 points. Results from the Adolescent Health Promoting Scale indicated that the study participants' had a mean total score of $100.25(S D=27.37)$ out of a total possible score of 200 points and a median score of 95.0 and interquartile range of 34.0. These results indicated that the Black American male adolescents in this study had a moderate 
level of participation in health-promoting activities. Study results for adolescents Tennessee residents revealed a mean score of $109.07(S E=6.53)$ compared to Louisiana with a mean score of $96.13(S E=2.80)$. Results suggested that although adolescents in Tennessee had a higher level of health promoting behavior participation when compared with Louisiana adolescents, these differences were non-significant ( $p=.076)$.

The Adolescent Health Promoting Scale is different from the other tools used in this study, because this scale provides both a total score as previously discussed and six subscale scores: nutrition, social support, health responsibility, life appreciation, exercise, and stress management. Details of the descriptive statistics for the ADHP subscales for the entire sample and by state of residence are summarized in Table 6. Only one difference was found, based on state of residence among the ADHP subscales using the Wilcoxon Rank Sums test. Adolescents in Tennessee had higher scores compared to Louisiana residents $\left(X^{2}=4.60, d f=1, p=.031\right)$ and therefore reported practicing more health promotion behaviors.

Question le. What are the cardiovascular health promotion behaviors reported by adolescent Black American males without known cardiovascular disease? The findings follow.

The cardiovascular risk factors reported by the study sample were examined using the Youth Risk Behavior Survey, fasting glucose and total cholesterol blood samples, and blood pressure and BMI measurements. The results of the screening for fasting glucose and total cholesterol blood samples and blood pressure measurements were provided to parents and/or guardians for medical follow-up as indicated. Three 
Table 6. Descriptive Statistics for Adolescent Health Promoting Scale Subscales for the Sample

\begin{tabular}{lllr}
\hline Subscale & Mean (SD) & Mdn (SE) & IQR \\
\hline Nutrition & $16.94(4.70)$ & $17.00(0.48)$ & 7.0 \\
Social Support & $17.61(6.32)$ & $17.00(0.65)$ & 7.0 \\
Health Responsibility & $19.95(5.87)$ & $19.00(0.60)$ & 6.0 \\
Life Appreciation & $17.65(8.25)$ & $16.00(0.85)$ & 12.0 \\
Exercise & $11.84(4.34)$ & $11.00(0.45)$ & 5.0 \\
Stress & $27.13(8.28)$ & $26.00(0.85)$ & 19.5 \\
& & & \\
\hline
\end{tabular}

Note: $\mathrm{IQR}=$ interquartile range 
subcategories of the Youth Risk Behavior Survey were chosen to examine the cardiovascular risk factors amongst participants: tobacco use, perception of body weight and physical activity. These categories were chosen because of their known association with cardiovascular disease. Fasting glucose and total cholesterol blood samples and blood pressure and body mass index measurements were collected as physiological data to help identify the adolescents' current risk factors for cardiovascular disease. Blood samples for fasting glucose and total cholesterol were collected by the researcher using capillary finger sticks prior to morning meals.

Results of tobacco use provided data about the sampled adolescents' smoking histories and habits. Thirty-one of the 92 adolescents (34\%) reported having tried cigarette smoking at least once, while 65 of 92 participants (71\%) reported they never tried cigarette smoking. Of those adolescents who reported a history of cigarette smoking, $7(7.69 \%)$ indicated their first smoking experience was at the age of 12 years.

Adolescents who reported never having used chewing tobacco, snuff, or dip was 98\% $(n=89)$. Details of the sample's tobacco use are provided in Table 7.

When asked about how they view their body weight, $68.47 \%(n=63)$ reported that their weight was about the right weight, 14.13\% $(n=13)$ reported being slightly overweight, $1.08 \%$ reported being very overweight, $6.52 \%(n=6)$ reported being very underweight, and 9.78\% (n=9) reported slightly underweight. When asked, "What are you doing about your weight?" $27.47 \%(n=25)$ reported trying to lose weight, $27.47 \%$ $(n=25)$ reported trying to gain weight, $18.68 \%(n=17)$ reported trying to maintain their weight, and $26.37 \%(n=24)$ reported not trying to change weight. 
Table 7. Tobacco Use in the Study Sample

Behavioral Information

$n(\%)$

Tried cigarette smoking (yes)

$22(23.65)$

Never smoked

71(78.02)

Age of first smoked cigarette*

20(21.97)

8 years or younger

2(2.19)

9 years old

$-$

10 years old

1(1.09)

11 years old

$-$

12 years old

$7(7.69)$

13 years old

$5(5.49)$

14 years or older

$5(5.49)$

Number of cigarettes smoked

daily in the last 30 days

did not smoke

$79(88.76)$

Less than 1 cigarette

$7(7.86)$

1 cigarette

$2(2.24)$

2 to 5 cigarettes

$1(1.20)$

6 to 10 cigarettes

More than 20 cigarettes

$-$

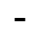

8(8.79)

Have you ever smoked daily? (yes)

Days smoked cigars

$$
\begin{aligned}
& 0 \text { days } \\
& 1 \text { or } 2 \text { days } \\
& 3 \text { to } 5 \text { days }
\end{aligned}
$$

during the last 30

days

0 days

$86(94.50)$

1 or 2 days

$5(5.49)$

Note: - indicates not applicable. 
Lack of daily physical activity has been shown to increase the risk of cardiovascular disease (Adeyanju, 1990). When asked about daily physical activity, 91 participants responded. Fifteen adolescents (16.48\%) reported engaging in 20 minutes of exercise 7 days a week compared to $11(12.08 \%)$ adolescents who reported not engaging in physical activity. The amount of time spent watching television may be an indicator of a sedentary lifestyle and was an important question for the adolescents in this study. The number of hours spent watching television on school days was reported to be 5 or more hours per day by $46 \%(n=42)$ of the adolescents. Participation in school physical education classes 3 days a week was reported by $31.53 \%(n=29)$ of the participants, and $20.65 \%(n=19)$ reported physical education class participation 5 days a week. The percentage of adolescents who reported not participating in school physical education classes was $19.56 \%(n=18)$, while team sports participation was reported by more than half the sample at $59.34 \%(n=54)$. A summary of the physical activity of the study sample are provided in Table 8.

Results of the biological screening of participating adolescents provided data about their predisposition for developing cardiovascular disease in adulthood. Seventy adolescents provided fasting blood glucose samples for physiological data analysis. However, most participating adolescents from the west Tennessee data collection site decided against having their finger pricked for blood samples. The sampled adolescents' fasting blood glucose levels were classified according to three parameters: low blood glucose (below 70mg/dl), acceptable blood glucose level (70 to $110 \mathrm{mg} / \mathrm{dl}$ ), and high blood glucose (above $110 \mathrm{mg} / \mathrm{dl}$ ) (Health Information Publications, 2004). Data for glucose levels were obtained from 70 participants, 7 Tennesseans, and 63 Louisiana 
Table 8. Physical Activity Reported by the Study Sample

Behavioral Information $\quad n(\%)$

Number of days exercised

for 20 minutes or more in the last 7 days - 0 days

11(12.08)

1 day

$10(10.98)$

2 days

$9(09.89)$

Number of days exercised for 20 minutes or more in the last 7 days - $\quad 3$ days

$17(18.68)$

4 days

5 days

$11(12.08)$

6 days

9(09.98)

7 days

$17(16.48)$

Hours spent watching

T.V. on school days - Do not watch television

$8(08.69)$

Less than 1 hour per day

9(09.78)

1 hour per day

2 hours per day

$9(09.78)$

3 hours per day

$14(15.21)$

4 hours per day

$10(10.87)$

5 or more hours per day

42(45.65)

Days participated in

school physical

education classes - 0 days

$18(19.56)$

1 day

$7(07.69)$

2 days

17(18.47)

3 days

29(31.52)

4 days

2(2.17)

5 days

19(20.65)

Participate in team sports (yes)

54(59.34)

Note: - indicates not applicable. 
residents. Results of the fasting glucose screening indicated that $80 \%(n=56)$ had fasting blood glucose levels within the acceptable range. Blood glucose levels that were hypoglycemic were found in $11.42 \%(n=8)$ of the sample, and $8.5 \%(n=6)$ had blood glucose levels that were classified as hyperglycemic. Adolescents with elevated fasting glucose levels were found to be either over weight or at risk for being over weight.

Fasting total cholesterol blood levels were collected from 69 adolescent males; 62 Louisianans and 7 Tennesseans. The total cholesterol blood levels of the sample were categorized into three groups: values of less than $170 \mathrm{mg} / \mathrm{dl}$ as acceptable, 170 to $199 \mathrm{mg} / \mathrm{dl}$ as borderline, and greater than or equal to $200 \mathrm{mg} / \mathrm{dl}$ as high (Medicinenet, 1999). Findings of the total cholesterol screening indicated more than half of the sample (73.91\%, $n=51)$ had blood values within an acceptable range, which was less than $170 \mathrm{mg} / \mathrm{dl}$. However, $23.18 \%(n=16)$ were found to have results that were considered borderline for high cholesterol, while none of the participants had a high total cholesterol level. Results of the fasting blood glucose and total cholesterol levels were not meaningful analysis due to missing data.

The blood pressure screening was conducted in the morning hours using an appropriate-sized auscultatory sphygmomanometer and stethoscope. The blood pressure measurements were evaluated to determine if adolescents in the study were prehypertensive. Prehypertension is defined as a systolic blood pressure greater than or equal to $120 \mathrm{~mm} \mathrm{Hg}$ or a diastolic blood pressure reading of greater than or equal to 80 mm Hg (USDHHS, 2005). Using these guidelines, results of the adolescent blood pressure screening indicated that $52.68 \%(n=49)$ of the study's adolescents had systolic 
blood pressures equal to or greater than $120 \mathrm{~mm} \mathrm{Hg.,} \mathrm{and} 32.25 \%(n=30)$ of the sample had a diastolic blood pressure reading greater than or equal to $80 \mathrm{~mm} \mathrm{Hg.,} \mathrm{indicating} \mathrm{pre-}$ hypertension. Each adolescent permitted the investigator to obtain a blood pressure measurement. Tennessee adolescents' blood pressures were higher than Louisiana adolescents however these differences were neither statistically nor clinically significant. Adolescents in Tennessee had a mean systolic blood pressure measurement of $118 \mathrm{~mm}$ $\mathrm{Hg}(S E=2.29)$, while Louisiana, participants' mean systolic pressure was $115 \mathrm{~mm} \mathrm{Hg}$ ( $\mathrm{S} E=1.41)$. Mean diastolic blood pressure results $75 \mathrm{~mm} \mathrm{Hg}(S E=1.54)$ for Tennessee and $73 \mathrm{~mm} \mathrm{Hg}(S E=0.95)$ for Louisiana adolescents. Neither systolic $(p=.101)$ nor diastolic blood pressure readings ( $p=.099)$ readings were significantly different between the two groups. Study findings suggest that more than half of the study sample could be prehypertensive and at risk for developing cardiovascular disease in adulthood if this one time measure reflected their usual blood pressure.

Adolescents' weight (pounds) was divided by their height (inches) to calculate body mass index. Values were then classified using the CDC-BMI percentile calculator (CDC, 2006). The body mass index calculations in this study were completed prior to the July 2006 update of the body mass index percentile calculator, which requires the entry of birthdates in the calculation. The CDC classifications of body mass index are based on body mass index-for-age-percentile charts that categorize each individual as underweight (less than the $5^{\text {th }}$ percentile), healthy weight $\left(5^{\text {th }}\right.$ percentile to less than the $85^{\text {th }}$ percentile), at risk of overweight $\left(85^{\text {th }}\right.$ to less than the $95^{\text {th }}$ percentile), and overweight (equal to or greater than the $95^{\text {th }}$ percentile). The results of the body mass index calculations of the study adolescents indicated that $5 \%(n=4)$ were underweight, $74 \%$ ( $n=$ 
$60)$ had a healthy weight, $21 \%(n=17)$ were at risk of being overweight, and $13 \%(n=12)$

were overweight. Louisiana participants had a higher mean body mass index compared to Tennessee, $26.0(S E=1.38)$ and $22.9(S E=0.78)$, respectively, reflecting statistically significant differences $(p=.0012)$

\section{Specific Aim 2}

Examine the association between perceived health status and self-efficacy of adolescent Black American males without known cardiovascular disease.

Aim 2 had one accompanying question: Question 2. What is the association between perceived health status and self-efficacy of adolescent Black American males without known cardiovascular disease? The findings follow.

Using Statistical Analysis Software, descriptive statistics were used to summarize perceived health status and self-efficacy distributions (normality) and ascertain measures of central tendency. The distributions for both variables were asymmetrical revealing negative skewed distributions. A visual examination of each data set confirmed negative skewness with flat kurtosis. Spearman Rho's correlation coefficient was performed because the variables were not normally distributed and to determine the extent to which values of perceived health status and self-efficacy were proportional (linearly related) to each other and the strength of the relationship. The results of the Spearman Rho correlation coefficient indicated a significant, moderate positive correlation between perceived health status and self-efficacy for the entire sample $(r=0.5608 ; p=<.0001)$ and Louisiana $(r=0.470 ; p=.0001)$ and Tennessee $(r=.729, p=.0001)$ adolescents. The level of perceived health status increased as the level 
of self-efficacy increased in the study sample and for Tennessee and Louisiana residents indicating that higher levels of self-efficacy were associated with better perceived health.

\section{Specific Aim 3}

Determine the influence of perceived health barriers, perceived health status, selfefficacy, and cardiovascular health risk on the health promotion behaviors of adolescent Black American males without known cardiovascular disease. Aim 3 had one accompanying question: Question 3. What is the influence of perceived health barriers, perceived health status, self-efficacy, and cardiovascular health risk factors on the health promotion behaviors of adolescent Black American males without known cardiovascular disease? The findings follow.

The influence of perceived health barriers was not established because of the qualitative nature of the Barrier Question tool. Results of the Barrier Question revealed subjective data reported by each adolescent. Furthermore, regression supports the use of correlation between variables in order develop a prediction equation (Munro, 2001), and the qualitative data findings were not appropriate for regression modeling. Because many of the Louisiana residents were affected by Katrina in the months preceding data collection we elected to use only Louisiana residents in the regression analyses. Thus, Tennessee residents were omitted from the stepwise regression modeling and results of specific aim 3 was limited to this subgroup.

Correlations and regression analyses were performed to determine the influence of perceived health status, self-efficacy, and cardiovascular health risk on the health 
promotion behaviors of adolescent Black American males without cardiovascular disease in this study. Both biological and self-report cardiovascular health risk factors were considered for inclusion in the regression model. Bivariate correlations of the independent variables (perceived health status, self-efficacy, age, body mass index, and glucose and total cholesterol levels) and the outcome variable, health promotion behavior, were performed to measure the direction and strength of associations among these study variables. Nonparametric Spearman Rho correlation coefficient was used to calculate the bivariate correlations for Louisiana adolescents only. A significance level of 0.2 is appropriate for exploratory research to determine inclusion of predictor variables in the regression model (Henkel, 1998) and therefore this parameter was applied to the current study. Results for Louisiana residents revealed that perceived health status $(r=$ $-.187, p=0.146)$ and self-efficacy $(r=-0.213, p=0.095)$ had significant negative correlations with health promotion behavior. Hence, as health status and self-efficacy levels increased, adolescents' health behaviors decreased. Additionally, significant positive associations were found between health promotion behavior and age $(r=.179$, $p=.165)$ as well as glucose levels $(r=0.199, p=.123)$. Higher health promotion scores were associated with greater age and higher glucose levels.

Bivariate correlations were also estimated using health behaviors reported by Louisiana residents on the Youth Risk Behavior Survey (smoking, physical activity, team sport participation, and eating activities) and health promotion behaviors. Variables were coded as 0 or 1 to indicate the absence or presence of a behavior. Weak non-significant positive associations were observed between health promotion behavior and body mass index $(r=0.135, p=.295)$, cholesterol $(r=0.047, p=.719)$ and systolic $(r=0.016, p=.899)$ 
and diastolic $(r=0.109, p=.399)$ blood pressure. Weak non-significant correlations were also found between relevant behaviors on the Youth Risk Behavior survey and health promotion behavior (smoking - $r=-0.0271, p=0.799$; exercise $-r=0.0172, p=0.872$; eating $-r=0.0679, p=0.5248$; sports $-r=0.0521, p=0.6275$ ). Thus, health promotion behavior scores were not significantly associated with selected health behaviors included on the Youth Risk Behavior Survey. Results of biological data for the sample indicated a weak but significant correlation for the fasting glucose $(r=0.184, p=0.129)$ and a weak and non-significant correlation for total cholesterol $(r=0.056, p=0.650)$ with the outcome variable, health promotion behavior.

Multivariate correlation analysis was performed to predict the value of the independent variables (perceived health status, self-efficacy, age, and body mass index) for outcome variable, health promotion behavior and to assess if differences existed for adolescents recruited from Louisiana and Tennessee. The level of significance was set at 0.05 for each research question, but because the current study was exploratory in nature, the level of significance was set at 0.20 for bivariate correlational analyses used in the regression model. Hence, the behavioral variables (smoking, physical activity, team sport participation, and eating activities) were not included in the multiple regression model. Using stepwise regression analyses with backward elimination the predictor variables (self-efficacy, perceived health status, and glucose) were entered into the model to determine which selected variables significantly contributed to the explained variance in health behavior scores. Although age was significantly correlated with health promotion behaviors the investigator decided to limit the analysis to the three variables that most strongly correlated with the outcome variable. This decision reflected the need to 
eliminate one candidate variable as only 60 participants had sufficient data for entry in the model. Tabachnick and Fidell (2000) suggest at least 5 times as many subjects as predictors but recommend a ratio of 40 to 1 for stepwise regression. Thus, including 3 variables and approximately 60 participants permitted a ratio of 20 cases for each variable. Results revealed that approximately $2.7 \%$ of the adjusted variance in health promotion behavior in the sample was explained by self-efficacy, perceived health, and fasting glucose levels although neither the model nor the individual predictor variables were statistically significant. The findings indicated that none of the predictor variables used in this study significantly predicted health promotion behaviors of Black American adolescent males suggesting that other variables such as family health, peer pressure, or parental perceptions of health promotion practices may have a greater influence. The overall statistical predictive capability of the regression model was low $\left(F_{3,61}=0.467\right.$, $p=0.706$ ). ANOVA results for the predictor variables in the study sample are provided in

\section{Table 9.}

Information about the eating habits of participating adolescent in the current study was collected using the 3-day food records. However, a review of the food records revealed incomplete food intake information documented by the adolescents during the 3 day period. The insufficient food record prevented the investigator's ability to enter the collected data into the computer food analysis software. Hence, results of the adolescents' food intake to assess if they practice healthy eating were not possible. The primary investigator has reserved the information for later analysis to determine patterns of eating behavior such as fast food intake. 
Table 9. ANOVA Table of Adolescents' Self-efficacy, Perceived Health, and Fasting Glucose by Health Promotion Behaviors

\begin{tabular}{lcccccc}
\hline $\begin{array}{l}\text { Predictor } \\
\text { Variable }\end{array}$ & $n$ & $d f$ & $\begin{array}{c}\text { Sum of } \\
\text { Squares }\end{array}$ & $\begin{array}{c}\text { Mean } \\
\text { Square }\end{array}$ & $F$ & $p$ \\
\hline Self-efficacy & 62 & 3 & 196.37 & 65.47 & 0.390 & 0.53 \\
Perceived health & 61 & 3 & 36.53 & 12.18 & 0.073 & 0.79 \\
Fasting glucose & 61 & 3 & 357.78 & 119.26 & 0.710 & 0.40 \\
\hline
\end{tabular}

Note. Total number of individual predictor variables are less than $\mathrm{N}(92)$ due to missing data. 


\section{CHAPTER V: DISCUSSION AND IMPLICTIONS}

Adult males in the U. S., on average, die 6 years earlier than adult females (DHHS, 2000). American males, in general, participate in less-healthy lifestyles than do American females and engage in fewer health-promoting behaviors (Courtenay, 2000d). These circumstances served as the impetus for conducting the current research study, which investigated the health perceptions, cardiovascular risk factors, and health promotion behaviors of Black American adolescent males. Systematic investigations of perceived health barriers, general health perceptions, and cardiovascular health risks reported by Black American male adolescents have been few. For this reason, the first aim of this study was to describe the perceived health barriers, perceived health perceptions, health promotion behaviors, and the cardiovascular risk factors reported by Black American adolescent males 13 to 18 years of age without known cardiovascular disease. The second study aim was to examine the association between perceived health status and self-efficacy of Black America adolescent males without known cardiovascular disease. The final aim of this study was to determine the influence of perceived health barriers, health perceptions, and cardiovascular risk factors on the health promotion behaviors of adolescent Black American males without known cardiovascular disease. An in-depth discussion of the findings with regard to the independent variables (health barriers, perceived health status, self-efficacy, cardiovascular risk factors) and the outcome variable (health promotion behaviors) is presented in the first part of this chapter. The chapter concludes with a discussion of the prediction model findings and 
study limitations and strengths as well as implications for practice, policy, theory development, and future research.

\section{Perceived Health Barriers}

There were four categories of perceived health barriers reported by Black American adolescent male study participants: diet, environment, finance, and other. Diet included food choices that are not nutrient dense, including fast foods, candy, and foods with high fat and sugar content. The second category identified was environment. Items categorized as environment included words and phrases that referred to their individual surroundings. The adolescent's choice of specific words and phrases may have been representative of the pressure and anxiety experienced in their individual communities. For example, written responses included "stress," "something is always coming up," "it's always a situation," and "pressure by my friends." These environmental pressures are probably not unique to Black American male adolescents because the developmental anxiety of trying to establish independence and a sense of self is common among adolescents (Lythgoe, 2003). Further research investigating psychological factors like stress in the environment that influence the lives of Black American teens could provide additional insights about their perceptions of health barriers. Some adolescents reported finances as a barrier to health. This barrier was identified by the use of one word, "money". Because no additional words or sentences were used to explain money as a health barrier, the investigator was unsure if the adolescents were referring to too much money or too little money as a health barrier. The investigator suspected that the problem was too little money given that many study participants received free school meals 
(71\%). The last reported health barrier was the category labeled as other. This category included reports of having a lack of confidence, not knowing how to be healthy, and the experience of racial bias. Furthermore, for those adolescents who reported "not knowing how to be healthy", health education seems warranted. Future research could examine detailed information about each of the reported barriers to health in order to describe and gain a clearer understanding of the perceived health barriers reported by Black American adolescent males. A review of the literature revealed that researchers have not studied the perceived health barriers reported by adolescent Black American males. However, two published studies explored perceived health barriers among adult Black Americans. Plowden and Young (2003) investigated health-seeking behaviors using an urban Black American adult male sample. One perceived health barrier emerged from the study findings, the lack of access to health care in their environment. Similarly, Hines-Martin et al. (2003), investigated perceived health barriers with a coed college Black American adult sample that focused on their experiences seeking mental health services for the first time. This study's findings also identified environment as a health barrier. Specifically, identified environmental barriers were problems they experienced within their families and community resources that they perceived interfered with their mental healthcare. The key similarity of these studies, compared to the current study, is that environment-related barriers were a consistently reported health barrier. This across study similarity suggests that regardless of age and gender, Black Americans report their environment as a healthrelated barrier. 


\section{Perceived Health Status and Self-Efficacy}

The investigator defined perceived health status in this study as the adolescents' self-rating of their level of health. An extensive search of published literature did not reveal studies that focused exclusively on the perceived health status among Black American adolescent males. Nonetheless, several investigators have explored perceived health status in samples that included Black Americans (Honig, 2002; McGee, Liao, Cao, \& Cooper, 1998; Tercyak, 2004; Rew, 1997; Weinrich, Weinrich, Priest, Fodi, \& Talley, 2001; Zullig, Valois, \& Drane, 2005).

Similar to the current study findings, both Honig (2000) and Rew (1997) included Black American adolescents in their study samples. Study participants in both studies reported having a moderately high level of perceived health status. These findings are consistent with the moderately high levels of perceived health status reported in the current study. Although participants in Rew's study reported moderately high levels of perceived health status, they also had lower scores compared to White and Latino American adolescents in the study. These two studies were the only studies that investigated the perceived health status of Black American adolescents, which validated the need for the current study. In contrast, studies that included adult Black American adult males revealed low levels of perceived health status in this population (Kim, Bramlett, Wright, \& Poon, 1998; Weinrich, Weinrich, Priest, Fodi, \& Talley, 2001). Although these studies were conducted in different settings with different samples, the results could reflect a worsening in perceived health from adolescence to adulthood. If this is true, this transition from moderately-high perceived health status in adolescents to low levels in adulthood raises the question of what life events transpire that explain this 
important change in perceptions. According to Erickson, (1956) during the adolescent years the fifth psychosocial crisis — identity versus identity diffusion—adolescents develop a sense of self-certainty as opposed to self-consciousness and doubt. While experimenting with different roles teens adopt an attitude of achievement instead of negative identity and it is at this point in development that they may feel that everything is possible. This developmental stage likely explains adolescents' perceived health status in the current study. The socialization of males in the U.S. may offer an alternative explanation for the potential worsening in perceived health status that might occur from adolescence to adulthood. According to Courtenay (2000), adult males demonstrate an ideal form of masculinity by participating in unhealthy behaviors and relying on genderspecific health beliefs. For example, these beliefs potentially explain the lower participation of adult males compared to females in health promotion behaviors. By taking risk, according to Courtenay, men illustrate their superiority as the stronger sex. Other investigators have concluded that high levels of stress associated with racial discrimination influences the physical and mental health of Black American men (Krieger, 1999; Williams, Neighbors, \& Jackson, 2003) as well. Although environment (i.e., environmental stressors such as peer pressure) was a barrier reported by $39 \%$ of participating adolescents, the current study did not address the relationship between this barrier to health and perceived health status. Therefore, a secondary analysis of the study data will explore this relationship. Because the barriers questionnaire did not result in a barrier score, it will be necessary to determine the presence or absence of a stressor using dummy coding before statistical analysis is possible. 
While investigators have studied self-efficacy in a variety of populations (Bandura, 1986; Robbins et al, 2004; Halpern-Felsher et al., 2004), researchers have not examined self-efficacy with regard to health as a predictor of health promotion behaviors. These studies include self-efficacy in such areas as exercise, communication, and healthy eating. A review of published literature revealed two studies that investigated selfefficacy in adolescents (Halpern-Felsher et al., 2004; Robbins et al., 2004). In each study, Black American adolescents comprised more than half of the study sample; the investigators did not discuss the sample's gender characteristics. Neither of these studies examined self-efficacy related to health promotion behaviors in adolescents. These studies of self-efficacy, similar to the current study, demonstrate that adolescents believe that they have the ability to care for themselves. For example, Robbins et al. (2004) reported higher levels of pre-activity self-efficacy among Black adolescent males associated with actual physical exertion compared to Black adolescent girls. HalpernFelsher et al. (2004) examined self-efficacy in a multi-ethnic urban sample in order to examine how self-efficacy affected the adolescents' ability to communicate with parents and peers about condom use. The study findings indicated that males demonstrated a greater level of self-efficacy to communicate with parents and peers compared to females. This is the only study that looked at self-efficacy related to health practices and the health practice focused on condom use for disease prevention.

Adolescents in the current study as in published studies reported that their levels of health promotion and physical activity. In the current study adolescents revealed a moderate level of participation in health promoting activities with Tennessee teens demonstrating a higher level than Louisiana adolescents. Less than $50 \%$ of the sample 
reported 20 minutes of daily exercise within a 7 day period, but more than $50 \%$ reported team sports participation. These findings suggest that study adolescents were physically active but did not equate physical activity with team sports. The findings suggest the need to educate adolescents that team sports are physical activities that provide health benefits that could help to improve their overall cardiovascular health outcomes as adults.

However, study instruments did not capture if the beliefs of these adolescents translated into actual health behaviors. Because an individual states that he believes something is possible, does not mean that he will follow through and act. However, a person must first believe that he or she can have an impact on their health before action is taken (Bandura, 1977).

\section{Cardiovascular Health Risk}

The cardiovascular risk of Black American adolescents is well documented in the literature (Berkey et al., 2000; Chen, Srinivasan, Elkasabany, \& Berenson, 1999; Davis et al., 2005; Ebbeling, Pawlak, \& Ludwig, 2002; Goran, 1998; Gutin et al., 2005; Luma \& Spiotta, 2006; Morrison et al., 1999; Smalley, Wittler, \& Oliverson, 2004). In the current study several cardiovascular risk factors were systematically examined including the prevalence of overweight, elevated systolic and diastolic blood pressure, and physical inactivity. Overweight children in the Bogalusa Heart Study (Freeman, Dietz, Srinivasan, \& Berenson, 1999) had higher systolic and diastolic blood pressures (4.5 times and 2.4 times, respectively) compared to children that were not overweight, suggesting that increased body weight attributes to elevated blood pressure. Similarly, in a school-based hypertension and obesity screening program, obese adolescents had a three times greater 
prevalence of elevated blood pressures compared to non-obese adolescents (Sorof, Poffenbarger, Franco, Bernard, \& Portman, 2002).

Increased body weight and body mass index are recognized risk factors in adolescents that may lead to the development of cardiovascular disease in adulthood. Although most participants in the current study (74\%) had an acceptable body mass index, $21 \%$ were at risk of being overweight and $13 \%$ were overweight. These findings contrast with the adolescents' perceptions of their body weight, as $14 \%$ perceived their body weight as slightly overweight, while only $1 \%$ perceived their body weight as very overweight. Several researchers have investigated body size perception of Black American adolescents and adults (Becker, Yanek, Koffman, \& Bronner, 1999; Gore, 1999; Kemper, Sargent, Drane, Valois, \& Husset, 1994; Neff, Sargent, McKeown, Jackson, Valois, 1997). Findings from these studies suggest that Black Americans, in particular females perceived that body size as larger compared to White Americans. This finding may explain the apparent incongruence between body size perception and actual body mass index results of the study sample. However, a recent study conducted by Snooks and Hall (2001) investigated the relationship of body size and image of Black, White, and Mexican American women. The study results did not support previous findings that Black Americans perceive their body image as larger. Despite ethnic difference, each group reported congruence between actual body size and body image. Additional research is needed to explore this theory of body size perception among Black American adolescents.

The current study results related to the risk of overweight and presence of overweight were significantly better than the national average; $30 \%$ of American youths, 
12 to 19 years of age, are considered overweight (American Obesity Association, 2005) in contrast to the $13 \%$ who were overweight in the current study. Davis et al. (2005) found that $46 \%$ of the Black American school children, which included adolescents, participating in their study were identified as at risk for overweight based on their body mass index measurements compared to the $21 \%$ in this study. More than $50 \%$ of the adolescents in the current study $(n=54)$ reported participation in team sports, which may account for the lower average body mass index observed in the sample as compared to Davis et al.'s study, which did not investigate team sports participation.

Socioeconomic factors and lifestyle may be important barriers to blood pressure control and increase the risk of other cardiovascular diseases in minority populations (National High Blood Pressure Program, 2003). In the current study $71 \%$ of the sample reported participation in the national free lunch program with a statistically significant higher level in Louisiana compared to Tennessee adolescents. Participation in this program is an important indicator of social economic status (Food Research and Action Center, 2007). The relationship between free lunch participation and body mass index was not examined in this study, but will be examined in a secondary analysis designed to profile the characteristics of participating teens that were at risk or overweight in the current study sample.

Of the adolescents who provided fasting blood samples $74 \%$ had acceptable fasting total cholesterol and $80 \%$ had acceptable glucose levels. The most current national average of total cholesterol levels among Black American adolescent males is $168 \mathrm{mg} / \mathrm{dl}$ (AHA, 2004), which is slightly higher than the $164 \mathrm{mg} / \mathrm{dl}$ obtained in the current study. However, adolescents had elevated systolic and diastolic blood pressure 
measurements ( $52.68 \%$ and $32.25 \%$, respectively), that if reflective of their typical pattern indicated a prehypertensive state. The accuracy of blood pressure measurements in adolescents are validated after sitting in a quiet environment for 5 minutes and checking the adolescent's blood pressure 2 more times during the same clinical visit (Luma \& Spiotta, 2006; National High Blood Pressure Education Program, 2003). The current study blood pressure measurements were recorded based on a one-time recording using the right upper arm and an aneroid manometer. While findings would have been more reliable with multiple blood pressure measures, more than $50 \%$ of the study participants reported a known family history of cardiovascular disease that included hypertension. Systolic blood pressures that were $120 \mathrm{~mm}$ Hg or greater were found in $53 \%$ of the sample, as compared with Davis et al. (2005) who found at-risk systolic blood pressure in $21 \%$ of their Black American adolescent sample. At-risk diastolic blood pressures in the current study were found in $32 \%$ of the sample, which was higher than the $6 \%$ found in Davis et al. (2005). Persistent prehypertensive blood pressure values could predispose the current study teenagers to early onset hypertension and associated cardiovascular disease in the future. Participants in the current study were generally active in team sports, which if maintained into adulthood could possibly reduce their potential of cardiovascular disease development.

National results of adolescent cigarette smoking and physical activities in the U. S., based on the Youth Risk Behavior Survey for 2005 (CDC, 2006) indicated that $26.5 \%$ of adolescents, of which $28.7 \%$ were male, participated in physical activity at least 30 minutes daily on five or more days a week. The current national statistic for cigarette smoking among adolescents is $23 \%$ overall, with males accounting for $22.9 \%$ of the 
study sample. A comparison of the national and current study findings using the 2005 Youth Risk Behavior Survey is provided in Table 10. Results of the current study indicate that participants reported less physical activity (18.67\%), but more than $50 \%$ of adolescents reported participation in team sports. This incongruity between the findings suggests that the adolescents did not recognize team sports as physical activity and thus, more than half the sample was physically active. Results for cigarette smoking were less than the national data collected with the 2005 Youth Risk Behavior Survey. Adolescents in the current study smoked and exercised less than the national average but were more overweight.

\section{Health Promotion Behaviors}

Health promoting behaviors of adolescents in this study were measured using the Adolescent Health Promoting Scale with a scoring range of 40 to 200. A high total score indicates a high level of participation in health promotion activity. Adolescents in the current study had an average score of 100 points, suggesting a moderate level of participation in health promoting activities. Study findings also indicated that Tennessee residents had a higher level of health promotion activity participation compared to Louisiana adolescents. These findings are important for two reasons. First, the mid-range scores of the sample indicate that adolescents in this study need continued guidance regarding participation in health promotion practices. The second reason is that health behaviors performed in adolescent years are usually carried over into adult years (Pender, 1996), which could potentially enhance the future health and decrease future morbidity if particular, this point is critical for Louisiana teens as study results revealed that this 
Table 10. Comparison of the Youth Risk Behavior Survey Results for Adolescent Males in the Current Study and in the 2005 Adolescent National Dataset

\begin{tabular}{|c|c|c|c|}
\hline & $\begin{array}{c}\text { Current } \\
\text { Cigarette Use }\end{array}$ & $\begin{array}{l}\text { Physical Activity } \\
>20 \text { minutes } \\
\text { during P. E. classes }\end{array}$ & Risk for Overweight \\
\hline National * & $23 \%$ & $26.5 \%$ & $15.7 \%$ \\
\hline Current Study $\S$ & $8 \%$ & $18.67 \%$ & $21 \%$ \\
\hline
\end{tabular}


group reported less participation in health promotion behaviors.

Studies investigating health promotion behaviors have ranged from adolescent to geriatric populations (Affenito et al., 2005; Arbeit et al., 1992; Jessor, 1993; Hendricks et al., 2000; Lee \& Cubbin, 2002). One study that investigated health promotion behaviors in Black American adolescent males in a southern community (Hendricks et al., 2000), similar to the current study, reported higher levels of health promotion behaviors regarding health responsibility, exercise, and nutrition. Bagwell and Bush (2000) suggested that health promotion programs help to support the concept of selfresponsibility, which is essential for adolescents if their health outcomes are to improve as adults. The practice of health promotion will be essential to the health and well-being of adolescents in the current study who were pre-hypertensive.

Lee and Cubbin (2002) examined the cardiovascular health behaviors (dietary habits, tobacco use, and physical activity) of a sample of adolescents 12 to 21 years of age. The study included a tri-ethnic sample of Black, White, and Hispanic American adolescents with a mean age of 16 years. This study was different from the current study because the age range of participants included slightly younger and older participants. Like the current study, Lee and Cubbin used the Youth Risk Behavior Survey to evaluate cardiovascular risk factors that included dietary habits, tobacco use, and physical activity. The inability to sustain health promotion practices to prevent cardiovascular disease among Black American adolescents residing in neighborhoods with lower socioeconomic status has been suggested by Lee and Cubbin (2002). In addition, Lee and Cubbin found that Black American adolescents reported poor eating habits and were less likely to smoke and be physically active than other participants. These findings were similar to the 
current study because of comparable levels of smoking at least 1 day during the previous month, which was $6 \%$ versus $10 \%$ for the Lee and Cubbin study. Findings were also similar regarding physical activity as $16 \%$ of adolescents in the current study reported participation in regular physical activity seven days a week, which is comparable to Lee and Cubbin's results of $17 \%$. In the current study, however more than half (59\%) reported participation in team sports; this finding suggests that the sample participants did not associate team sports participation with the concept of exercise. Thus, adolescents in this study were actually more physically active than revealed by the response to the Youth Risk Behavior Survey Scale.

\section{The Association Between Perceived Health Status and Self-Efficacy}

There was a moderate, positive association between perceived health status and self-efficacy scores with equivalent findings based on state of residence. As the levels of perceived health status increased, so did the level of self-efficacy in the study sample and for Louisiana and Tennessee adolescents. No studies were found in the literature for adults or adolescents that examined a relationship between perceived health status and self-efficacy. This point is important because in order for adolescents to participate in health promotion activities, they must believe that they can complete the task (Bandura, 1986). Adolescents in the current study demonstrated confidence in their ability to care for their health needs with moderate high levels of perceived health status and selfefficacy. 


\section{The Influence of Perceived Health Barriers, Perceived Health Status, Self-Efficacy, and Cardiovascular Health Risk on Health Promotion Behaviors}

The qualitative nature of the results gained from the reported health barriers was not suited for determining the influence of perceived health barriers on health promotion behaviors in the study sample. The negative relationship between health perceptions (perceived health status and self-efficacy) and health promotion behaviors was significant in the study sample. In contrast, there were significant, positive relationships between health promotion behavior scores and age and glucose levels. Hence, as health perceptions in the adolescents in Louisiana and Tennessee increased, their health promotion behaviors were found to decrease. Nevertheless, we determined that as health promotion behaviors increased, so did the age and glucose levels of the participating adolescents. Despite this relationship, none of the adolescents in the study reported a personal or family history of diabetes, although 6 adolescents (8.5\%) in the sample had elevated fasting glucose levels. An explanation for the relationship between increased age and fasting glucose blood levels may have been influenced by one factor. These adolescents may have been pre-diabetic, which could have been related to increased body weight. Because this subgroup of adolescents is small $(n=6)$ statistical analysis is not warranted, however 4 of the 6 students were at risk for being overweight and 1 was overweight. A possible reason for the increase in health promotion behaviors as age increased in the sample is the accumulation of health awareness and health knowledge for older students, gained from years of health education in their school health classes.

Behavior variables (smoking, physical activity, and team sports participation) examined among Louisiana and Tennessee adolescents were not significantly or strongly 
associated with reported health promotion behaviors. The same findings were also associated with biological variables (body mass index, total cholesterol levels, systolic and diastolic blood pressure), that is these variables did not have a strong significant association with health promotion behaviors. When we examined biological variables based on the entire sample a significant, but weak relationship with health promotion behaviors was found for glucose levels, while the weak association between total cholesterol levels and health promotion behaviors was non-significant. These relationships were likely non-significant because there was little variability in both the glucose and cholesterol levels of study participants, as most had normal levels. Moreover, there were significant missing data for the sample as 22 students did not undergo glucose testing and 23 did not consent to the cholesterol testing. In contrast there was greater variation in health promotion behavior scores. For a significant correlation to exists scores of the two variables must "vary together", cholesterol and glucose levels varied little.

The independent variables: perceived health status, self-efficacy, and glucose did not significantly influence the health promotion behaviors of the study adolescents, accounting for less than 3\% of the adjusted variance. These results were not an anticipated finding because a continued practice of health promotion behavior is usually linked to higher levels of perceived health status and self-efficacy. Furthermore, the findings suggest that although the relationship between the health perceptions (health status and self-efficacy) and health promotion behavior were significantly correlated, the correlations were not strong. Hence, while three predictor variables were significantly correlated with the outcome variable, none significantly explained the variance in the 
scores. Also, because no other study was found in the literature that investigated the influence of perceived health status and self-efficacy on the health promotion behaviors of Black American adolescent males, additional studies exploring the association between health perceptions and health promotion behavior among Black American adolescent males is needed. Black American male adolescents' participation in health promotion activities seems to be contingent upon other variables that were not included in this study, such as parental or peer influence. These potential explanatory variables and others merit investigation to design interventions to enhance health promotion behavior and ultimately reduce cardiovascular disease in this population.

According to the American Heart Association (2006) 36\% of 290,000 Black Americans die each year from cardiovascular disease illness. Improving health promotion behavior practices and awareness may aid in reducing the existing high cardiovascular disease morbidity rate among Black American males. Most of the literature about health promotion behaviors among Black Americans has focused on adult populations, however Rozmus, Evans, Wyoschansky, and Mixion (2005) reported that college youths (mean age-19 years) engaged in behaviors that increase their risk of morbidity and mortality, such as alcohol and drug use, unprotected sex, and unhealthy eating leading to increased body mass index. Experimentation with risky behavior is not uncommon in late adolescents; in fact, adolescents expand and strengthen their sense of efficacy through the process of mastery through experiences (Bandura, 1994). Because adolescence is a period of experimentation and mastery, providing experiences that increase their understanding and use of health promotion practices could possibly reduce the development of cardiovascular disease. 


\section{Limitations and Strengths}

In addition to the six study limitations initially acknowledged, several additional unexpected limitations emerged while conducting this research study. First, the use of several instruments appeared to have been a burden on the student participants. Specifically, instruments included the use of a questionnaire booklet that contained five instruments, a food record booklet, and demographic and medical health history questionnaire. Although the packet was shared with the adolescents and their parents during the information sessions, many of the participants seemed surprised by the number of questionnaires in the booklet. The investigator sensed the reluctance of a few adolescents to complete the study questionnaires, which seemed to be substantiated by their attempts to submit incomplete test booklets and the slow walking pace observed as they returned to the area where they completed the questionnaires. The Youth Risk Behavior Survey, which was one of the instruments, had 49 questions. Retrospectively, in order to reduce the participation burden on the study participants the investigator could have explored two possible options. Option one is using two consecutive days for data collection: collect physiological samples on day one and complete questionnaire booklets and deliver the study incentive on day two. The second option would have been to find shorter, valid, and reliable instruments to capture the study variables.

The second study limitation identified was that the conceptual framework was developed and designed by the investigator and based on influences of health behaviors reported by Black American men documented in the literature. The research findings did not support the conceptual framework, which guided the study. Multiple regression 
analysis revealed that predictor variables did not significantly influence reported health promotion behaviors for the study sample. Study finding suggests that other variables have a greater influence on health promotion behaviors of Black American adolescent males. Alternative factors that might be more relevant for this population may include the health promotion beliefs and behaviors of the adolescents' families and peer group (e.g. socialization), the availability of parents or guardian to supervise idle time and activity, and the types of food and food preparation strategies used in the home. The review of the literature did not provide guidance related to factors that may influence the health promotion behaviors of Black adolescent males, suggesting that additional research is needed in the area.

Third, there were two limitations associated with use of the Barrier Questionnaire. First, several adolescents did not fully understand that the questionnaire was asking for the factors that prevented him from making healthy choices for the sake of his health. Instead these adolescents provided answers that reflected how he could promote a healthier lifestyle. These responses are opposite sides of the coin. Adolescents who responded in this fashion described facilitators instead of barriers to healthier lifestyles. This problem suggests that the Barrier Questionnaire lacked the clarity needed in order for the adolescents to understand the question. Second, data collected using this instrument could not be included in correlation and multiple regression analyses conducted to address the study aims. The questionnaire was designed to obtain descriptive information that was not easily translated into the scores needed for statistical analyses. Therefore, the perceived health barrier findings were analyzed using content analysis to identify health barrier reported by the sample. Perceived health barriers could 
be explored as the presence or absence of a barrier using dummy coding in future studies, as this would allow quantitative analysis of these findings.

The fourth and last limitation included the use of the 3-day food record, which was developed by the investigator in order to assess and evaluate the food intake of participating adolescents using specific food analysis software. However, a limitation that was not anticipated was the incomplete food intake information recorded by participating adolescent males. Most of the participants did not record portion sizes, location of meals, condiments used, and the brand names of foods eaten as instructed. Brand names and portion sizes were a requirement of the software for accurate analysis, which was confirmed with a telephone call to the software representative. An instrument developed for adolescents over 14 years of age may not be suitable for adolescents younger than 14 years and using an instrument in a sample that includes both age groups would require a pilot study to examine the utility of the instrument and its psychometric properties (Dashiff, 2000). Although the 3-day food record was not specifically designed for adolescents 14 years of age or older, the investigator failed to consider the cognitive differences that may have existed among the different age groups participating in the study. In retrospect, in order to ensure that the adolescents completely understood recording instructions of their food portion sizes, the investigator should have used measuring cups and artificial food samples to illustrate specific portion sizes and spoke with each adolescent individually instead of providing verbal instructions collectively in a group setting. Schmidt et al. (2005) successfully used the 3-day food records in a study that included an exclusively female sample and registered dieticians who monitored the adolescents' intake on a daily basis. Conceivably, adolescent girls may be more aware of 
what they are eating because of their exposure to societal concerns about weight and body image through media such as teen girl magazines and television. However, these food record data can be analyzed in the future to explore dietary patterns such as fast food intake and foods that are traditionally known for high sugar, sodium, and fat content.

Despite the methodological limitations of this study, the current study has several significant strengths. First, this is the only study to examine the perceived health barriers, health perceptions, and modifiable and non-modifiable cardiovascular risk factors of Black American adolescent male. Prior studies with Black American adolescents have focused on health risk behaviors. Second, very few studies have investigated the health promotion behaviors of Black American adolescent males. Several studies have examined health aspects of adult Black American males, but none have exclusively investigated an adolescent population. Third, this study recruited adolescents from three different geographic locations in the southeastern U.S., which likely enhances the external validity of study findings. The fourth and final strength of this study is that the findings provided important direction for practice, policy, and future research studies.

\section{Practice and Policy Implications}

The implications for nursing practice and policy for this study emphasize the importance of school officials providing cafeteria food choices for students that are low in fat, sugar, and calories, based on the elevated blood pressures and weight observed in a clinically significant proportion of the study participants. These findings suggest that school and health officials should monitor food preparation and offerings because more than $70 \%$ of study adolescents reported participating in the free lunch program and 
received two meals at school each day. In addition, many of the food intake records confirmed that these two meals were the only meals consumed daily by the teens and after-school snacking was common. Furthermore, more than half of the study sample had elevated systolic blood pressure readings and $32 \%$ had elevated diastolic blood pressures, despite the fact that $59 \%$ were involved in school sports. Because of the increasing prevalence of overweight and hypertension in adolescents particularly Black American adolescents, school-based health promotion programs seem warranted.

As the study's independent variables were not significantly associated with health promotion behaviors, clinicians must consider other variables, such as home and community factors that may influence the health promotion practices of this population. The results of this study also have clinical implications for health promotion education for the significant adults participating in the lives of Black American male adolescents. School officials who provide after-school programs and who lead the sports activities of youth should improve educational programs directed at teaching adolescents the importance of practicing health promotion for healthier outcomes. Currently the focus of sports programs is on winning the event but this philosophy could be expanded in terms of winning with regard to health and its impact on winning the game. This approach might be a particularly useful approach for males, who are socialized to value physical superiority. Additional practice and policy implications based on the current study findings suggest that clinicians need to assess the health practices and behaviors of adolescents and their families. Once the health practices and behaviors are assessed and their needs are understood, clinicians can collaborate with significant adults to design individualized health interventions that will improve food choices and encourage 
increased physical activity. By incorporating these health promotion behaviors into daily routines, adolescents can reduce and maintain a healthy weight, while lowering elevated blood pressure and other modifiable cardiovascular risk.

Developing specific evidence-based interventions that enhance continued positive health status and self-efficacy in these adolescents as they transition into adulthood is imperative for the health of Black American men. Furthermore, programs offered in high schools, vocational schools, recreational and community centers, and job sites are needed that foster the positive attributes found in this study (high perceived health status and self-efficacy). By publishing the findings of the perceived health barriers reported by Black American adolescent males, other researchers can design studies to investigate additional potential health barriers that add to the literature and inform practice. Positive health perceptions are developed through personal experiences and success contributes to a strong sense of perceived health status and self-efficacy, while aiding the reduction of health barriers.

Additional consideration includes developing and designing programs that are appropriate for specific adolescent stage of development. During early adolescence (age 11 to 13 years) teens test values, have a weak sense of individual identity, and feel a need to participate in worthy activities. During middle adolescence (age 14 to 16 years) independence and personal identity become important aspects of their lives, while learning to cooperate with adults. The late stage of adolescence (17 to 19 years) reveals independence and identity (Ohio State University, 2007). This maturational process assists with preparing adolescents to leave home and care for self. Hence, it is imperative that health promotion programs are designed with appropriate elements based on the 
adolescent stage of development. Effective, evidence and community-based programs that focus on team sports might provide opportunities for improving the health outcomes of Black American males.

Helping policymakers to understand the significance of Black American male health and the impact that it has upon the U. S. society is important for future research and probably the cost of health care. In the U. S. that preventive care is exponentially less expensive than disease-oriented care (Health Resources Publishing, 2007). Federal financial support is necessary to organize community-based committees that include health promotion experts and Black American men who understand the specific issues affecting the health of Black American males. This committee would focus their attention on designing longitudinal community-based participatory studies that provide evidence as to what interventions are effective for this at risk population.

\section{Theoretical Implications}

The study findings provided partial support for the conceptual model, as it demonstrated a significant relationship for some of the independent variables but these independent variables were not predictive of the outcome variable. The adolescents participating in the current study acknowledged several of the variables in the conceptual model, as important factors in their lives. For example, a few participants reported finance and race as health barriers. This finding was notable because these variables represented two of the four health barriers depicted in the conceptual model as influencing health promotion behaviors of Black American adolescent males. Finance as a health barrier is representative of both economic and social concerns described as 
socioeconomic status in the study model Race as a health barrier reported by one participant may be reflective of racism which is included in the model. Perceived health status and self-efficacy were positive attributes for more than $50 \%$ of the study sample, while several of the cardiovascular risk factors illustrated in the model were present in clinically significant proportions of participants in the study sample. Inadequate physical activity levels, poor diet, excessive weight, and at risk blood pressures and glucose levels were present for clinically relevant numbers of adolescents in this study. For example, blood glucose and total cholesterol levels were elevated in less than $10 \%$ and $25 \%$ of the population, respectively. Based on these findings, the conclusion is that changes seem warranted in the current model to reflect reported health barriers such as diet, environment, and finance.

\section{Recommendations for Future Research}

The results of this descriptive correlational study provide several options for future research into the health promotion behaviors of Black American adolescent males. Since little research has focused on this population, this study provides key insights and has provided a foundation for future studies. Psychosocial factors, such as home life, peer influence, and adult influence other than parents, are possible areas for future research. Furthermore, the use of focus groups with Black American adolescent males as a research strategy would ensure an opportunity to capture the true perspective regarding the health barriers that significantly influence the health promotion behaviors of this population. A health barrier instrument developed specifically for adolescent populations would aid greatly with research initiatives. This statement is based on the troubles encountered with 
the adolescents in the current study using a health barrier instrument that was developed initially for adults. This instrument could be developed using data from these focus groups. Results from these focus groups and from the current study could also lead to additional studies designed to determine if identified variables better explain the factors influencing the health promotion behaviors of Black American adolescent males.

Findings from the current study, for example, suggest that environmental factors such as peer pressure could be an important factor influencing the health promotion behaviors of Black American adolescent males.

Moreover, longitudinal studies could provide important data about the health promotion behaviors of Black American adolescent males transitioning into adulthood. One such study could investigate the age at which Black American adolescents begin to experience a reduction in their level of perceived health status and identify those factors that contribute to this change in perception. Another study could examine if health promotion education programs taught in elementary and middle school could have a long-term influence on health promotion practices, such as when these students reach their high school and young adult years. Settersten and Lauver (2004) found that health perception is directly related to cognitive abilities in combination with participation in healthy behaviors, while Merrill, Friedrichs, and LaDene (2000) reported that knowledge concerning health promoting activities did not ensure healthy behaviors. While further studies to clarify the understanding of health promotion behaviors in this population would be useful, it would be more useful to determine those factors that promote the use of these behaviors from adolescence to adulthood. As a final point about future research, the importance of finding the correct and appropriate tools that will accurately capture the 
data needed and are developmentally appropriate for adolescent samples is a valuable consideration for the planning of future research studies.

\section{Summary}

In conclusion, this study provided partial support for the conceptual model in two specific ways. First, two of the four health barriers found in the model were identified by the study sample. Second, perceived health status and self-efficacy were significantly correlated, but did not significantly influence health promotion behaviors. Study findings emphasized the importance of health promotion practices among Black American adolescent males because of the cardiovascular health risk factors (increased blood pressure and elevated body mass index) identified in the study sample. In addition, this study identified known cardiovascular risk factors in the study sample and provided important health information that parents probably did not know. Although predictor variables (perceived health status, self-efficacy, age, and body mass index) were weakly correlated with the outcome variable, health promotion behavior, the findings of this study provide information that is not available in the current literature. Furthermore, these findings provide the foundation for future research that focuses on health promotion behavior of Black American adolescent males.

Although some cardiovascular risk factors such as gender, race, and family history, are not modifiable, several of the cardiovascular risk factors identified in the study sample are modifiable (e.g., physical activity level, weight, blood pressure) by practicing healthy lifestyle choices. While is uncertain if study adolescents will develop cardiovascular disease, the high prevalence of obesity, pre-hypertension, physical 
inactivity, and positive family histories suggest that many are at risk. Thus, this study underscores the essential role that health promotion behaviors could have and the need for risk reduction programs early in life to reduce the cardiovascular health disparity experienced by Black American adult males. Furthermore, if we are to reduce the health disparity in the U. S., it is imperative that community based programs, such as healthier meals within the public school systems are implemented, since more than half of the study participants received at least two meals during school hours. 


\section{LIST OF REFERENCES}

Adeyanju, M. (1990). Adolescent health status, behaviors, and cardiovascular disease. Adolescence, 25 (97), 155-167.

Affenito, S., Thompson, D., Barton, B., Franko, D., Daniels, S., Obarazanek, E., Schreiber, G., \& Striegel-Moore, R. (2005). Breakfast consumption by African American and White adolescent girls correlates positively with calcium and fiber intake and negatively with body mass index. Journal of the American Dietetic Association, 105, 938-9435.

Albert, M., Torres, J., Glynn, R. \& Ridker, P. (2004). Perspectives on selected issues in cardiovascular disease research with a focus on Black Americans. Circulation, 110 (2), e7-e12.

American Academy of Pediatrics (2001). Retrieved July, 2005, from http://www.aap.org/

American Heart Association (2002). Heart disease and stroke statistics. Retrieved April, 2004, from http://www.americanheart.org/downloadable/heart/ 104391091015HDS_Stats_03.pdf

American Heart Association (2004). African American and cardiovascular diseasestatistics. Retrieved September, 2004, from http:/www.americanheart.org/ downloadable heart/1107370380764F501AF05rev0131.pdf

American Heart Association (2005). Heart facts 2005: African Americans. Retrieved April, 2005 from http://www.americanheart.org/downloadable/heart/ 1106668161495AllAMAFamHeartFacts05.pdf

American Heart Association (2006). Heart facts 2006: African Americans. Retrieved March, 2006, from http://www.americanheart.org?downloadable/heart/ 1106668161495AllAMAFamHeartFacts06.pdf

American Obesity Association (2002). Obesity in youth. Retrieved September, 2006, from http://www.obesity.org/subsfastfacts/obesity_youth.html

Anderson, E., Wojcik, J., Winett, R. A., \& Williams, D. M. (2006). Social-cognitive determinants of physical activity: the influence of social support, self-efficacy, outcome expectations, and self-regulation among participants in a church-based health promotion study. Health Psychology, 25 (4), 510-520.

Arluck, S. 1., Branch, J. D., Swain, D. P., \& Dowling, E. A. (2003). Childhood overweight's relationship to time spent in sedentary behavior. Military Medicine, $168,583-586$. 
Bagwell, M. M. \& Bush, H. A. (2001). Improving health promotion for blue-collar workers. Journal of Nursing Care Quality, 14(4), 65-71.

Bandura, A. (1977). Cognitive processes mediating behavior change. Journal of Personality and Social Psychology, 35, 125-139.

Bandura, A. (1986). Social foundation of thought and actions: A social cognitive theory. Englewood Cliffs, New Jersey: Prentice Hall.

Bandura, A. (2004). Health promotion by social cognitive means. Health Education \& Behavior, 31 (2), 143-164.

Bandura, A. Adams, N., \& Beyer, J. (1977). Cognitive processes mediating behavioral change. Journal of Personality \& Social Psychology, 35(3):125-139, March 1977.

Becker, D. M., Yanek, L. R., Koffman, D. M., \& Bronner, Y. C. (1999). Body image preference among urban African Americans and Whites from low income communities. Ethnic Disease, 9 (3), 377-386.

Becker, G. \& Newsom, E. (2003). Socioeconomic status and dissatisfaction with health care among chronically ill African Americans. American Journal of Public Health, 93 (5), 742-748.

Becker, H., Stuifbergen, A., Oh, H., \& Hall, S. (1993). The self-rated abilities for health practices scale: A health-efficacy measure. Health Values, 17, 42-50.

Bem, S. L. (1981). Gender schema theory: A cognitive account of sex typing source. Psychological Review, 88, 369-371.

Berenson, G. S. (1999). The relation of overweight to cardiovascular risk factors among children and adolescents: The Bogalusa heart study. Retrieved January, 2005 from http://www.highbeam.com/library/doc1.asp?DOCID=1G1:54912540\&num=3\&ct r1Info=R

Berenson, G. S. \& Srnivasan, S. R. (2004). Cardiovascular risk factors in youth with implications for aging: The Bogalusa heart study group. Neurobiology of Aging, 26, 303-307.

Berkey, C. S., Rockett, H. Field, A. E., Gillman, M. W., Frazier, L., Camargo, C. A., \& Graham, A. C. (2000). Activity, dietary intake, and weight changes in a longitudinal study of preadolescent and adolescent boys and girls. Pediatrics, 105 (4). Retrieved December, 2006 from http://www.pediatrics.org/cgi/content/full/ $105 / 4 / \mathrm{e} 56$ 
Blendon, R. J., Scheck, A. C., Donelan, K., Hill, C. A., Smith, M., Beatrice, D., \& Altman, D. (1995). How White and African Americans view their health and social problems: Different experiences, different expectations. Journal of the American Medical Association, 273 (4), 341-346.

Boehringer Mannheim Corporation (1997). Accu-chek advantage blood glucose monitor. Indianapolis, IN.

Bowen-Reid, T. L. \& Harrell, J. P. (2002). Racist experiences and health outcomes: An examination of spirituality as a buffer. Journal of Black Psychology, 28 (1), 1836.

Brener, N., Kann, L., Garcia, D.,MacDonald, G., Ramsey, F., Honeycutt, S., Hawkins, J., Kinchen, S., \& Harris, W. (2007). Youth risk behavior surveillance-Selected steps communities, 2005. Retrieved February, 2007 from http://www.cdc.gov/mmwr/ preview/mmwrhtml/ss5602al.htm

Brown, D. J. (2004) Everyday life for Black American adults stress, emotions, and blood pressure. Western Journal of Nursing Research, 26 (5), 499-514.

Burns, N. \& Groves, S. K. (2001). The Practice of Nursing Research: Conduct, Critique and Utilization $\left(4^{\text {th }}\right.$ ed.). W. B. Saunders: Philadelphia.

Callaghan, D.M. (2003). Health-promoting self-care behaviors, self-care self-efficacy, and self-care agency. Nursing Science Quarterly, 16 (3), 247-254.

Carter, K. F. \& Kulbok, P. A. (1995). Evaluation of the interaction model of client health behavior through the first decade of research. Advances in Nursing Science, 18 (1), 62-73.

Center for Disease Control (2000). Body mass index for age percentiles. Retrieved August, 2006 from http://www.cdc.gov/growthcharts

Center for Disease Control (2002). Youth risk behavior survey questionnaire. Retrieved November, 2004 from http://www.cdc.gov/HealthyYouth/yrbs/

Center for Disease Control (2004). Methodology of he youth risk behavior surveillance system. Morbidity and Mortality Weekly, 53 (RR-12). Retrieved January, 2005 from http://www.cdc.gov/mmwr/PDF/rr5312.pdf.

Center for Disease Control (2006). Youth Online: Comprehensive Results. Retrieved October, 2006 from http://apps.nccd.cdc.gov/yrbss/QuestYearTable.asp?path= byHT \&ByVar $=$ CI\&cat $=6 \&$ que.

Cervone, D. (2000). Thinking about self-efficacy. Behavior Modification, 24 (1), 30-56. 
Chen, M., Wang, E., Yang, R., \& Liou, Y. (2003). Adolescent health promotion scale: Development and psychometric testing. Public Health Nursing, 20(2), 105-110.

Chlebowy, D. \& Garvin, B. (2006). Social support, self-efficacy, and outcome expectations. American Association of Diabetes Educators, 32 (5), 777-786.

Colon, R. \& Franklin, F. (1997). Prevalence of obesity with increased blood pressure in elementary children. Southern Medical Journal, 90(8), 806-814.

Conner, N. \& Eller, L. (2004). Spiritual perspectives, needs and nursing interventions of Christian African-Americans. Journal of Advanced Nursing, 46(6), 624-632.

Corbie-Smith, G. (1999). The continuing legacy of the Tuskegee syphilis study: Considerations for clinical investigations. American Journal of the Medical Sciences, 317(1), 5-8.

Courtenay, W. H. (2000). Constructions of masculinity and their influence on men's well-being: A theory of gender and health. Social Science \& Medicine, 50, 13851401 .

Courtenay, W. H. (2000d). Social work, counseling, and psychotherapeutic interventions with men and boys. Men and Masculinities, 2(3), 330-352.

Courtenay, W., McCreary, D., \& Meirghi, J. (2003). Gender and ethnic differences in health beliefs and behaviors. Journal of Health Psychology, 7(3), 219-231.

Cox, C. L. (1982). An interaction model of client health behavior: Theoretical prescription for nursing. Advances in Nursing Science, 41-56.

Crawford, P. B., Story, M., Wang, M. C., Ritchie, L. D., \& Sabry, Z. I. (2001). Ethnic issues in the epidemiology of childhood overweight. Pediatric Clinics of North America, 48, 855-878.

Cromwell, S. L. \& Adams, M.M. (2006). Exercise, self-efficacy, and exercise behavior in hypertensive older African-Americans. Journal of National Black Nurses Association, 17 (1), 17-21.

Crosby, R. A., Wingood, G. M., \& DiClemente, R. J. (2002). Family-related correlates of sexually transmitted disease and barriers to care: A pilot study of pregnant African American adolescents. Family \& Community Health, 25 (2), 16-27.

Daniels, P. Noe, G.. F., \& Mayberry, R. (2006). Barriers to prenatal care among Black women of low socioeconomic status. American Journal of Health Behavior, 30 (2), 188-198. 
Dashiff, C. (2001) Data collection with adolescents. Journal of Advanced Nursing, 33 (3), 343-349.

Daviglus, M. L., Liu, K., Pirzada, A., Yan, L. L., Garside, D. B., Feinglass, J., Guralnik, J. M., Greenland, P., \& Stamler, J. (2003). Favorable cardiovascular risk profile in middle age and health related quality of life in older age. Archives of Internal Medicine, 163, 2460-2468.

Davis, C. L., Flickinger, B., Moore, D., Bassali, R., Baxter, S. D., \& Yin, Z. (2005). Prevalence of cardiovascular risk factors in schoolchildren in a rural Georgia community. American Journal of the Medical Sciences, 330 (2), 53-59.

Davy, B. M., Harrell, K., Stewart, J., \& King, D. S. (2004). Body weight status, dietary habits, and physical activity levels of middle school-aged children in rural Mississippi. Southern Medical Journal, 97 (6) 571-577.

DeForge, B., Stewart, D., DeCoe-Weston, M., Graham, L., \& Charleston, J. (1998). The relationship between health status and blood pressure in urban African Americans. Journal of National Medical Association, 90(11), 658-664.

Deshmukh-Taskar, P., Nicklas, T. A., Morales, M., Yang, S. J., Zakeri, I., \& Berenson, G. S. (2005). Tracking of overweight status from childhood to young adulthood: the Bogalusa Heart Study. European Journal of Clinical Nutrition, 1-10.

Dietz, W. (2004). Overweight in childhood and adolescence. New England Journal of Medicine, 350(9), 855-857.

Dowda, M., Ainsworth, B. E., Addy, C. L., Saunders, R., \& Riner, W. (2001). Environmental influences, physical activity, and weight status in 8 to 16 year olds. Archives of Pediatric Adolescent Medicine, 155, 711-171.

Dressler, W. W., Bindon, J. R., \& Neggers, Y. H. (1998). John Henryism, gender, and arterial blood pressure in an African American community. Psychosomatic Medicine, 60, 620-624.

Earl, C. E. \& Penny, P. J. (2001). The significance of trust in the research consent process with African Americans. The Western Journal of Nursing Research, 23(7), 753762.

Ebbeling, C. A., Pawlak, D. B., \& Ludwig, D. S. (2002). Childhood obesity: Public health crisis, common sense cure. The Lancet, 360, 473-482.

Ellison, C. G. (1991). Religious involvement and subjective well-being. Journal of Health Social Behavior, 32, 80-99. 
Ellison, C. G. \& Taylor, R. J. (1996. Turning to prayer: Social and situational antecedents of religious coping among African Americans. Review of Religious Research, 38, 111-131.

Ensminger, M. E. (1990). Sexual activity and problem behaviors among Black urban adolescents. Child Development, 61, 2032-2046.

Erlich, P. M., Cui, J. Chazaro, I., Farrer, L. A., Baldwin, C. T., Gavras, H., \& DeStefano, A. L. (2003). Genetic variants of WNK4 in Whites and African Americans with hypertension. Hypertension, 41 1191-1199.

Fang, J., Madhavan, S., \& Alderman, M. H. (1996). The association between birthplace and mortality from cardiovascular causes among Black and White residents of New York City. New England Journal of Medicine, 335 (21), 1545-1551.

Ferguson, J. (2005). Teens and risky behavior. Retrieved January, 2007 from http://ezinearticles.com/?Teens-and-Risky-Behavior\&id=86747

Ferraro, K. F. (1993). Are Black older adults health-pessimistic? Journal of Health and Social Behavior, 34 (September), 201-214.

Ferraro, K. F. \& Kelley-Moore, J. A. (2000). Religious consolation among men and women: Do health problems spur seeking? Journal for the Scientific Study of Religion, 39 (2), 220-234.

Ferraro, K. \& Koch, J. R. (1994). Religion and health among Black and White adults: Examining social support and consolation. Journal for the Scientific Study of Religion, 33, 362-375.

Food Research and Action Center (2007). Federal Food Programs. Retrieved March, 2007 from http://www.frac.org/html/federal_food_programs/programs/nslp.html

Freedman, B. I. (2003). Susceptibility genes for hypertension and renal failure. Journal of the American Society of Nephrology, 14, S192-S194 [supplement article].

Freedman, D. S., Khan, L. K., Dietz, W. H., Srinivasan, S. R., \& Berenson, G. S. (2001). Relationship of childhood obesity to coronary heart disease risk factors in adulthood: The Bogalusa heart study. Pediatrics, 108(3), 712-718.

Freedman, D. S., Khan, L. K., Serdula, M. K., Dietz, W. H., Srinivasan, S. R., \& Berenson, G. S. (2005). The relation of childhood BMI to adult adiposity: The Bogalusa heart study. Pediatrics, 115, 22-27.

Frenn, M., Malin, S., Villarruel, A. M., Slaikeu, K., McCarthy, S., Freeman, J., Nee, E. (2005). Public Health Nursing, 22 (2), 89-97. 
Garb, H. N. (1997. Race bias, social class bias, and gender bias in clinical judgment. Clinical Psychology Science Practice, 4, 99-120.

Gandy, O. H. (2001). Racial identity, media use, and the social construction of risk among African Americans. Journal of Black Studies, 31 (5), 600-618.

Gary, L. E. (1995). African American men's perceptions of racial discrimination: A sociocultural analysis. Social Work Research, 19(4), 207-217.

Geronimus, A. T., Bound, J., Waidmann, T. A., Hillemeier, M. M., \& Burns, P. B. (1996). Excess mortality among Blacks and Whites in the United States. New England Journal of Medicine, 335 (21), 1552-1558.

Goodman, E. \& Huang, B. (2002). Socioeconomic status, depressive symptoms, and adolescent substance use. Archives Pediatric Adolescent Medicine, 156, 448-453.

Gore, S. V. (1999). African-American women's perceptions of weight: Paradigm shift for advance practice. Holistic Nursing Practice, 13 (4), 71-79.

Gortmaker, S. L., Must, A., Sobol, A. M., Peterson, K., Colditz, G. A., \& Dietz, W. H. (1996). Television viewing as a cause of increasing overweight among children in the United States, 1986-1990. Archives of Pediatrics \& Adolescent Medicine, 150, 356-362.

Graham-Garcia, J., Raines, T., Andrews, J., \& Mesah, G. (2001). Race, ethnicity, and geography: Disparities in heart disease in women of color. Journal of Transcultural Nursing, 12(1), 56-67.

Graves, K. \& Miller, P. (2003). Behavioral medicine in the prevention and treatment of cardiovascular disease. Behavioral Modification, 27(1), 56-67.

Griffiths, S. (1996). Men's health: Unhealthy lifestyles and an unwillingness to seek medical help. [Editorial] British Medical Journal, 312(7023), 69-70.

Grubbs, S., Hardin, S., Weinrich, Weinrich, M., Garrison, C., Pesut, D., \& Hardin, T. (1992) Self-efficacy in normal adolescents. Issues in Mental Health Nursing, 13, 121-128.

Guidry, M. L. \& Wilson, A. M. (1999). Health promoting behaviors of African-American registered nurses. Journal of National Black Nurses Association, 10 (2), 37-42.

Gutin, B., Yin, Z., Humphries, M. C., Bassali, R., Le., N., Daniels, S., \& Barbeau, P. (2005). Relations of body fatness and cardiovascular fitness to lipid profile in Black and White adolescents. Pediatric Research, 58, 78-82. 
Haas, D. C., Gerber, L. M., Shimbo, D., Warren, K., Pickering, T. G., \& Schwartz, J. E. (2005). A comparison of morning blood pressure surge in African Americans and Whites. Journal of Clinical Hypertension, 7 (4), 205-209.

Halpern-Felsher, B. L., Kropp, R. Y., Boyer, C. B., Tschann, J. M., \& Ellen, J. M. (2004). Adolescent's self-efficacy to communicate about sex: Its role in condom attitudes, commitment, and use. Adolescence, 39 (155), 443-456.

Hardin, S. Weinrich, S., Garrison, C., Hardin, T., \& Weinrich, M. (1990). Intervention to decrease disaster stress in adolescents (NIMH Grant 1RO1MH47551-01).

Bethesda, MD: National Institute of Mental Health.

Hatchett, B. F., Holmes, K., Duran, D. A., \& Davis, C. (2000). African Americans and research participation. Journal of Black Studies, 30, (5), 664-675.

He, J., Klang, M. Appel, L., Charleston, J., Whelton, P. (1998). Seven-year incidence of hypertension in a cohort of middle-aged African and Whites. Hypertension, 31, 1130-1135.

Health Information Publishers (2004). Diabetes in children. Retrieved April, 2006 from http://www.ehealthmd.com/library/diabetesinchildren/dch_monitoring.html

Hendricks, C. S., Murdaugh, C., Tavakoli, A., \& Hendricks, D. L. (2000). Health promoting behaviors among rural southern early adolescents. Journal of National Black Nurses Association, 123-128.

Henkel, R. (1998). Tests of Significance. Sage Publications: Thousand Oaks, CA.

Hines-Martin, V., Malone, M., Kim, S., \& Brown-Piper, A. (2003). Barriers to mental health care access in an African American population. Mental Health Nursing, 24, 237-256.

Holloway, A. \& Watson, H. E. (2002). Role of self-efficacy and behavior change. International Journal of Nursing Practice, 8, 106-115.

Honig, J. (2002). Perceived health status in urban minority young adolescents. Journal of Maternal/Child Nursing, 27 (4), 233-237.

Hopkins, P. \& Hunt, S. (2003). Genetics of hypertension. Genetics in Medicine, 5(6), 413-429.

Hu, T., Lin, Z., Keeler, T. E. (1998). Teenage smoking, attempts to quit, and school performance. American Journal of Public Health, 88 (6), 940-943.

Huff-Corzine, L., Corzine, J., \& Moore, D. C. (1991). Deadly connections: Culture, poverty, and the direction of lethal violence. Social Forces, 69 (3), 715-732. 
Idler, E. L. \& Kasl, S. V. (1995). Self-rating of health: Do they also predict change in functional ability? Journal of Gerontology: Social Science, 50B (6), S344-S353.

Jenkins, T. S. (2006). Mr. nigger the challenges of education Black males within American society. Journal of Black Studies, 37(1), 127-155.

Jennings-Sanders , A. (2003). Using health fairs to examine health promotion behaviors of older African Americans. Journal of the National Black Nurses Association, 13-16, January/February.

Jessor, R. (1993). Successful adolescent development among youth in high risk settings. American Psychologist, 48 (2), 117-126.

Johnson, R. L., Saha, S., Arbelaez, J. J., Beach, M. C., \& Cooper, L. A. (2004). Racial and ethnic differences in patient perceptions of bias and cultural competence in health care. Journal of General Internal Medicine, 19(2), 101-110.

Johnson, R. J. \& Wolinsky, F. D. (1994). Gender, race, and health: The structure of health status among older adults. The Gerontologist, 34 (1), 24-35.

Jones, M., Granger, B., Short, L., \& Taylor, M. (2004). A new response to heart disease in women. Nursing Management, 35(7), 19-25.

Kann, L., Kinchen, S., Williams, B., Ross, J., Lowry, R., Hill, C., Grunbaum, J., Blumson, P., Collins, J., Kolbe, L. (1998). Youth risk behavior surveillanceUnited States, 1997. Journal of School Health, 68 (9).

Katzmarazyk, P., Srinivasan, S., Chen, W., Malina, R., Bouchard, C., \& Berenson, G. (2004). Body mass index, waist circumference, and clustering of cardiovascular disease risk factors of a biracial sample of children and adolescents. Pediatrics, 114(2), e198-e205. Retrieved November, 2005 from http://222.pediatrics.org/ cgi/content/full/114/2/e198.

Keil, J. E. Sutherland, S. E., Hames, C. G., Lackland, D. T., Gazes, P. C., Knapp, R. G., \& Troyler, H. A. (1995). Coronary disease mortality and risk in Black and White men: Results form the combined Charleston, SC and Evans County, Georgia heart studies. Archives of Internal Medicine, 155(14), 1521-1527.

Kim, J., Bramlett, M. H., Wright, L. K., \& Poon, L. W. (1998). Racial differences in health status and health behaviors of older adults. Nursing Research, 47 (4) 243 250 .

Kim, Y. S., Gynn, N. W., McMahon, R. P., Voorhees, C. C., Striegel-Moore, R. H., \& Daniels, S. R. (2006). Self-perceived barriers to activity participation among 
sedentary adolescent girls. Medicine \& Science in Sports \& Exercise, 38(3), 534540.

King, C. A., Meadows, B. B., Engelke, M. K., \& Swanson, M. (2006). Prevalence of elevated body mass index and blood pressure in a rural school-aged population: Implications for school nurses. Journal of School Health, 76 (4), 145-149.

Kohn, M. \& Jacobson, M. (2004). Cholesterol and cardiovascular risk in adolescence. Current Opinions in Pediatrics, 16(4), 357-362.

Krause, N. \& Tran, V. T. (1989). Stress and religious involvement among older African Americans. Journal of Gerontology: Social Science, 44, S4-S13.

Kreiger, N. \& Sidney, S. (1996). Racial discrimination and blood pressure: The CARDIA Study of young Black and White Adults. American Journal of Public Health, 86(10), 1370-1378.

Kupper, N., Ge, D., Treiber, F. A., \& Sneider, H. (2006). Emergence of novel genetic effects on blood pressure and hemodynamics in adolescence. Hypertension, 47, 948-954.

LaVeist, T., Nickerson, K. J., \& Bowie, J. V. (2000). Attitudes about racism, medical mistrust, and satisfaction with care among African American and White cardiac patients. Medical Care Research and Review, 57, 146-161. [Supplement].

Lee, R. \& Cubbin, C. (2002). Neighborhood context and youth cardiovascular health behaviors. American Public Health Association, 92 (3), 428-436.

Levin, J. S., Chatters, L. M., \& Taylor, R. J. (1995). Religious effects on health status and life satisfaction among Black Americans. Journal of Gerontology Psychology Science Society, S154-S163.

Levin, J. S., Lyons, J. S., \& Larson, D. B. (1993). Prayer and health during pregnancy: findings from the Galveston Low-Birth Weight Survey. Southern Medical Journal, 86, 1022-1027.

Lillie-Blanton, M., Brodie, M. Rowland, D., Altman, D., The Henry J Kaiser Family Foundation, \& Princeton Survey Research Associates (2000). Race ethnicity, and the health care system: Public perceptions and experiences, Medical Care Research and Review, 57 (1), 218-235.

Litaker, D., Koroukian, S. M., \& Love, T. E. (2005). Context and healthcare access: Looking beyond the individual. Medical Care, 43 (6), 531-540.

LoBiondo-Wood, G. \& Harber, J. (2002). Nursing research. Methods, critical appraisal, and utilization $\left(5^{\text {th }}\right.$ ed.). Mosby, Inc.: St. Louis, MO. 
Loeb, S. J. (2004). Older men's health: Motivation, self-ratings, and behaviors. Nursing Research, 53(3), 198-206.

Lowry, R. (2007). Vassar Stats. Retrieved March, 2007 from http://faculty.vassar.edu/ lowry/newcs.html.

Luma, G. B. \& Spiotta, R. T. (2006). Hypertension in children and adolescents. Retrieved September, 2006, from http://www.aafp.org/afp

Lythgoe, K. (2003). Adolescence: Change and continuity. Retrieved March, 2007 from http://www.oberlin.edu/faculty/ndarling/adolesce.htm

MacDowell, L. G. \& Short, A. (2002). Preventive health services use, lifestyle health behavior, risks, and self-reported health status of women in Ohio by ethnicity and completed education status. Women's Health Issues, 12 (2), 96-102.

Martin, J. C.,Hathaway, D. K., Eddi, F., Wicks, M. N., Muriel, M. C., Gaber, A. O., \& Cetingok, M. (1999). Grant application: Staying alive: A targeted cardiovascular risk reduction intervention for female survival kidney transplantation. Funded by The University of Tennessee Health Science Center Women's Health Research Grant Program.

Mayberry, R. M., Mili, F., \& Ofili, E. (2000). Racial and ethnic differences in access to medical care. Medical Care Research and Review, 57(1), 108-145.

McGee, D. 1., Laio, Y., Cao, G., \& Cooper, R. S. (1998). Self-reported health status and mortality in a multiethnic US cohort. American Journal of Epidemiology, 149(1), 41-46.

McSherry, W. \& Ross, L. (2002). Dilemmas of spiritual assessment: Considerations for nursing practice. Journal of Advanced Nursing, 38, 479-488.

MedicineNet (1999). Blood cholesterol levels and children. Retrieved August, 2006 from $\mathrm{http}: / / \mathrm{www} . \mathrm{medicinenet.com} / \mathrm{script} / \mathrm{main} / \mathrm{art}$.asp?articlekey=10058\&pf=3\&page= 1

Mendelson, C. (2003). The roles of contemporary Mexican American women in domestic health work. Public Health Nursing, 20(2), 95-103.

Merrill, R. M., Friedrichs, M., \& Larsen, L. (2002). Perceptions of healthy behaviors versus practices. Health Promotion Practice, 3 (4), 497-500.

Meyer, J. (2003). Improving men's health: Developing a long-term strategy. American Public Health Association, 93(5), 709-711. 
Middleton, R. (1976). Regional differences in prejudice. American Sociological Review, $41,94-117$.

Miller, M. A. (1995). Culture, spirituality, and women's health. Journal of Obstetrics Gynecology Neonatal Nursing, 24, 257-263.

Millon-Underwood, S., Sanders, E., \& Davis, M. (1993). Determinants of participation in state-of-the-art cancer prevention, early detection/screening, and treatment trials among African-Americans. Cancer Nursing, 16(1), 25-33.

Moore, L. L., Singer, M. R., Bradlee, M. L., Djousse', L., Proctor, M. H., Cupples, L. A., \& Ellison, R. C. (2005). Intake of fruits, vegetables, and dairy products in early childhood and subsequent blood pressure change. Epidemiology, 16 (1), 4-11.

Morrison, J. A., Barton, B. A., Biro, F. M., Daniels, S. R., \& Sprecher, D. L. (1999). Overweight, fat patterning and cardiovascular disease risk factors in Black and White boys. Journal of Pediatrics, 135(4), 451-457.

Munro, B. (2001). Statistical methods for health care research (4th ed.) Lippincott: Philadelphia.

Myers, R. (Editor). (2006) Stages of social-emotional development in children and teenagers. Retrieved August, 2006 from http://www.childdevelopmentinfo.com/ development/erickson.html

Nash, D. (2003). Treating cardiovascular disease in African Americans: Real treatment in the real world. Retrieved May, 2004 from http://www.medscape.com/viewarticle/ 462094

National Center for Health Statistics (1997). Black or African American Populations. Retrieved February, 2004 from http://www.cdc.gov/ohm/amh/factsheets/ cardio.htm

National Center for Health Statistics (2000). In collaboration with the National Center for Chronic Disease Prevention and Health Promotion. Retrieved September, 2006 from http://www.cdc.gov/growthcharts

National High Blood Pressure Education Program (2003). The seventh report of the joint national committee on prevention, detection, evaluation, and treatment of high blood pressure. Retrieved February, 2006 from http://www.nhlbi.nih.gov/ guidelines/hypertension/jnc7full.pdf

Nazroo, J. Y. (2003). The structuring of ethnic inequalities in health: Economic position, racial discrimination, and racism. American Public Health Association, 93 (2), 277-284. 
Neff, L. J., Sargent, R. G., McKeown, R. E., Jackson, K. L., \& Valois, R. F. (1997). Black-White differences in body size perceptions and weight management practices among adolescent females. Journal of Adolescent Health, 20 (6), 459465 .

Neighbors, H. W., Jackson, J. S., Campbell, L., \& Williams, D. (1989). The influence of racial factors on psychiatric diagnosis: A review and suggestions for research. Community Mental Health Journal, 25 (4), 1989.

Nesbitt, S. \& Victor, R. (2004). Pathogenesis of hypertension in African Americans. Retrieved April, 2004, from http://www.medscape.com/viewarticle/468120_print

Norman, G. J., Schmid, B. A., Sallis, J. F., Calfas, K. J., \& Patrick, K. (2005). Psychosocial and Environmental Correlates of Adolescent Sedentary Behaviors. Pediatrics, 116 (4), 908-916.

Nyamanthi, A., Sands, H., Pattatucci-Aragon, A., Berg, J., Leake, B., Hahn, J. E., \& Morisky, D. (2004). Perception of health status by homeless US veterans. Family \& Community Health, 27(1), 65-74.

Ofili, E., Igho-Pemu, P., \& Bradford, T. (1999). The prevention of cardiovascular disease in Blacks, Current Opinion in Cardiology, 14(2), 169-179.

Ogden, C. L., Flegal, K. M., Carroll, M. D., \& Johnson, C. L. (2002). Prevalence and trends in overweight among U. S. children and adolescents, 1999-2000. Journal of American Medical Association, 288 (14), 1728-1732.

O’Hea, E., Boudreaux, E., Jefferies, S., Carmack Taylor, C., Scarinci, I., \& Brantley, P. (2004). Stage of change movement across three health behaviors: the role of selfefficacy. American Journal of Health Promotion, 19 (2), 94-102.

Ohio State University On-Line (2007). Retrieved January, 2007 from http://ogioline. osu.edu/4-H/tl7.html.

Ohkubo, T., Imai,Y., Hozawa, A., Yamaguchi, J., Kikuya, M., Ohmori, K., Michimata, M., Matsubara, M., Hashimoto, J., Hoshi, H., Araki, T., Tsuji, T., Satoh, H., Hisamichi, S., \& Imai, Y. (2002). Prognostic significance of the nocturnal decline in blood pressure in individuals with and without high 24-hour blood pressure: The Ohasama study. Journal of Hypertension, 20, 2183-2189.

Ohkubo, T., Imai, Y., Tsuji, I., Nagai, K., Watanabe, N., Minami, N., Kato, J., Kikuchi, N., Nishiyama, A., Aihara, A., Sekino, M., Satoh, H., Hismichi, S. (1997). Relation between nocturnal decline in blood pressure and mortality. American Journal of Hypertension, 10, 1201-1207. 
Onwanyi, A., Hodges, D., Avancha, A., Weiss, L., Rabinowitz, D., Shea, S., \& Francis, C. (1998). Hypertension vascular disease as a cause if death in Black versus Whites: Autopsy findings in 587 adults. Hypertension, 31(5), 1070-1076.

Palacios, C., Wigertz, K., Martin, B. R., Jackman, L., Pratt, J. H., Peacock, M., McCabe, G., \& Weaver, C. M. (2004). Sodium retention in Black and White female adolescents in response to salt intake. The Journal of Clinical Endocrinology \& Metabolism, 89 (4), 1858-1863.

Pate, R. R., Trost, S. G., Levine, S., \& Dowda, M. (2000). Sports participation and health-related behaviors among U. S. Youth. Archives of Pediatric Adolescent Medicine, 154, 904-911.

Pender, N. J. (1987). Health promotion in nursing practice $\left(2^{\text {nd }}\right.$ ed.). Appleton and Lange: Stamford, CT.

Pender, N. J. (1996). Health promotion in nursing practice $\left(3^{\text {rd }}\right.$ ed.), p. 96. Appleton and Lange: Stamford, CT.

Pete, J. M. \& DeSantis, L. (1990). Sexual decision making in young Black adolescent females. Adolescence, 25 (97), 145-162.

Pettaway, L. \& Frank, D. (1999). Health promoting behaviors of urban African American female heads of household. Journal of National Black Nurses Association, 10 (1), 14-19.

Pickering, T. (2001). Why is hypertension more common in African Americans? Journal of Clinical Hypertension, 3(1), 50-52.

Piper, S. (1997). The limitations of well men clinics for health education. Nursing Standards, 11 (30), 47-49.

Plowden, K. O., \& Miller, J. L. (2000). Motivators of health seeking behavior in urban African- American Men: An exploration of triggers and barriers. Journal of National Black Nurses Association, 11 (1), 15-20.

Plowden, K. O. \& Young, A. F. (2003). Sociostructural factors influencing health behaviors of urban African-American men. Journal of National Black Nurses Association, 14 (1), 45-51.

Polit, D. F. \& Hungler, B. P. (1999). Nursing research: Principles and methods $\left(6^{\text {th }}\right.$ ed.) Philadelphia: JB Lippincott.

Poss, J. E. (2001). Developing a new model for cross-cultural research: Synthesizing the health belief model and the theory of reasoned action. Advances in Nursing Science, 23 (4), 1-15. 
Prochaska, J. O. \& DiClemenite, C. C. (1983). Stages and processes of self-change of smoking: Toward an integrative model of change. Journal of Consulting and Clinical Psychology, 51 (3), 390-395.

Reed, P. G. (1992). An emerging paradigm for the investigation of spirituality in nursing. Research in Nursing and Health, 15 (5), 349-357.

Rees, C., Jones, M., \& Scott, T. (1995). Exploring men's health in a men-only group. Nursing Standard, 9(43), 38-53.

Ren, X. S. \& Amick, B. C. (1996). Race and self-asessed health status: The role of socioeconomic factors in the USA. Journal of Epidemiology and Community Health, 50, 269-273.

Rew, L. (1997). Ethnic differences in adolescents' perceived health status: Preliminary findings. Journal of Pediatric Nursing, 12 (4), 223-227.

Rich, J. A. (2001). Primary care for young African American men. Journal of American College Health, 49, 183-186.

Rimal, R. N. (2000). Closing the knowledge-behavior gap in health promotion: The mediating role of self-efficacy. Health Community, 12, 219-237.

Rise, J. (2004). Modifying adolescent health behaviors. Current Opinion in Psychiatry, 17 (2), 129-132.

Roach Diagnostics Corporation (2000). Accu-Check Instant Plus Dual Testing System, Indianapolis, IN.

Robbins, L. B., Pender, N. J., \& Kazanis, A. S. (2003). Barriers to physical activity perceived by adolescent girls. Journal of Midwifery \& Women's Health, 48(3), 26-212.

Robbins, L. B., Pender, N. J., Ronis, D. L., Kazanis, A. S., \& Pis, M. B. (2004). Physical activity, self-efficacy, and perceived exertion among adolescents. Research in Nursing \& Health, 27, 435-446.

Robinson, R. F., Batisky, D. L., Hayes, J. R., Nahata, M. C., \& Mahan, J. D. (2005). Significance of heritability in primary and secondary pediatric hypertension. American Journal of Hypertension, 18, 917-921.

Rocchini, A. P. (2000). Coarctation of the aorta and interrupted aortic arch. In Moller, J. H. and Hoffman, U. Pediatric cardiovascular medicine. New York: Churchill Livingstone, p. 570. 
Rodin, J. \& McAvay, G. (1992). Determinants of change in perceived health in a longitudinal study of older adults. Journal of Gerontology, 47 (16), 373-184.

Rozmus, C. L., Evans, R., Wysochansky, M., \& Mixon, D. (2005). An analysis of health promotion and risk behaviors of freshman college students in a rural southern setting. Journal of Pediatric Nursing, 20 (1), 25-33.

Rutledge, T., Reis, S. E., Olson, M., Owens, J., Kelsey, S. F., Pepine, C. J., Reicheck, N., Rogers, W. J. (2003). Socioeconomic status variables predict cardiovascular disease risk factors and prospective mortality risk among women with chest pain. Behavior Modification, 27(1), 54-67.

Sankar, P., Cho, M. K., Condit, C. M., Hunt, L. M., Koenig, B. A., Marshall, P. A., SooJin, S., \& Spicer, P. (2004). Genetic research and health disparities. Journal of American Medical Association, 291 (24), 2985- 2989.

Satcher, D. (2003). Overlooked and underserved: Improving the health of men of color. American Journal of Public Health, 93 (5), 707-709. [Editorial].

Savoca, M. R., Evans, C. D., Wilson, M. E., Harshfield, G. A., \& Ludwig, D. A. (2004). The association of caffeinated beverages with blood pressure in adolescents. Archives of Pediatric Adolescent Medicine, 158, 473-477.

Schmidt, M., Affenito, S. G., Striegel-Moore, R., Khoury, P. R., Barton, B., Crawford, P., Kronsberg, S., Schreiber, G., Obarzanek, E., \& Daniels, S. (2005). Fast-food intake and diet quality in Black and White girls. Archives Pediatric Adolescents Medicine, 159, 626-631.

Schneider, R., Castillo-Richmond, C., Alexander, C., Hector, M., Kaushik, V., Aranguri, C., Norris, K., Haney, C., Rainforth, M., Calderon, R., \& Nidich, S. (2001). Behavioral treatment of hypertension heart disease in African Americans: Rationale and design of a randomized controlled trail. Behavioral Medicine. Retrieved on January 11, 2006, from http://www.findarticles.com/cf_0/m0GDQ/ 2_27/81390110/print.html

Schlosser, E. (2001). Fast food nation: The dark side of the all-American meal. New York: Houghton Mifflin.

Schoenfield, D. E., Malrose, L. C., Blazer, D. G., Gold, D. T., \& Seeman, T. E. (1994). Self-rated health and mortality in the high-functioning elderly: A closer look at healthy individuals. MacArthur field study of successful aging. Journal of Gerontology, Medical Sciences, 49(3), M109-M115.

Settersten, L. \& Lauver, D. R. (2004). Critical thinking, perceived health status, and participation in health behaviors. Nursing Research, 153 (1), 11-18. 
Sharma, S., Malarcher, A., Giles, W., \& Myers, G. (2004). Racial, ethnic, and socioeconomic disparities in the clustering of cardiovascular disease risk factors. Ethnicity \& Disease, 14, 43-48.

Shengxu, L., Chen, W., Srinivasan, S. R., Bond, M. G., Tang, R., Urbina, E. M., Berenson, G. S. (2003). Childhood cardiovascular risk factors and carotid vascular changes in adulthood. Journal of American Medical Association, 290 (17), 2271-2276.

Simmons, S. J. (1990). The health-promoting self-care system model: Directions for nursing research and practice. Journal of Advanced Nursing, 15, 1162-1166.

Sinaiko, A. R., Donahue, R. P., Jacobs, D. R., Prineas, R. J. (1999). Relation of weight and rate of increase in weight during childhood and adolescence to body size, blood pressure, fasting insulin, and lipids in young adults. Circulation, 99, 14711476.

Smalley, S. E., Wittler, R. R., Oliverson, R. H. (2004). Adolescent assessment of cardiovascular heart disease risk factor attitudes and habits. Society for Adolescent Medicine, 35, 374-379.

Smith, A. L. (2003). Health policy and the coloring if an American male crisis: A perspective on community-based health services. American Journal of Public Health, 93(5), 749-752.

Snieder, H., Harshfield, G. A., \& Treiber, F. A. (2003). Heritability of blood pressure and hemodynamics in African and European American youth. Hypertension, 41, 1196-1201.

Snooks, M. K. \& Hall, S. K. (2002). Relationship of body size, body image, and selfesteem in African American, European American, and Mexican American middle-class women. Health Care for Women International, 23, 460-466.

Snowden, L. R. (1999). African American service use for health problems. Journal of Community Psychology, 27, 303-313.

Sorof, J. M. (2001). Systolic hypertension in children: Benign or beware? Pediatric Nephrology, 16, 517-525.

Sorof, J. M., Alexandrov, A. V., Cardwell, G., \& Portman, R. J. (2003). Overweight, ethnicity, and the prevalence of hypertension in school-aged children. Pediatrics, $1133,475-482$.

Sorof, J., Lai, D., Turner, J., Poffenbarger, T., \& Portman, R. (2004). Overweight, ethnicity, and the prevalence of hypertension in school-aged children. Pediatrics, $1133,475-482$. 
Sowers, J. Ferdinand, K., Bakris, G., \& Douglas, J. (2001). Hypertension-related disease in African Americans. Postgraduate Medicine, 112(4), 24-32.

Srinivasan, S. R., Myers, L., Berenson, G. S. (2002). Predictability of childhood adiposity and insulin for developing insulin resistance syndrome (syndrome $\mathrm{x}$ ) in young adulthood. Diabetes, 51, 204-209.

Stepnowsky, C. J., Nelesen, R. A., DeJardin, D., \& Dimsdale, J. E. (2004).

Socioeconomic status is associated with nocturnal blood pressure dipping. Psychosomatic Medicine, 66, 651-655.

Stuifbergen, A. K. \& Becker, H. A. (1994). Predictors of health-promoting lifestyles in persons with disabilities. Research in Nursing \& Health, 17, 3-13.

Tabachnick, B. \& Fidell, L. (2000).Using multivariate statistics (4th ed.). Allyn \&Bacon: Boston, MA.

Takashi, U. \& Genjiro, K. (1999). Diuretics shift circadian rhythm of blood pressure from nondipper to dipper in essential hypertension. Circulation, 100, 1635-1638.

Tappe, M. K., Duda, J. L., \& Ehrnwald, P. M. (1989). Perceived barriers to exercise among adolescents. Journal of School Health, 59(4), 153-156.

Thomas, S. B., \& Curran, J. W. (1999). Tuskegee: From science to conspiracy to metaphor. American Journal of the Medical Sciences, 317, 1-3.

Thorson, J. A. (1983). Spiritual well-being in the secular society. Generations, 8, 10-11.

Togo, P., Heitman, B. L., Sorenson, T. I., \& Olser, M. (2003). Consistency of food intake factors by different dietary assessment methods and population groups. British Journal of Nutrition, 90, 667-678.

United States Census Bureau (2005). U. S. Census Bureau News. Retrieved on September, 2006 from http://www.census.gov/Press-Release/www/releases/ archives/income_wealth/005647.html. Statistics Reports, 48 (11)

United States Department of Health and Human Services [DHHS] (2000). Deaths final data for 1998. DHHS Publication Number (PHS) 2000-1120. National Vital Statistics Reports, 48 (11), Hyattsville, MD: National Center for Health Statistics.

United States Department of Health and Human Services (2003). The seventh report of the Joint National Committee on Prevention, Detection, Evaluation, Evaluation, and Treatment of High Blood Pressure. NIH Publication Number 035233. Retrieved on May, 2004 from http://www.nhlbi.nih.gov/guidelines/ hypertension/express.pdf 
Walcott-McQuigg, J. A. \& Prohaska, T. R. (2001). Factors influencing participation of African American elders in exercise behavior. Public Health Nursing, 18 (3), $194-$ 203.

Watts, W. D. \& Wright, L. S. (1990). The relationship of alcohol, tobacco, marijuana, and other illegal drug use to delinquency among Mexican-American, Black and White adolescent males. Adolescence, 25 (97), 171-182.

Weinrich, S. P., Weinrich, M. C., Priest, J., Fodi, C., \& Talley, C. (2001). Perceived health status in African American and Caucasian men 40 to 70 years. Holistic Nursing Practice, 16, 65-72.

Werner, P. \& Mendelson, G. (2001). Nursing staff members' intentions to use physical restraints with older people: Testing the theory of reasoned action. Journal of Advanced Nursing, 35 (5), 784-791.

Whaley, A. L. (2001). Cultural mistrust and mental health services for African Americans: A review and meta-analysis. The Counseling Psychologist, 29(4), 513-531.

Whitehead, D. (2004). A social cognitive model for health education/health promotion practice. Journal of Advanced Nursing, 36(3), 417-425.

Williams, D. (2003). The health of men: Structured inequalities and opportunities. American Journal of Public Health, 93(5), 724-731.

Williams, D. E., Cadwell, B. L., Cheng, Y. J., Cowie, C. C., Gregg, E. W., Geiss, L. S., Engelgau, M., M., Narayan, K. M., \& Imperatore, G. (2005). Prevalence of impaired fasting glucose and its relationship with cardiovascular disease risk factors in U. S. adolescents, 1999-2000. Pediatrics, 116, 1122-1126.

Williams, D. R., Neighbors, H. W., \& Jackson, J. S. (2003). Racial/ethnic discrimination and health: Findings from community studies. American Journal of Public Health, 93, 200-208.

Wilson, D. K., Bayer, L., \& Sica, D. A. (1996). Variability in salt sensitivity classifications in Black males versus female adolescents. Hypertension, 28, 250255 .

Wilson, D. K., Kliewer, W., Teasley, N., Plybon, L., \& Sica, D. (2002). Violence exposure, catecholamine excretion, and blood pressure nondipping status in African American male versus female adolescents. Psychosomatic Medicine, 64, 906-915. 
World Health Organization (2004). Cardiovascular disease: Prevention and control. Retrieved July, 2004, from http://www.who.int/topics/cardiovascular_diseases/ en/

Yarcheski, A., Mahon, N., \& Yarcheski, T. J. (1997). Alternate models of positive health practices in adolescents. Nursing Research, 46 (2), 85-92.

Zullig, K. J., Valois, R. F., \& Drane, J. W. (2005). Adolescents distinctions between quality of life and self-rated health in quality of life research. Health and quality of life outcomes, 3 (64). Retrieved February, 2006, from http://www.hqlo.com/ content $/ 3 / 1 / 64$ 


\section{VITA}

Desmarie Jackson DeCuir was born in Baton Rouge, Louisiana, on January 20, 1956. She attended elementary and high school in Baton Rouge and graduated from Glen Oaks High School in 1974. In the spring of 1976 she was awarded a certificate of Practical Nursing from Capitol Area Vocational School in Baton Rouge. Two years later she entered college and in May 1981 received a Bachelor of Science Degree in Nursing from Southeastern Louisiana University located in Hammond, Louisiana. Desmarie's 20year career as a registered nurse has included an array of nursing roles: neonatal intensive care nursing, burn and trauma nursing, public health nursing, gynecological nursing, home health care, and clinical nursing supervision.

In May 2003 she graduated from Tennessee State University in Nashville, Tennessee with a Master of Science in Nursing. She has dual certification as a family nurse practitioner by the American Nursing Credentialing Center and Academy of Nurse Practitioners. She is a recipient of the National League of Nursing Foundation Scholarship Award. Desmarie entered the University of Tennessee Health and Science Center, Memphis in July 2003 and received a Doctor of Philosophy in nursing degree in May, 2007. Her dissertation research focused on Perceived Health Barriers, Perceived Health Perceptions, and Cardiovascular Risk Factors of Black American Adolescent Males. Presently she is employed by Veteran Affairs as Program Director for the Women Veteran Health Program in Memphis, Tennessee. 